慶應義塾大学学術情報リポジトリ

Keio Associated Repository of Academic resouces

\begin{tabular}{|c|l|}
\hline Title & Assessing the sense of presence to evaluate the effectiveness of virtual reality wildfire training \\
\hline Sub Title & \\
\hline Author & $\begin{array}{l}\text { 黄, 禾瑶(Huang, Heyao) } \\
\text { 小木, 哲朗(Ogi, Tetsurō) }\end{array}$ \\
\hline Publisher & 慶應義塾大学大学院システムデザイン・マネジメント研究科 \\
\hline Publication year & 2021 \\
\hline Jtitle & \\
\hline JaLC DOI & \\
\hline Abstract & \\
\hline Notes & 修士学位論文. 2021年度システムエンジニアリング学 第332号 \\
\hline Genre & Thesis or Dissertation \\
\hline URL & $\begin{array}{l}\text { https://koara.lib.keio.ac.jp/xoonips/modules/xoonips/detail.php?koara_id=KO40002001-0000202 } \\
\text { 1-0002 }\end{array}$ \\
\hline
\end{tabular}

慶應義塾大学学術情報リポジトリ(KOARA)に掲載されているコンテンッの著作権は、それぞれの著作者、学会または出版社/発行者に帰属し、その権利は著作権法によって 保護されています。引用にあたっては、著作権法を遵守してご利用ください。

The copyrights of content available on the KeiO Associated Repository of Academic resources (KOARA) belong to the respective authors, academic societies, or publishers/issuers, and these rights are protected by the Japanese Copyright Act. When quoting the content, please follow the Japanese copyright act. 


\title{
Assessing the Sense of Presence to Evaluate the Effectiveness of Virtual Reality Wildfire Training
}

\author{
Heyao Huang \\ (Student ID Number: 81934516)
}

Supervisor Tetsuro Ogi

September 2021

Graduate School of System Design and Management,

Keio University

Major in System Design and Management SUMMARY OF MASTER'S DISSERTATION 


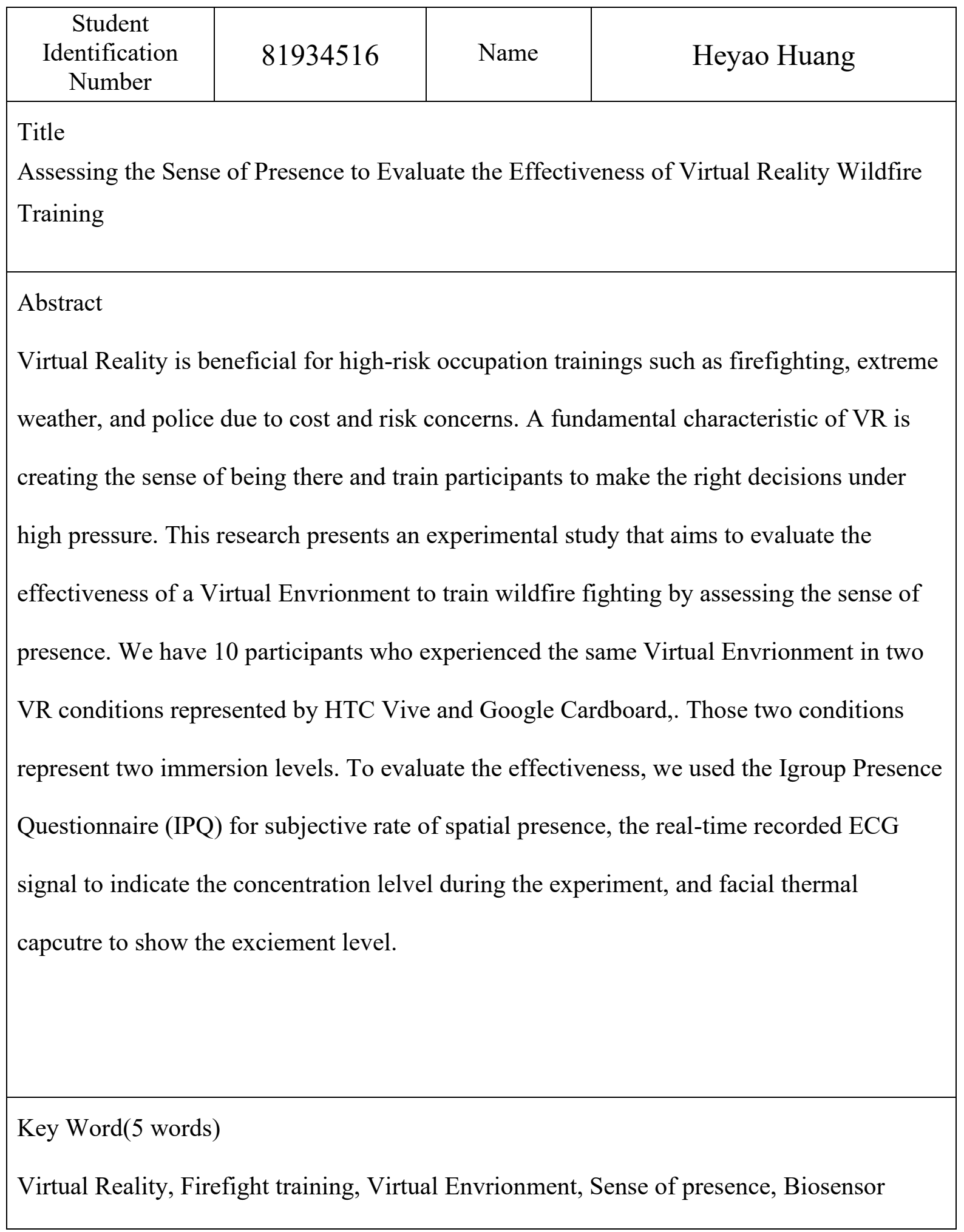




\section{Table of Contents}

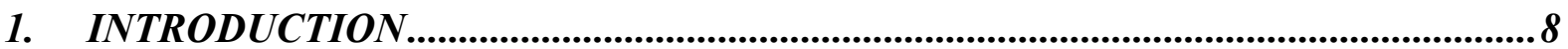

$1.1 \quad$ Wildfire and Training ........................................................................................................

$1.2 \quad$ Virtual Reality …..................................................................................................................... 10

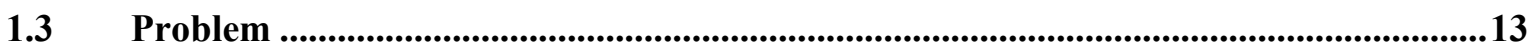

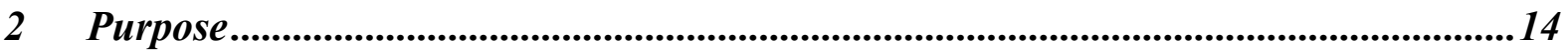

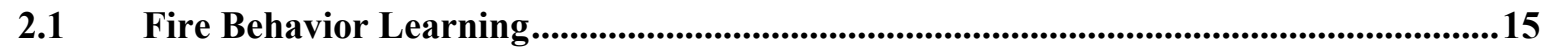

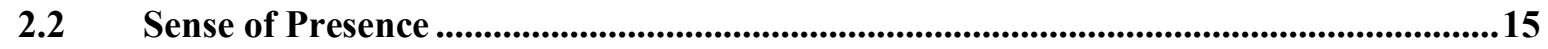

$3 \quad$ Related Works .......................................................................................................................16

$4 \quad$ Methdology of Fire Behavior Learning ..............................................................................19

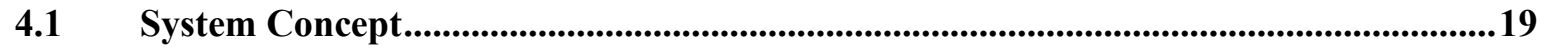

4.2 Virtual Contents Development …..............................................................................................20

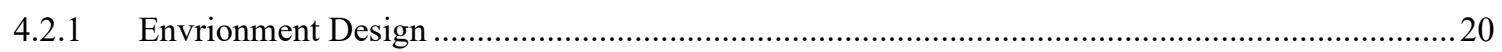

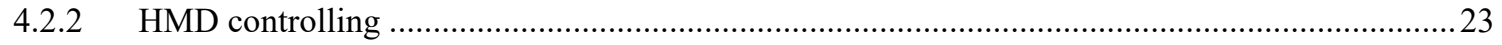

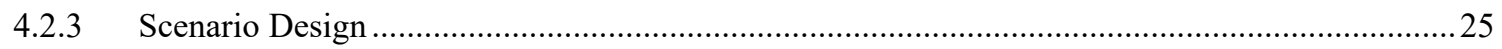

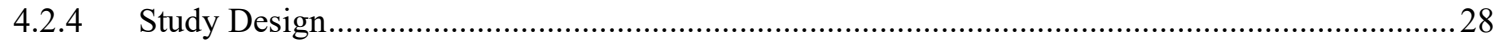

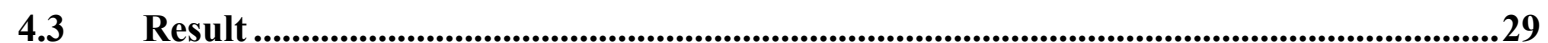

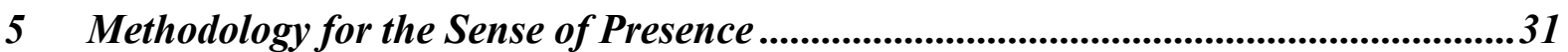

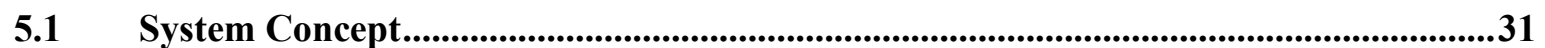

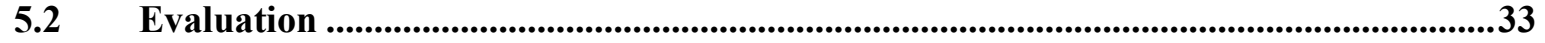

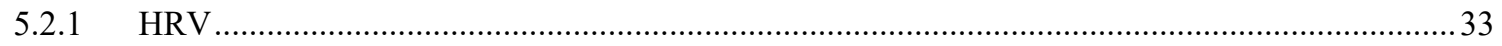

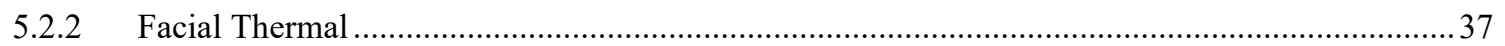

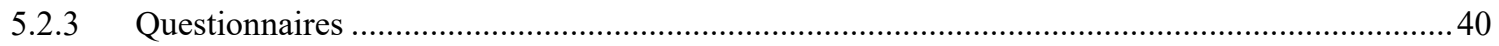

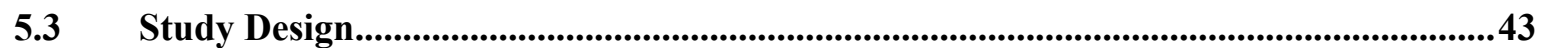




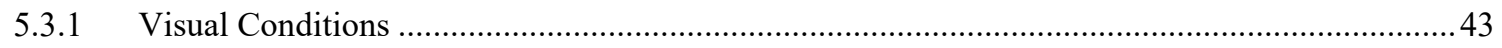

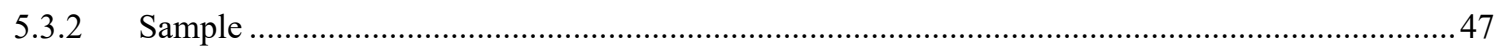

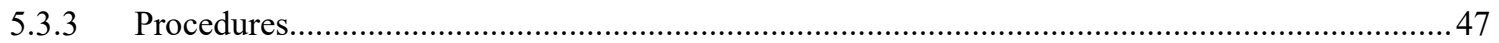

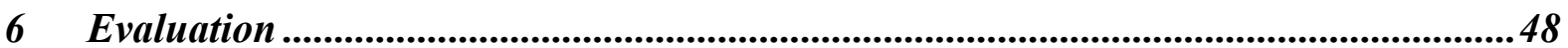

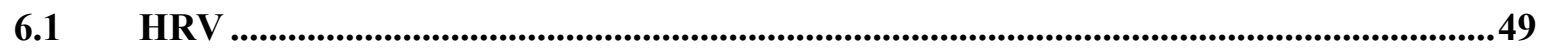

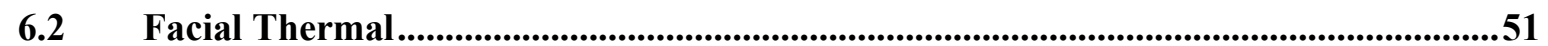

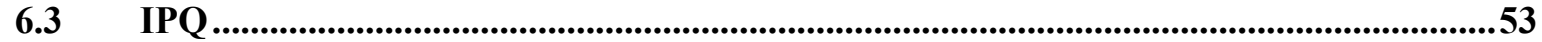

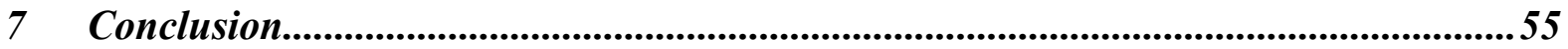

Acknowledgement ............................................................................................................................5

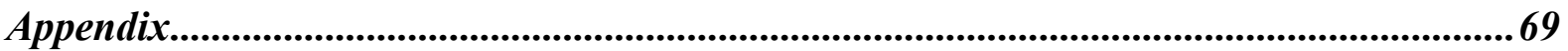

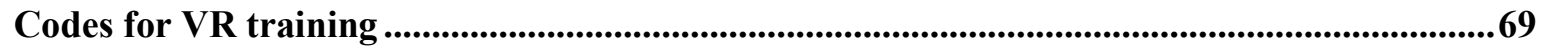

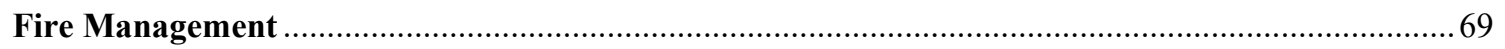

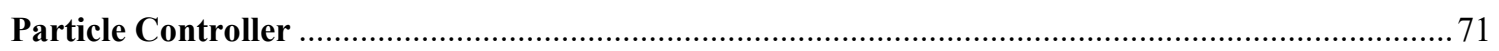

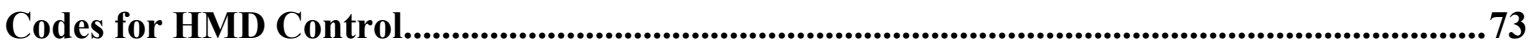

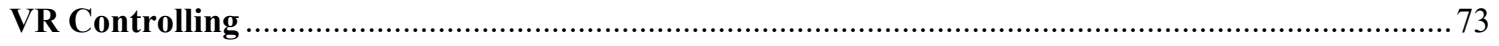

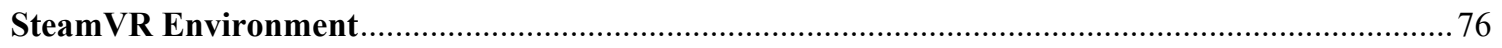

Play Area

VRCamera

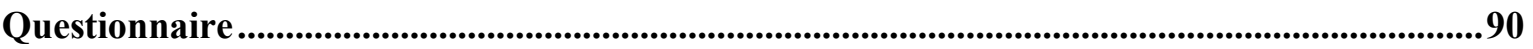

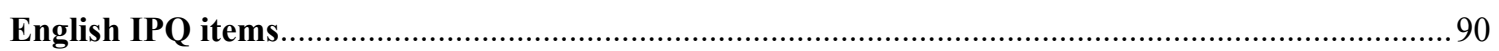

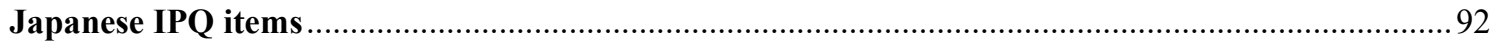




\section{List of Figures}

Figure 1 Example characteristics of the fire envrionment (top to bottom) that promotes rapid chages in the fire behaviour (left to right).

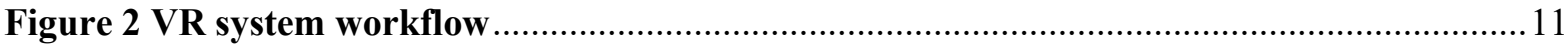

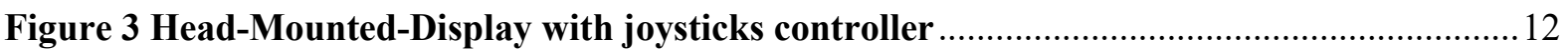

Figure 4 VR headset with smarkphone. Google Cardboard .....................................................13

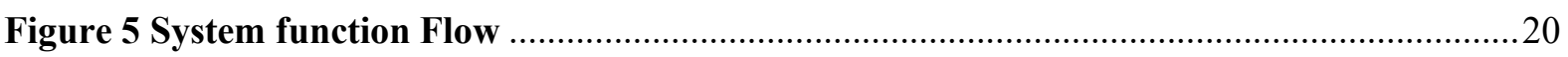

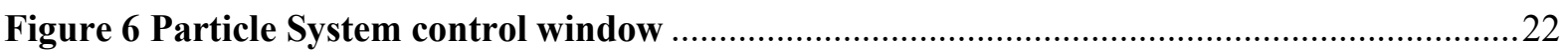

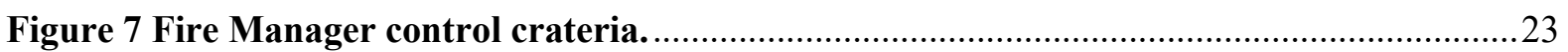

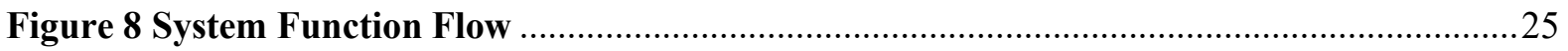

Figure 9 . First-person point-of-view during the actual VR training......................................26

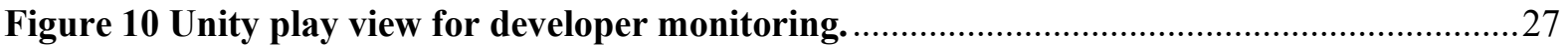

Figure 11 Over view of complex scene scenario B with Northwest wind, The highlighted fire is

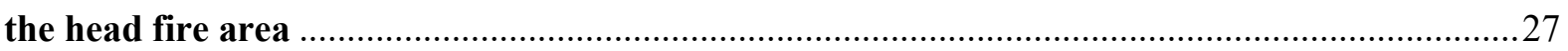

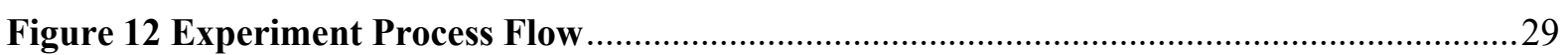

Figure 13 the different body parts Parasympathetic and Sympathetic nerve system control .....34

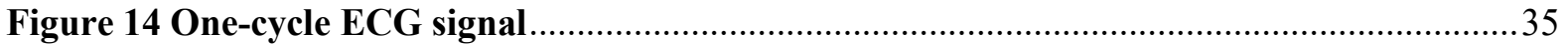

Figure 15 Each peak shows a successive $R R i$, and the distance from each $R R i$ is count in

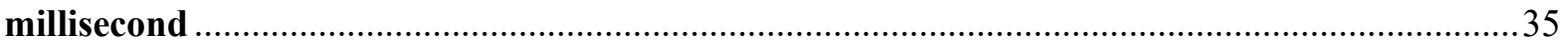

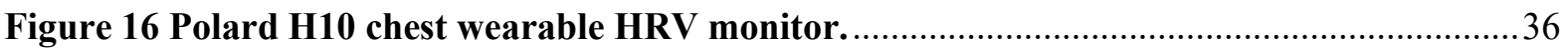

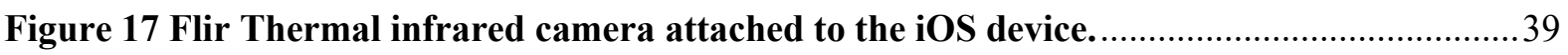

Figure 18 Application screen of capture the nose-tip temperature by using Flir infrared camera

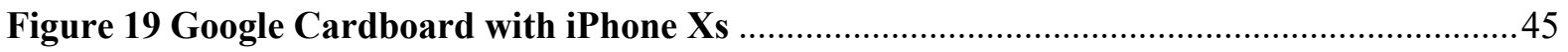

Figure 20 3D video for Google Cardboard display ................................................................... 46

Figure 21 Participant during the higher immersion condition experiment ................................48 
Figure 2220 smallest RR-variances comparisons for each participant in 110-degree environment and 30-degree environment for all 10 participants.

Figure 23 The result of Igroup presence questionnaire. Greener the score, more sense of presence participant subjectively feels. 


\section{List of Tables}

Table 1 Average fire cases, burnt area, and the number of damages in Japan from year 2015 2020.

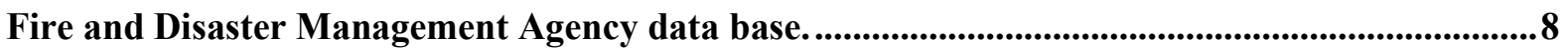

Table 2 Result of participant's time speed in the experiment......................................................30

Table 315 published questionnaires about the sense of presence .........................................................41

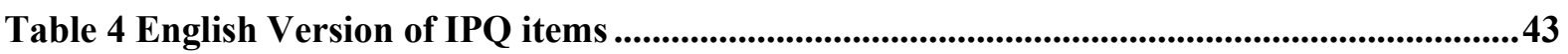

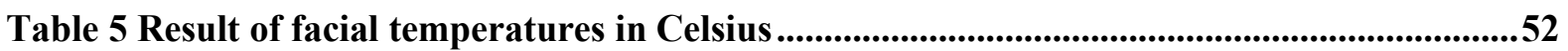




\section{INTRODUCTION}

\subsection{Wildfire and Training}

For the past decade, we have experienced the warmest time on record, accompanied by the record is the widespread and devastating wildfire from the Amazon to California, the Arctic Circle to Australia. Based on article review [1], the wildfire season will be expended, the wildfire season will be expended, and extreme wildfire is going to be more common. Even for a humid country as Japan has an annual average of 1.2 thousand wildfire cases with 700 ha burnt area from 2015 to 2020 [2].

Table 1 Average fire cases, burnt area, and the number of damages in Japan from year 2015 2020. Fire and Disaster Management Agency data base.

\begin{tabular}{|c|r|r|r|r|r|r|}
\hline 区分/年次 & 平成27年 & 平成28年 & 平成29年 & 平成30年 & 令和元年 & $\begin{array}{c}\text { 平均 } \\
\text { (平成27年 令和元 } \\
\text { 年) }\end{array}$ \\
\hline 出火件数 (件) & 1,106 & 1,027 & 1,284 & 1,363 & 1,391 & 1,234 \\
\hline 焼損面積 (ha) & 538 & 384 & 938 & 606 & 837 & 661 \\
\hline 損害額 (百万円) & 255 & 157 & 900 & 202 & 269 & 357 \\
\hline
\end{tabular}

Understanding the principle of fire behavior, and how the elements interact with each other is important for the firefighter to train in the current firefighting training process. For most fires, a fire triangle constitutes by oxygen, heat, fuel is often used for firefighters to understand the necessary ingredients. Wildfire training has a similar model called the fire behavior triangle consists of weather, topography, and fuel is well known for learning the open space fire behavior. The weather here refers to specific weather conditions, for example, wind, air humidity, temperature scale, heat, and precipitation at the fire ground. Topography is the slope or aspect side of the land fire is spreading, the more slope and narrower terrain generally cause faster fire spread. The amount and arrangement of fuel are the other important ingredients 
of fire behavior. How moisture the grass and how many of them are distributing among the fire ground determined the speed and scope of fire spreading.

Because of the above reasons, wildfire suppression is complex due to the interaction of wind, terrain, and plants in the landscape can cause a variety of unusual yet significant effects on fire propagation. Below in the figure. 1 shows the potential of each characteristic would entrap the firefighters, change in wind direction and speed is in the highest rank.

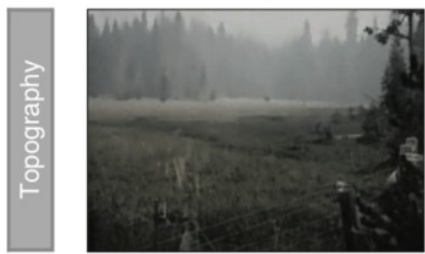

Flat terrain

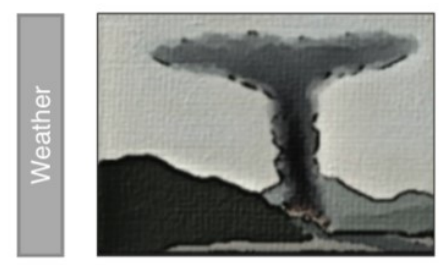

Stable, low winds

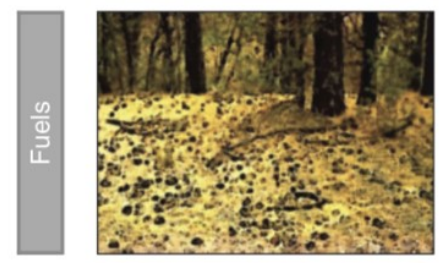

Timber litter

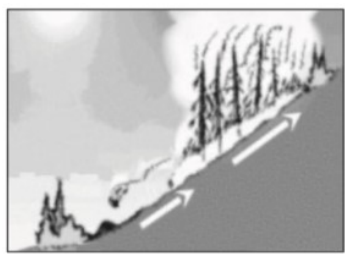

Steep slopes

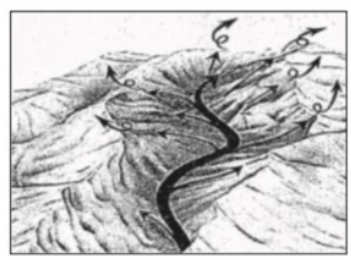

Solar heating, upslope winds

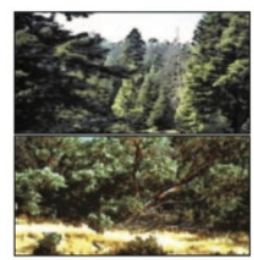

Crown

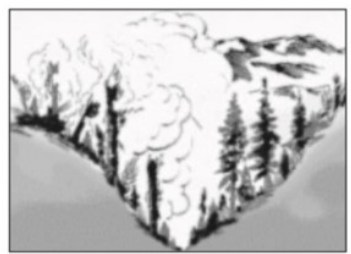

Narrow canyons

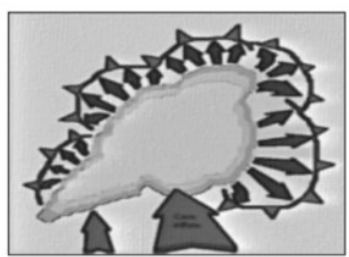

Change in wind direction, $\uparrow$ in speed

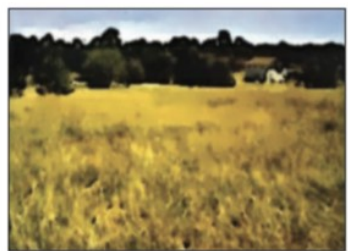

Grass

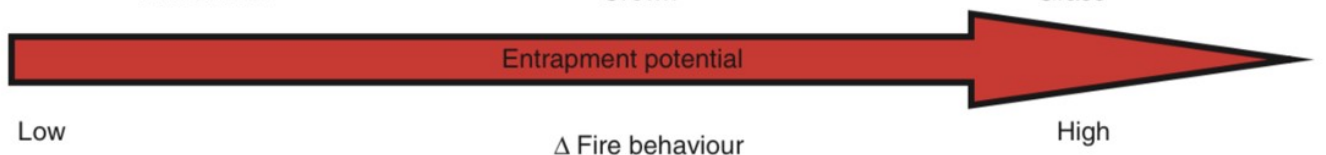

$\frac{\Delta \text { Fire behaviour }}{\text { Time }}$

High

Figure 1 Example characteristics of the fire envrionment (top to bottom) that promotes rapid chages in the fire behaviour (left to right).

Among the three sides of the triangle, the weather is the most dynamic cause of the fire behavior because of the unpredictable natural characteristic. Very slight wind turbulence and direction change would allow the "flanks" to become active head fire. Head fire is the term in fire behavior that refers to the side of the fire having the fastest rate of spread. When wind direction changes, it increases head fire area in a very short amount of time and rapidly 
increases fire spread rate and intensity in the area downwind of the fire front, also known as the 'dead-man zone' [3] The form of head fire has been considered as one of the most terminal causes of firefighter's entrapment. In 2013, during the fire season on the Yarnell Hill Fire in Arizona. 19 fire-fighters dead because of the rapid increase in wind speed and change in wind direction Unfortunately, although fire weather service forecast is supporting fire extinguish crew, the current technology of the most numerical weather prediction (NWP) models and the forecasts partially based on them generally have low skill for point forecast the wind speed and direction [4]. Firefighting is Understand the interaction between head fire and wind is one of the important parts of basic knowledge of fire safety techniques, methods, and tactics of members of firefighting crews. Beyond the knowledge of fire behavior, as the first responders in the dynamic changing environment, situation awareness and accurate decision making under stress and tension are also integrant for a firefighter.

\subsection{Virtual Reality}

In 1980, Minsky introduced the concept of telepresence to present an experience that a human operator might feel when interacting through a teleoperator system. The operator sees through the remote monitor and operates the effectors by using his limbs. Following the machine "became" a part of the human body, it is possible to produce the sense of being somewhere else. This experience was thought to be conducive to effectively operate tasks from remote environment [5]. Later, the concept of telepresence has applied to Virtual environments (VE). In this case, the user can immerse into a computer-generated environment, as well as make an influence to the environment.

Following the development of the technology and contribution of academic research, the concept is now applied to a well-known technology of Virtual Reality (VR). VR has been defined in many different ways and can range from simple software programs presented on a laptop to fully immersive multi-sensory environment experienced with complicated head, 
vision, tactile or haptic-related instruments [6]. What we refer to as reality is based upon something we call the external physical world [7]. When utilizing a three-dimensional computer-generated graphics system encompassing a majority of the user's visual field, VR can mimic a natural setting while preserving the risk-free and uncontaminated qualities offered by a controlled laboratory environment [8]. Hardware and software technology play important roles to establish a VR experiment like other computer-based technology, but the human participant is also indispensable to integrate the experiment as the engagement is a part of the modeled virtual world.

In most case [9], a central computing system bringing together the hardware and software system required to create the overall user experience. Reading input, producing simulation, and calculating the behaviors in the virtual world are all components for the computer to resolve. On the technology side, the main components for VR system includes computation; inputs; outputs; world presentation; and user interaction. The information flow within a VR system shows below:

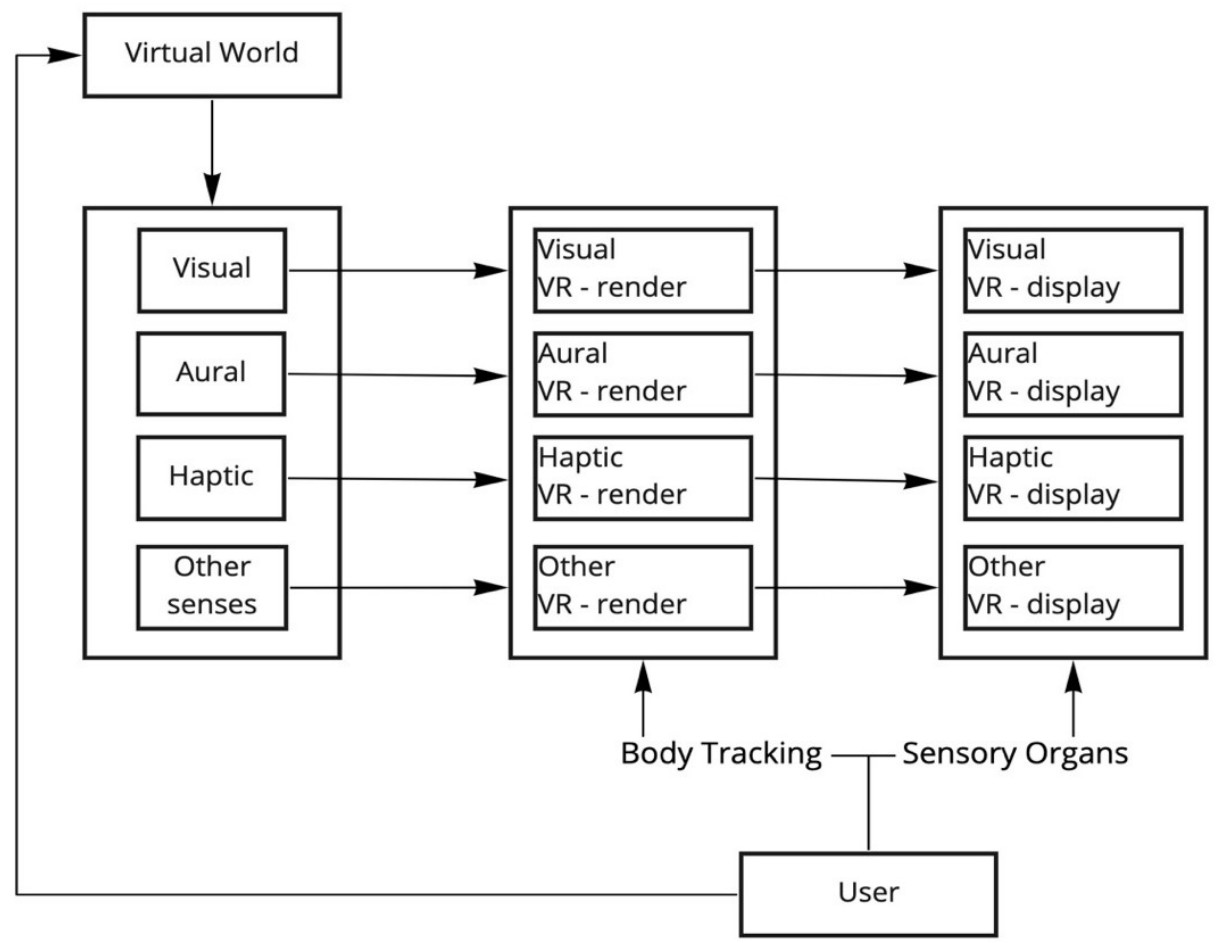


Currently, multi-screen display simulation (Cave Automatic Virtual Environment, CAVE) and Head-Mounted Display (HMD) are the two standard VR systems. Unlike CAVE, HMD is smaller in structure and size. By wearing the headset or the helmet, the user can immerse into the $3 \mathrm{D}$ virtual environment. The head tracking of the user is done with the help of built-in accelerometers or/ and gyroscope and the position tracking could be done with the help of infrared sensors placed right in front of the HMD headsets [10]. In addition to that, the position and rotation of the controllers are tracked so that the user has flawless interaction in the VE. As the marketing exploring the alternative way of approaching VR, there is miniaturization and even more portability VR HMD system with separated devices - VR headset plus smartphone solutions.

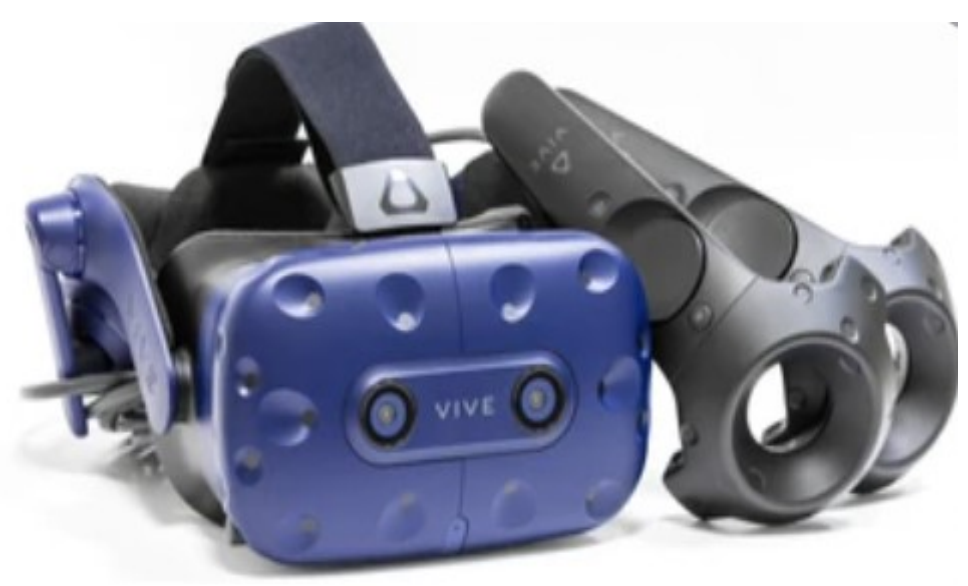

Figure 3 Head-Mounted-Display with joysticks controller 


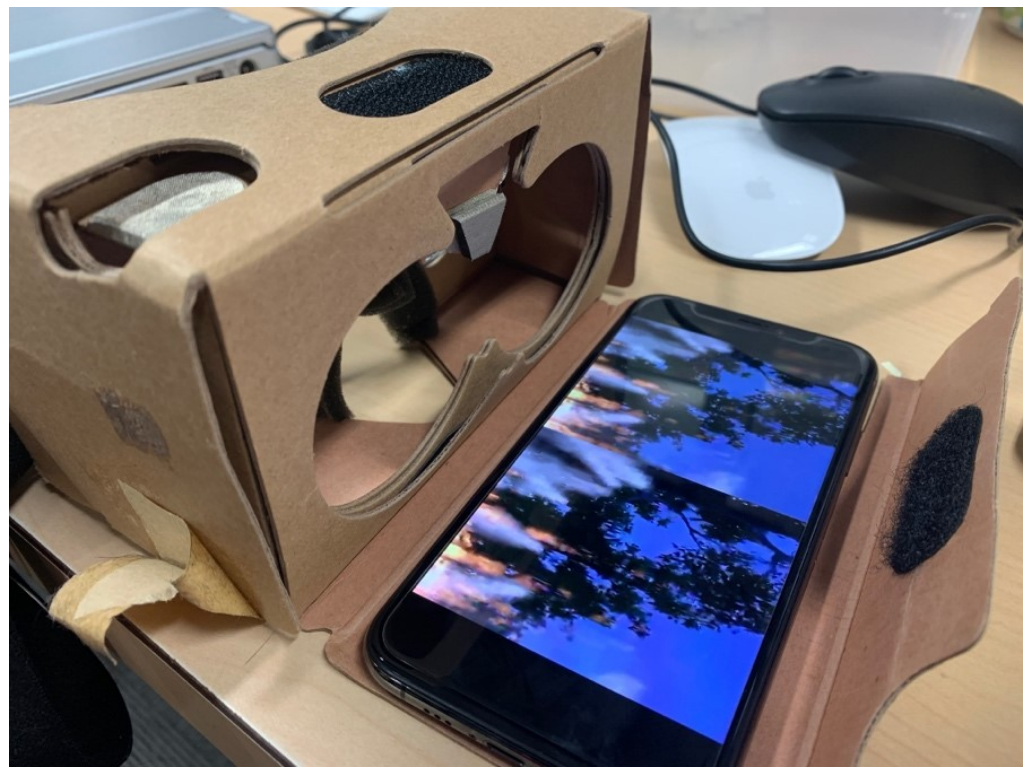

Figure 4 VR headset with smarkphone. Google Cardboard

\subsection{Problem}

As mentioned earlier, wildfire suppression involves multiple interactions between many possibilities. A frequent, consistent, and quality training plays an important role in the success and security firefighter. Fire fighter's practice in the scenarios as real as possible is crucial to understand the fire behavior and adjust pressure for better decision making. Despite these needs, often firefighters held training sessions with less frequency or quality than desired because of safety concerns and budget cuts. According to the National Wildfire Coordinating Group [11], to complete firefighter training, two processes are necessary, first one is S-190, a 7 hours instructor-led training of understanding the foundational wildland fire behavior, and the S-130 field review course contains an 8-12 hours field exercise. In Japan, natural disaster is the main training focus for the fire department, and according to the 2018 Fire and Disaster Management Agency white paper [12], a total of 732 disaster prevention drills were conducted by prefectures, and a total of 7,976 disaster prevention drills were also conducted in municipalities. Most of the disaster assumptions for training correspond to earthquakes and tsunamis in both prefectures and municipalities. Among the 8,708 drills around Japan in 2018, 
only 101 pieces of training cases are practical field exercises for wildland firefighting. Moreover, training in field exercise is a life threat as a real foreground. From 2008 to 2019 [13], 110 firefighters dead during training sessions that involved putting out real fires, climbing ladders, hauling heavy equipment, and other essential parts of the job that a firefighter would have to take in duty when it is an actual emergency.

In the past two decades, Virtual Reality (VR) technology has been developed and widely known in various realms. Because of this ability to stimulate and allow the user to fully engage in the virtual environment, VR technology is broadly adapted for education and training purposes, especially those that require workers to operate in dangerous conditions (e.g., mine, military, medical emergency, firefighting) that are difficult or impossible to recreate the training scenario in the real-world. They see the potentials of reducing time for training and infrastructure, reducing operational costs, reducing labor costs, and increasing productivity, while trainee's safety and facilities are ensured. Compared to the traditional fire training methods, VR provides a simulated experience for trainees to explore various emergency scenarios repeated without exposure to the hazard. Moreover, using technology allows the study and collection of certain aspects such as human behavioral and psychological data under emergencies that are not possible or feasible in reality [14]. These advantages are valuable to support firefighters from traditional fire training methods because it allows them to practice the scenarios repeatedly until they are familiar with the situations and master the skills.

\section{Purpose}

This study is specifically designed to train junior or volunteer firefighters who have none or little experience to conduct theoretical knowledge of fire behavior in practical VR training, in order to respond fast in the real wildfire situation. The effectiveness of the training is the challenge of using VR training. Training environment VR immerse the trainee ideally 
should provide an experience the same way as reality. However, the current technology is not capable to replicate all stimuli in the virtual environment with the same fidelity as in the Real Environment. Although the current VR technology cannot produce the simulation with the same fidelity, it is still promising to have effective training by using VR. According to Harter et al. [15] the suspension of disbelief can cause the same sort of autonomic reactions as if users were experiencing the situation in real life.

The aim of this study is to examine the use of VR in wildfire training from two stages experiments. In the first stage, this study took an explorative approach toward the use of simulated VE in a fire prevention drill course aimed at understanding the head fire behavior and its relationship with the wind speed and direction. The second step was taken further away from the first step to improve the effectiveness of the training system by validating the sense of the presence of the system. The motivation of this study is to provide an effective supporting training system for entry-level firefighters to absorb field experiences and hence reduce property damage and causalities in the future.

\subsection{Fire Behavior Learning}

This stage presents an experiment with non-wild firefighting experienced participants where the effectiveness of a training VE was assessed comparing the participant's response time to the target. The goal of this study is to compare two VR scenarios by using HMD and joysticks to see if participants spend less time to find and put out the head fire in scenario B (harder) after repeat practices in scenario A (simple). The experiment considers effective if the participant is able to process the wind information and put out the head fire in a shorter time.

\subsection{Sense of Presence}

In this stage, the system is further evaluated for its immersion function to simulate the realistic mental states of the participant. The training is considered effective if the virtual 
environment is able to evoke the mental state where the person feels the sense of presence while knows that the scenario being experienced is not real. The level of presence was measured subjectively using igroup presence questionnaire (IPQ), objectively through concentrate and stress analysis from Heart-Rate Variability (HRV), and excitement analysis from skin temperature. The experiment compared conditions of 3D and 360 images, viewing angles, the resolutions of the displayed images, and the interaction functions by two VR Head Mount Displays (HMD) - HTC Vive and Google Cardboard. The goal of this experiment is to see if one of the conditions provided a more concentrated, stressful environment for participants.

\section{Related Works}

Adapting VR technology for training the first responder has been an ongoing research topic for over two decades [16]. Following the technological advancements in VR in the past few years, the high demand for cost-efficient and safety training has led to diverse fields such as medicine [17, 18, 19] [20], education [21] [22], and mine safety [23]. Firefighting as a highdemand training field has various successful virtual training examples. Bliss, Tidwell, and Guest [24] presented an experimental study to prove the effectiveness of spatial navigation training to firefighters by using VR. Omodei and Wearing [25] presents an experiment using computer-simulated microworlds to study the complex decision-making for fire chief. Narciso el al. measured the fire VR training's effectiveness by assessing a Presence Questionnaire (PQ) and Hear-Rate Variability [26]. Outside of academia, countries, and regions with frequent wildfire attacks, for example, Fire Department in California [27] and Australia Fire Department [28], are collaborating with hardware or software VR developers to design their VR training systems. In the paper, there are other works that present VEs to train firefighters. However, the evaluations are focus either on hands-on training, such as how to use the fire extinguisher and 
navigation in the buildings; or focus on evaluate the cybersickness and mental states during the experiment.

There are two stages in this paper to evaluate the effectiveness of VR training, first is by comparing the time participant used before and after the VR training, and the second is measuring the psychological awareness by adapted biosensor [26] [29] and presence questionnaire [30]. In order to design an efficient VE, the study has referred to the Firefighting manual and past wildfire cases report [31] [32] to design the training scenarios. Hence for the trainee to understand the interaction between weather and fire behavior in a wild fire ground. For the second stage, accurate measuring of physical features is important for psychological sense analysis. Diverse measures have been proposed in the paper and can be divided into two categories: subjective, in which participants were asked to report their own judgment of [33]psychological state related to the VE [34] and objective, where biosensors like HRV [35] [36] and facial thermal [26] [37] assisted to measure the concentration and stress level of the participants.

In current lecture reviews of using VR for fire extinguishing training, the advantage of this method is revealed compare to less interactive methods. "VR training provided a more effective training result in terms of knowledge acquisition and retention, and self-efficacy [38]" in comparison with traditional video training. While some others reviewed, compared with traditional video training, VR training enhanced motivation and cognitive of threat. Manson discovered trainees who participated in VR extinguisher training in ICU scenarios have better performance in the real-life fire extinguisher operation than those who didn't. To assure and improve the effective training quality, it is suggested considering wider target group and skill level when design VR training. For the entry-level trainee, a less realistic setup is sufficient for basic knowledge practice and skill exercise. Following the increasing professional skills and experiences, realism must increase accordingly [39]. 
As the areas with the most severe wildfires in the decade, USFA (United States Fire Administration) has published articles [40] advocates the advantages of adapting VR as a supporting system for fire training. In the article, the author explains how trainees can experience a scenario that is not able to replicate in real-life because of the cost and dangerous concerns. From October 2019, Cosumnes Fire Department in California has successfully provided VR training by using Pico Interactive for 20 entry-level firefighters [41]. The training is focused on in-building firefighting. The scenarios include a 3-level fire ground for the trainee to navigate with the low-invisible level environment, a narrow room with a limited range of movement such as a bedroom, and a 10x10 simulated creche. From the result of the anonymous evaluation form 2- recruits filled, 80 percent thought that VR allowed them to absorb the most information, 50 percent reflect VR is the best source to reinforces the lecture knowledge.

On the other hand, Companys such as Flaim Systems, a specialist on VR firefighting training, is approaching a training system by accessing both VR and haptic technology to simulate an integrated fire training system. This system actives body sensors by assets HTC Vive Pro, heat suit, breathing apparatus, hose with haptic technology, and scenario software. Flaim Systems provides various environments for the trainee to practice, for instance, residential, factories, mining, and car accidents in different scenarios. Currently, the commercial uses are served in two ways: first, is Flaim Extinguisher, a facility training for extinguisher use.

Trainee uses VR to enters the scenario and access the physical fire extinguisher to practice the use of it in different environments. The second product is the Flaim Trainer, as shown in Figure.6 is an escalated training of Flaim Extinguisher. The product provides an integrity evaluable extinguish equipment and VR to create a real-time physical interface to create a fidelity training experience. The hose sends real-time force feedback to the trainee, a head-suit simulates the fire heat for the immersive experiment and a VR for visual simulation. 
The backpack and strip on the waist are for data storage and software generating, however, it also uses as a simulation for equipment weight.

\section{Methdology of Fire Behavior Learning}

\subsection{System Concept}

According to Salas et al [42], the concept of training is revolved around "planned and systematic activities designed to promote the acquisition of knowledge (i.e., need to know), skills (i.e., need to do), and attitudes (i.e., need to feel)". The desired output from training is the change of cognition (improve the knowledge), change of action (new and/or better level of skill), and change of affective (enhanced motivation and sense of efficacy) [43]. The effectiveness of training is also known as learning transfer. It's the degree to which the material learned during real-life training or simulator training affects job performance. The learning process allowed the trainee to transfer from a structural training environment to a non-structural and unpredictable real-life environment [44].

VR training at this point, as many authorities have reviewed, is not enough to replace the existing training sessions. However, as Cosumns Fire Department reported from their VR fire training, it is a powerful tool that helps to practice the lecture knowledge and support based on current training techniques. The current development on using VR to train first responders such as firefighters is flourishing, however, the focus on wildfire training, especially help them to understand the fire behavior is relatively absented. This wildfire virtual environment is designed to simulate the real wildfire case for firefighters to understand how the dynamic wind affects the fire behavior in the open space. By using HMD, the participant can immerse in the 360 virtual environments with already flaming fire. For the training purpose of helping them to understand how the wind speed and change of direction affect the head fire, the study designed multiple situations where head fire locations are different due to weather differences. 
The system generated participants as the first person-point-of-view avatar to create a more realistic experience. The participant can control the avatar and the water hose by using joysticks that function as input interfaces for the user to interact with designed objects in the VE. In this case, interact with flame fire with water to prevent the expansion.

System function flow shows in figure 5 below. The whole process is supported based on the game engine Unity. The system recognizes the enters of the participant and generated it to the avatar, then the non-real-time fire starts to expand and form the head fire based on the wind direction, following by the participant's moves, water particle will collide in fire particle and result, extinguish the fire particle.

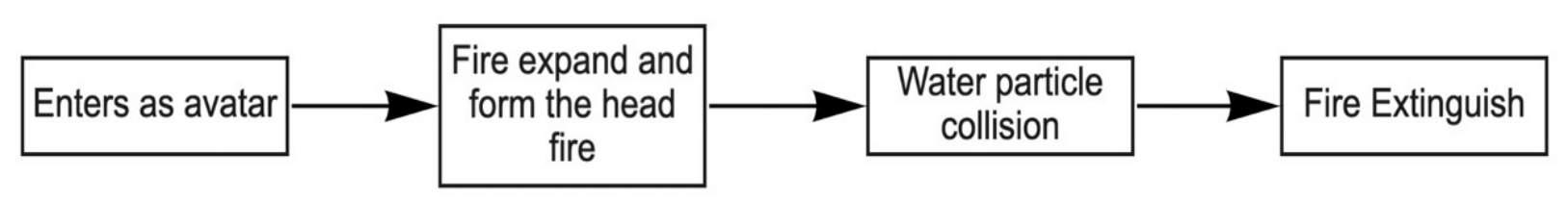

Figure 5 System function Flow

\subsection{Virtual Contents Development}

\subsubsection{Envrionment Design}

There are three types of elements categorized in the virtual learning envrionment: contextual, fundamental, and interactive elements [45]. Contextual elements help the user to identify the training background and scene; fundamental elements provide the structural elements of a scene, and interactive elements are the parts training focus on in the scene and will either be directly or indirectly interacted with. For this study, the contextual elements are the open wild environment with fundamental elements of trees, grass, and flowers. To fulfill 
the training purpose, the interactive elements are fire, water, and wind. There are three scenarios designed for this experiment with the same contextual and fundamental elements designs on Unity. Unity is a mainstream game with multi-platform features for creating interactive 3D content. To develop the environment, this study refers to wildfire cases studied by the United States Department of Agriculture Forest Service's fire management handout on wildfire behaviors [37]. Cases includes the Mack Lake fire, the Bass River fire, and Butte fire. The main focus of this experiment is to train the participant to understand how the wind interacts with fire and creates head fire, thus, although the topography is not considered as the parameter here, it has an important effect to shape the form of head fire in all above studies. Thus, the environment simulated a terrain with various topography such as flatlands and hills by using the Unity terrain function to create more dynamic possibilities.

For accurate validated results, there are three different sets of scenarios for the participant to familiar, practice, and final evaluation. The differences between the three scenarios are wind direction, wind speed, and head fire location. Despite the different outputs, the function of the inputs is the same. To have fire and water that can interact and counteract with each other, this study uses the particle system provided by Unity. The particle system in Unity is a particle effect system uses to simulate natural elements such as moving liquid, smoke, flames. Shapes, When the user sets any property on a module struct, Unity immediately assigns that value to the Particle System. 


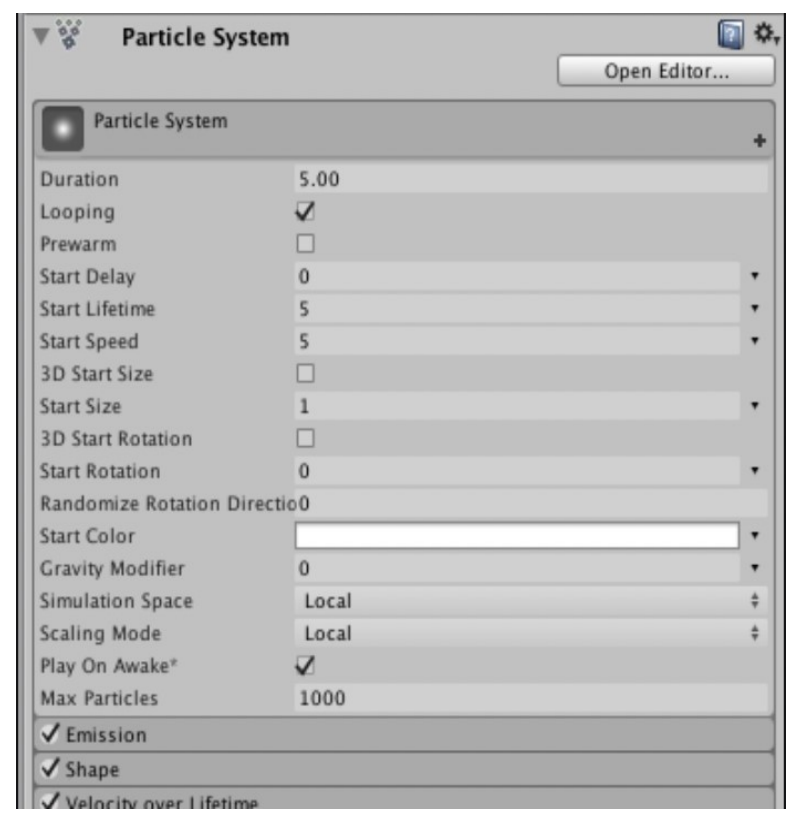

Figure 6 Particle System control window

Considering the fire prevention purpose of this training, the fire particle is vanquishable by collapse with the water particle by using the collision module. When the system detected an enabled collision script, particles will be removed from the system after a collision. To have a more realistic interactive of fire behavior, We use the already written C\# script Fire Manager provided by Unity assets store to calculate the rare fire locations by input wind speed, direction, and air temperature data. The fire Manager is able to simulate the fire spread speed and 
direction by considering the input data and terrain design in the environment. If the segment of the terrain is burning, fire will be shown in the particular segment.

\begin{tabular}{|c|c|}
\hline$\nabla$ ఏ $\checkmark$ Fire Manager (Script) & 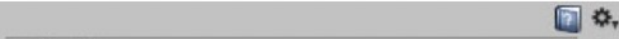 \\
\hline Script & FireManager \\
\hline Wind Zone & WindZone (Wind Zone) \\
\hline Pre Allocated Fire Index Size & 65 \\
\hline Air Temperature & $\mathbf{0}$ \\
\hline Ground Moisture & 0 \\
\hline Cell Size & 1 \\
\hline$\nabla$ Cell Fire Spawn Positions & \\
\hline Size & $\mathbf{0}$ \\
\hline Combustion Rate & 5 \\
\hline Node Combustion Rate & 5 \\
\hline Propagation Bias & 0.4 \\
\hline Propagation Hill Bias & 1 \\
\hline Propagation Wind Bias & 0.99 \\
\hline Max Hill Propagation Distance & 0.6 \\
\hline Visual Extinguish Threshold & 0.2 \\
\hline Day Time & $\checkmark$ \\
\hline$\nabla$ Terrain Textures & \\
\hline Size & 4 \\
\hline$\nabla$ Element 0 & \\
\hline Texture ID & 0 \\
\hline Flammable & $\checkmark$ \\
\hline Is Ground Burn Texture & $\square$ \\
\hline Fuel Lower Value & 20 \\
\hline Fuel Higher Value & 25 \\
\hline HP Lower Value & 20 \\
\hline HP Higher Value & 45 \\
\hline Moisture & 0 \\
\hline Fire Propagation Speed & 20 \\
\hline Element 1 & \\
\hline$\nabla$ Element 2 & \\
\hline Texture ID & 2 \\
\hline Flammable & $\square$ \\
\hline Is Ground Burn Texture & $\checkmark$ \\
\hline Fuel Lower Value & 0 \\
\hline Fuel Higher Value & 0 \\
\hline HP Lower Value & 0 \\
\hline HP Higher Value & 0 \\
\hline Moisture & 0 \\
\hline Fire Propagation Speed & 0 \\
\hline Element 3 & \\
\hline Burnt Grass Texture Index & $\mathbf{1}$ \\
\hline Detailed Simulation & $\square$ \\
\hline Remove Grass Once Burnt & $\square$ \\
\hline
\end{tabular}

Figure 7 Fire Manager control crateria.

\subsubsection{HMD controlling}

Two major requirements need to be fulfilled to achieve the training process. First, users can move in the VE as free as in the real world. Second, users are able to operate the water hose to put down the fire. To meet the two requirements, the system design employed a wire Head-Mounted Display (HMD), featuring HTC Vive with room-scale tracking technology 
[45]. HTC Vive allowed the user to move in 3D space at 360degree angles and use a motiontracked handheld - joysticks controller to interact with the environment. All the interaction scripts are designed with Unity by adapting C\# language.

The user enters the VE by wearing the HMD and appears as the computer-generated avatar in a first-person perspective. Considering the different heights sees the scene differently and that would cause the effect on situation awareness, HMD enables the script to detect the height from movement to the ground, and the height would scale the avatar in the environment, hence recreating a more realistic level of seeing to the different height users. A script of orientation detection is attached to the avatar object. HMD tracks the head motion of the user and simulates the movement to the avatar to synchronize the looking direction. Meanwhile, walking movement is controlled by Presspad on the joystick, the integration between Unity environment and Joystick controlling is provided by steam VR. By linking the movement script to the Joystick, pressing on the Presspad triggers the script and the user can move towards the direction he/she looks at by press the joystick. To achieve the virtual "first-hand" perspective purpose, the water hose is designed to attach to the avatar. The water hose is responsible for release water particles by the particle system in the shape of a water column. As described earlier in the environment design, the water particle enables the collision module added on the fire particle and eventually puts out the fire as tasks require. 


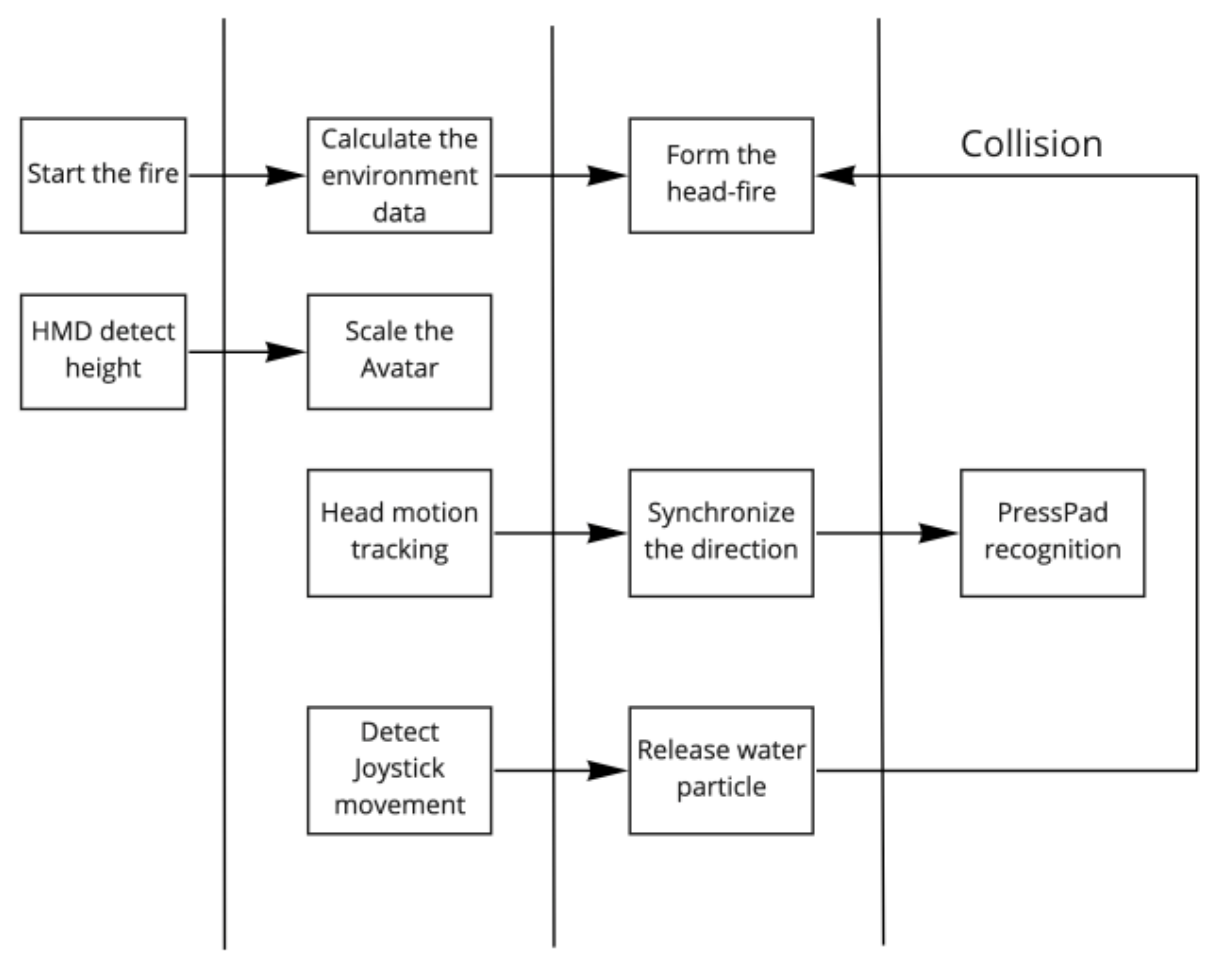

Figure 8 System Function Flow

\subsubsection{Scenario Design}

To evaluate the effectiveness of the VR wildfire training system, this study adapted a comparison experiment for the participants. We designed three single-user virtual scenarios: a pre-scene for the participant to understand the use of HMD, Joystick, interactions, and the rules; a simple scene (scenario A) for the repeated practice to understand the fire behavior; a hard scene (scenario B) using for comparing the time to evaluate the effectiveness. All three scenarios share the same terrain and background and terrain design. On fire is a $24 \times 24$ terrain with scrubby pines on a sunny day, the ground moisture level is 4 , and the air temperature is 30 . Pre-scene starts with a sporadic fire at the weather of $3 \mathrm{mph}$ wind to suit the purpose of understanding the use of equipment. Scenario A consists of a west wind with a speed of 5mph. The close distance between head fire and participant forced participant's quick response of information processing and direction orientating. The complexity of scenario B made it more likely for the participant to lose in. The $20 \mathrm{mph}$ Northwest wind 
spreads more rare fire in the fire ground between the head fire and participant.

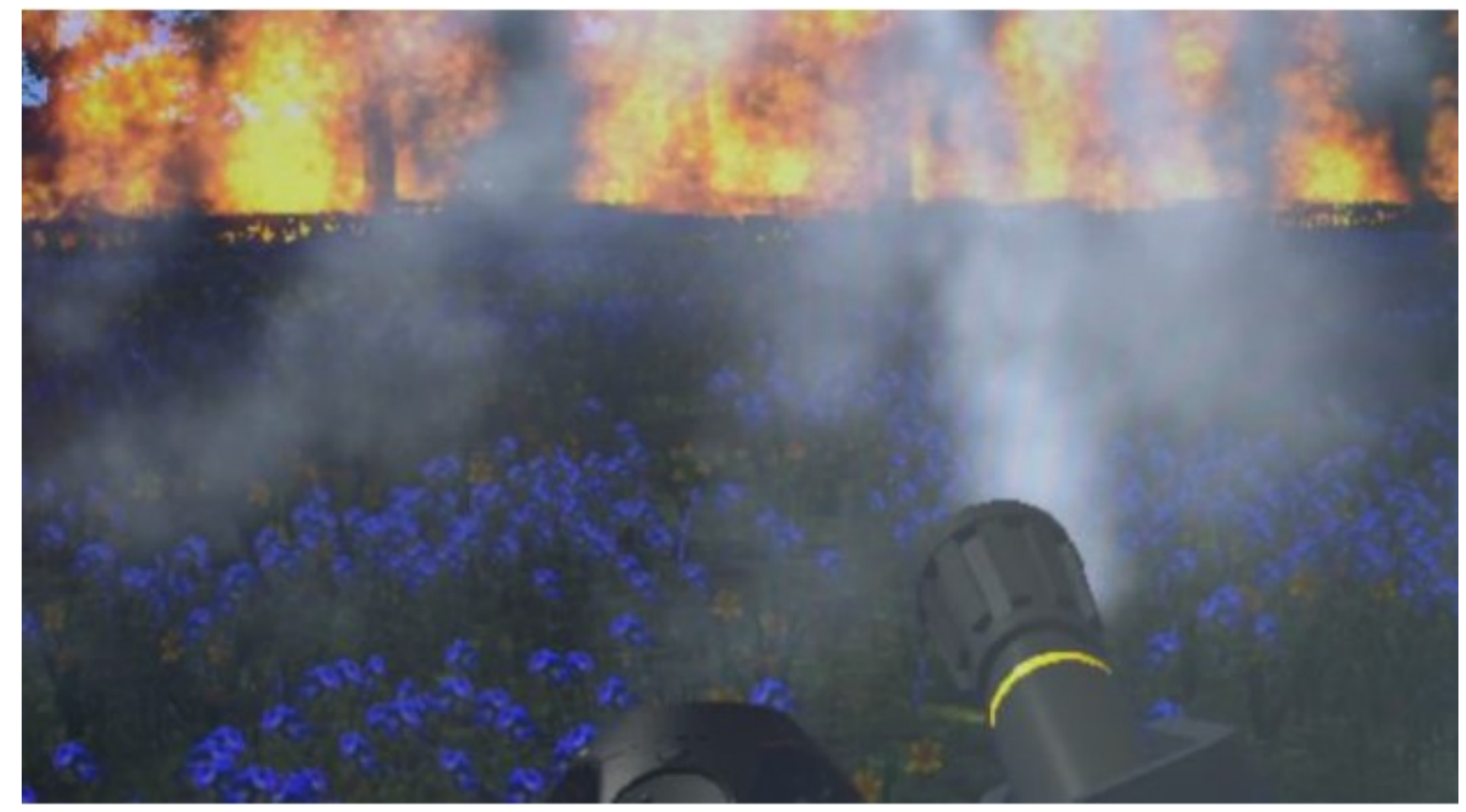

Figure 9 . First-person point-of-view during the actual VR training.

Furthermore, to monitoring participant's movement and obtain accurate fire extinguish time measurements, we used the Unity play window as the monitor. Instead of watching the firstperson perspective as mirroring the user's point of view, the play window helps to track the user's movement in a 2D view real-time, and the user was shown as the object box. That means, 
during the whole experience, we can see participant's movement and fire extinguish progress by tracking the Unity play window.

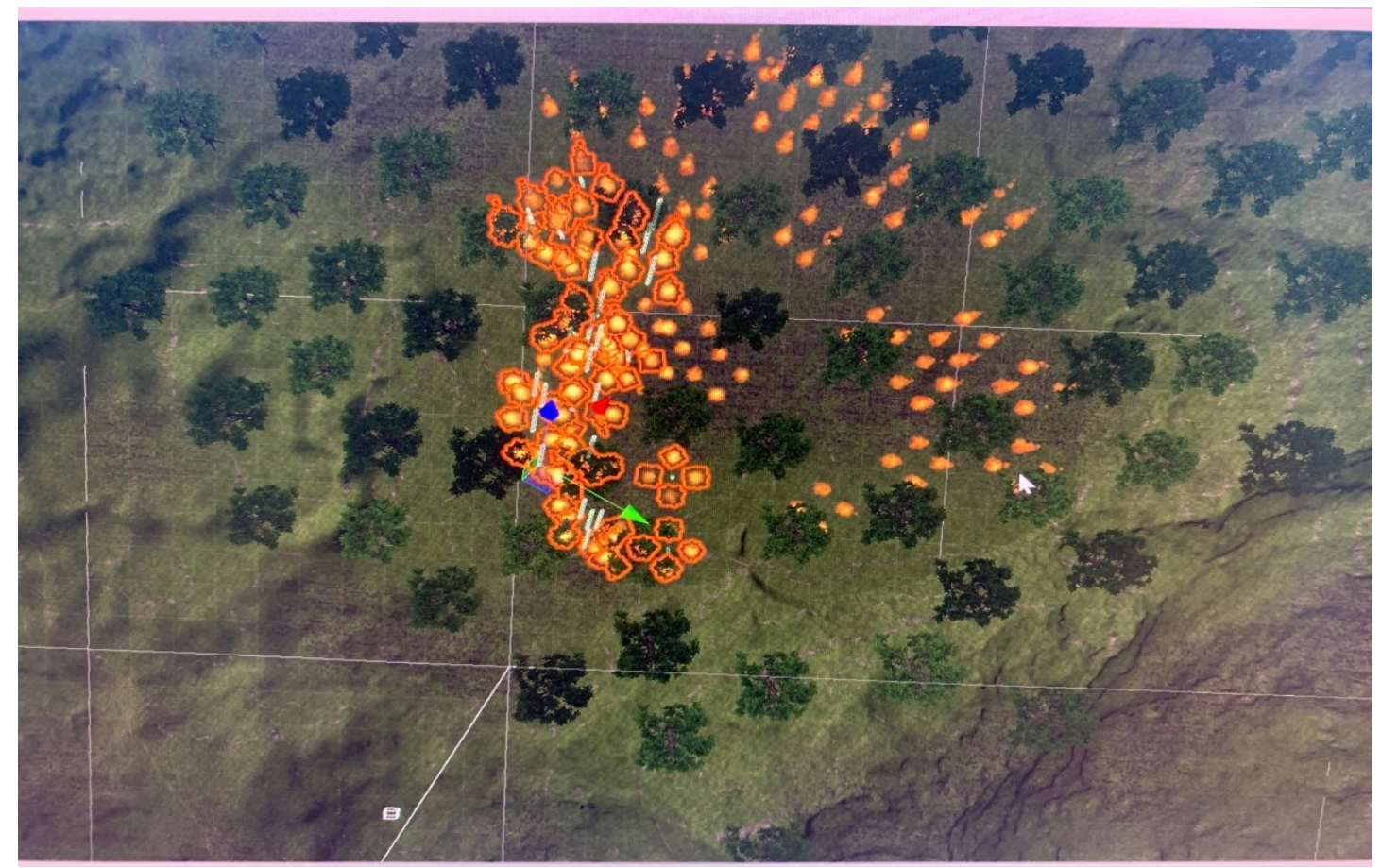

Figure 10 Unity play view for developer monitoring.

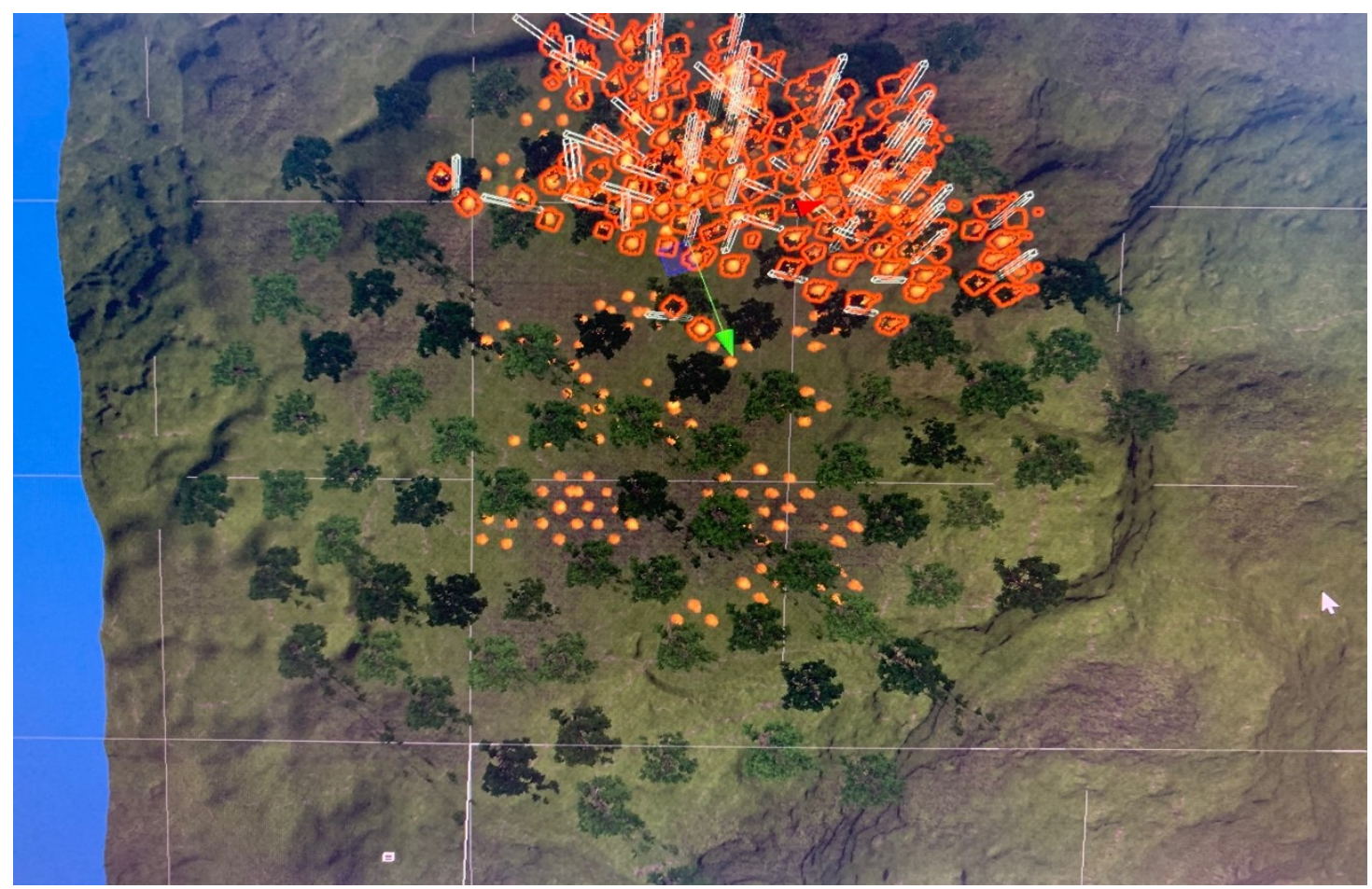

Figure 11 Over view of complex scene scenario B with Northwest wind, The highlighted fire is the head fire area 


\subsubsection{Study Design}

The study procedure for each participant consisted of 5 steps: 1. Introduction, 2. familiarize with virtual training system with a pre-scene, 3. Information processing and extinguish the head-fire in scenario $\mathrm{B}, 4$. the head-fire orienting and extinguish training in scenario A for 4 times, 5. participate in scenario B again to extinguish the head-fire. Due to the time comparison purpose, the order of scenarios A and B are strickly in order for the participant. At step 1, participants were informed about the study and the procedure. Then the user was introduced to the fire behavior knowledge as well as input and output of the system by explanation and demonstration. In step 2, the participant has time to familiarize the experiment by attending the pre-scene to walk freely and put down the fire by using Joystick under the breeze weather condition. The information of direction participant faced at the beginning and the direction wind blows were provided as instruction. The same instructions are given to the following steps. As soon as the participant feels confident, the participant was asked to enter the hard scene scenario B. Participants are told the time counting starts from this step to simulate the time pressure as in the real fire ground. Time of participant reaches the head fire area and the total time he has spent from start to extinguish the head fire was recorded. This simulates the authentic time length junior or volunteer firefighters would use to locate the head fire in the real wildfire without practical practice. After measuring time in scenario B, participants could start the actual training in scenario A four times. During those four times, the participant was free to explore the relationship between each fire behavior element and interact with them. Next at step 5, the participant was asked to conduct again with the same environment and time record criteria as the first time in scenario B. The time participant used in scenario B the first time and the second time is used to evaluate the effectiveness of this training system. If the time trainee spends locating and extinguish the head fire the second time is shorter than the first time, then the training system is potent. 


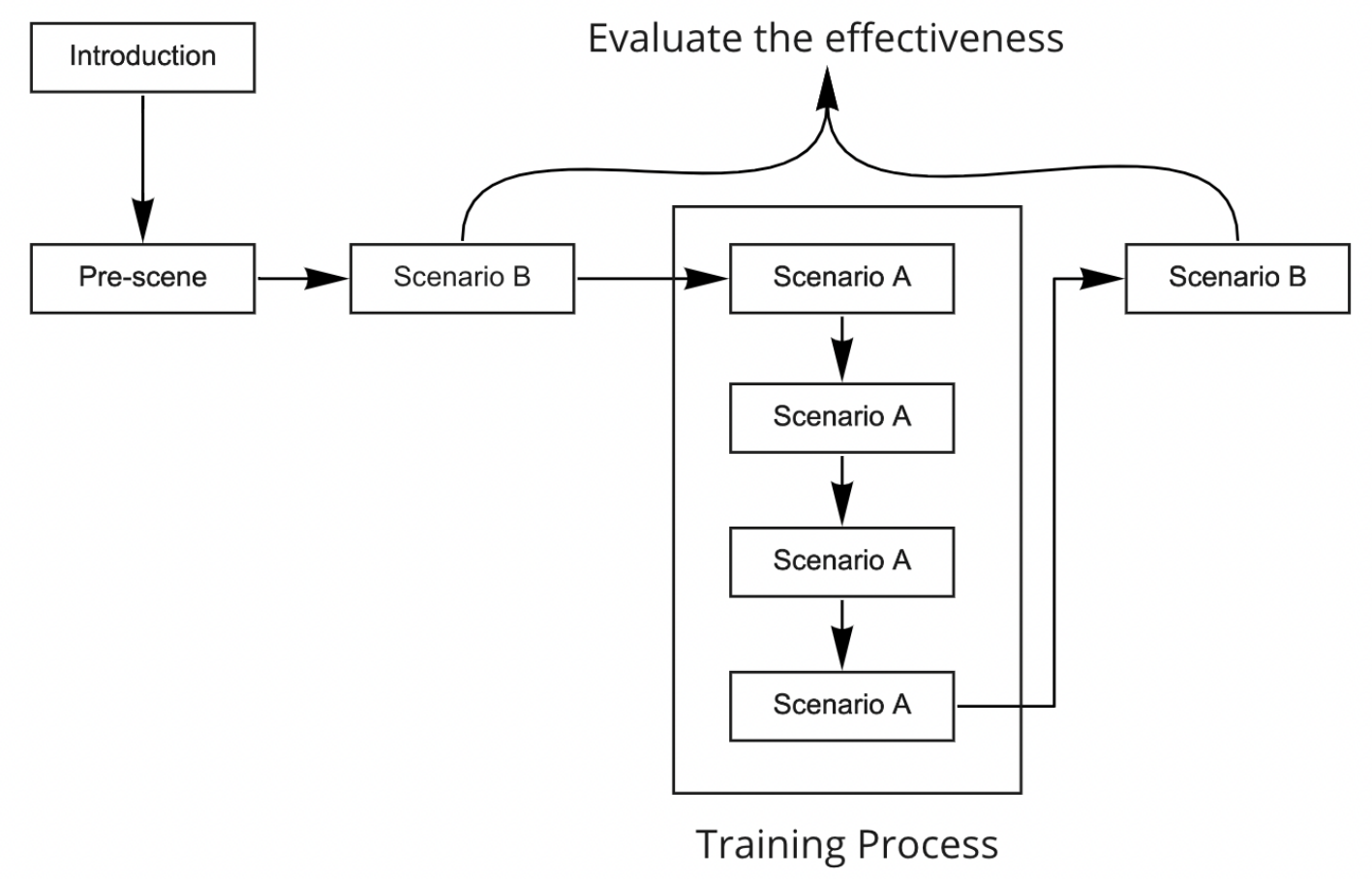

Figure 12 Experiment Process Flow

\subsection{Result}

Due to the lack of sample for statistical analysis, this study chose to make a descriptive analysis with an inferential character. Because of the VR training at this stage is a supporting training system beside traditional training, the main user group is novice firefighter who has no or few professional experience at actual firegrounds. Hence, the sample of this experiment doesn't require professional firefighters to evaluate. Ordinary people with understanding of the wildland fire behavior also qualify for this study. Four male and female participants from age 23-26 attend this study. All participants have few VR using experience and no significant cybersickness in previous VR experiences. The result of fire behavior experience is shown below in Table 2 and 3. 
Table 2 Result of participant's reaches head fire area

\begin{tabular}{|c|c|c|c|c|}
\hline & Sample 1 & Sample 2 & Sample 3 & Sample 4 \\
\hline Test 1 & $01: 15.26$ & $01: 41.53$ & $03: 21.14$ & $02: 02.63$ \\
\hline Practice 1 & $00: 40.79$ & $00: 37.13$ & $01: 53.92$ & $00: 45.97$ \\
\hline Practice 2 & $00: 12.93$ & $00: 50.78$ & $01: 35.12$ & $00: 38.93$ \\
\hline Practice 3 & $00: 14.08$ & $00: 38.95$ & $01: 05.83$ & $00: 27.89$ \\
\hline Practice 4 & $01: 16.34$ & $00: 36.44$ & $00: 55.35$ & $00: 30.52$ \\
\hline Test 2 & $01: 14.04$ & $01: 04.32$ & $01: 56.37$ & $01: 51.75$ \\
\hline
\end{tabular}

Table 3 Result of total time spent

\begin{tabular}{|c|c|c|c|c|}
\hline & Sample 1 & Sample 2 & Sample 3 & Sample 4 \\
\hline Test 1 & $02: 58.44$ & $04: 10.41$ & $05: 01.09$ & $04: 02.27$ \\
\hline Practice 1 & $02: 21.58$ & $03: 33.67$ & $4: 20: 06$ & $03: 27.66$ \\
\hline Practice 2 & $02: 13.17$ & $02: 43.85$ & $03: 04.09$ & $01: 41.47$ \\
\hline Practice 3 & $02: 09.84$ & $03: 03.45$ & $03: 34.22$ & $01: 35.89$ \\
\hline Practice 4 & $02: 49.02$ & $02: 32.30$ & $03: 00.73$ & $01: 33.05$ \\
\hline Test 2 & $02: 09.19$ & $03: 30.03$ & $03: 01.35$ & $03: 04.63$ \\
\hline
\end{tabular}

Due to the individual orientation and information process skills, the improvement off time reaches head fire area and total time they spent are various. Participant stricktly followed the order of pre-scene, scenario B, four times of scenario As, and scenario B again for an accurate time comparison. As shown in the table 2 and 3, all participants have performed faster results on both records. By looking at the time participant reaches the head fire area in all 6 experiments, time improvement is not obvious. From the feedback participant gives after the experiment, he reported because of the faster and stronger wind, he is able to orientated the 
head fire direction by calculated the direction he is facing and observe the tree branch movement. That has caused the test 2 has no siginificant inprovement in time reaches the head fire are than the test 1 . However, it also proved that the participant has the knowledge of understand the interaction of wind speed and direction with the head fire.

To have better understanding of the training process, the study also recorded the time participants spended in scenario A. Despite the short amount of time participant used to reach the head fire area, it is hard to determain orientated within the head fire zone and approve extinguish time. However, the practices was been told participant has freedom to explore the possibilities, hence, the critical time data for comparison are focus on scenario B. Besides the improval on time recording, all four participants have also reflected that after the practice, the training as helped them to understand the concept of head fire than verbal and image explanation before the training.

After the experiment, participant reported that he is not able to remember the location of the head fire once he entered the fire zone because the first-person point of view doesn't allow panorama map. This has indicated improved performance was a result of the practices of training system and not from increased familiarity with the environment.

\section{Methodology for the Sense of Presence}

\subsection{System Concept}

$\mathrm{T}$ The purpose of learning fire behavior by using VR and VE has been evaluating effectively due to the result of the time comparison. However, by reviewing the experiment and further research on the extreme situation first responder training, we realized to effectively train a firefighter, a simulated mental environment is as important as the simulated physical training environment. Being aware of the situation and make the right decision under stress and time pressure are crucial skills for a first responder to practiced. According to Project 
Responder 4 [46], situation awareness is defined as the capability to obtain and distill specific knowledge concerning threats, hazards, and conditions in a timely matter to support incident management decisions across all phases of catastrophic incident response.

The nature of emergency first response involves extreme time pressure, often confusing situations with emerging characteristics, and high stakes consequences associated with selected courses of action [46]. According to Klein et al.'s study of decision making on the fire ground [47], the experts choose a course of action that they experimented having chosen in a similar situation before under the time-pressured situation. That means the first responder's decisionmaking ability is to reply on whether they can recall a similar situation before. The given situation is recognized as "typical" in the study, meaning that experience plays an important role in the process. While the commander of a team often has excellent situation management skills and is able to make decisions based on professional experiences, operations, in general, are largely based on established standard operating procedures [48]. When communication breaks down, leading to emergencies, individual firefighters resort to making decisions on their own, often based on immediate environment cues and nearby team members, sometimes neglecting the needs and operations of distant or unseen team members [49].

The important fact to train user's situational awareness is user feels the same pressure, stress, and concentration as in the real fire ground. It has been proved the emotional induction is related to the level of sensitivity of the presence in the VE. Different conditions of input would affect the immersion level, hence distract the user from the external surrounding environment. To confirm the effectiveness of the VR wildfire training system is legit in any aspect of the wildfire training, the study takes to the second stage of evaluating the emotion evocation. Two VR conditions are given as the comparison pair. The evaluation compares the biological information of electrocardiogram, facial skin thermogram for stress and concentration level during the training in both conditions as the objective data. Meanwhile, 
after every condition experiment, participants also require to evaluate the subjective sense of presence questionnaire.

\subsection{Evaluation}

\subsubsection{HRV}

The two branches of the autonomic nervous system, the sympathetic nervous system, and parasympathetic nervous system, are a coordinated response system underlying arousal, stress, and flight/fight behavior [50]. The amount of variation in the unit of milliseconds of the beat-to-beat interval is controlled by the nervous system with less variation under greater control of the sympathetic nervous system and more variation under greater control of the parasympathetic nervous system [51]. When the sympathetic system reacts to a fight/flight response it helps the body to prepare for a perceived threat, following by the increases in heart rate. On the other hand, the parasympathetic system alters a number of functions in the body to help it recover. Those functions are largely mirror opposites of sympathetic system activation, which means usually follows with the decrease in heart rate. These processes optimize functions in the body at rest and allow it to focus on maintenance. 

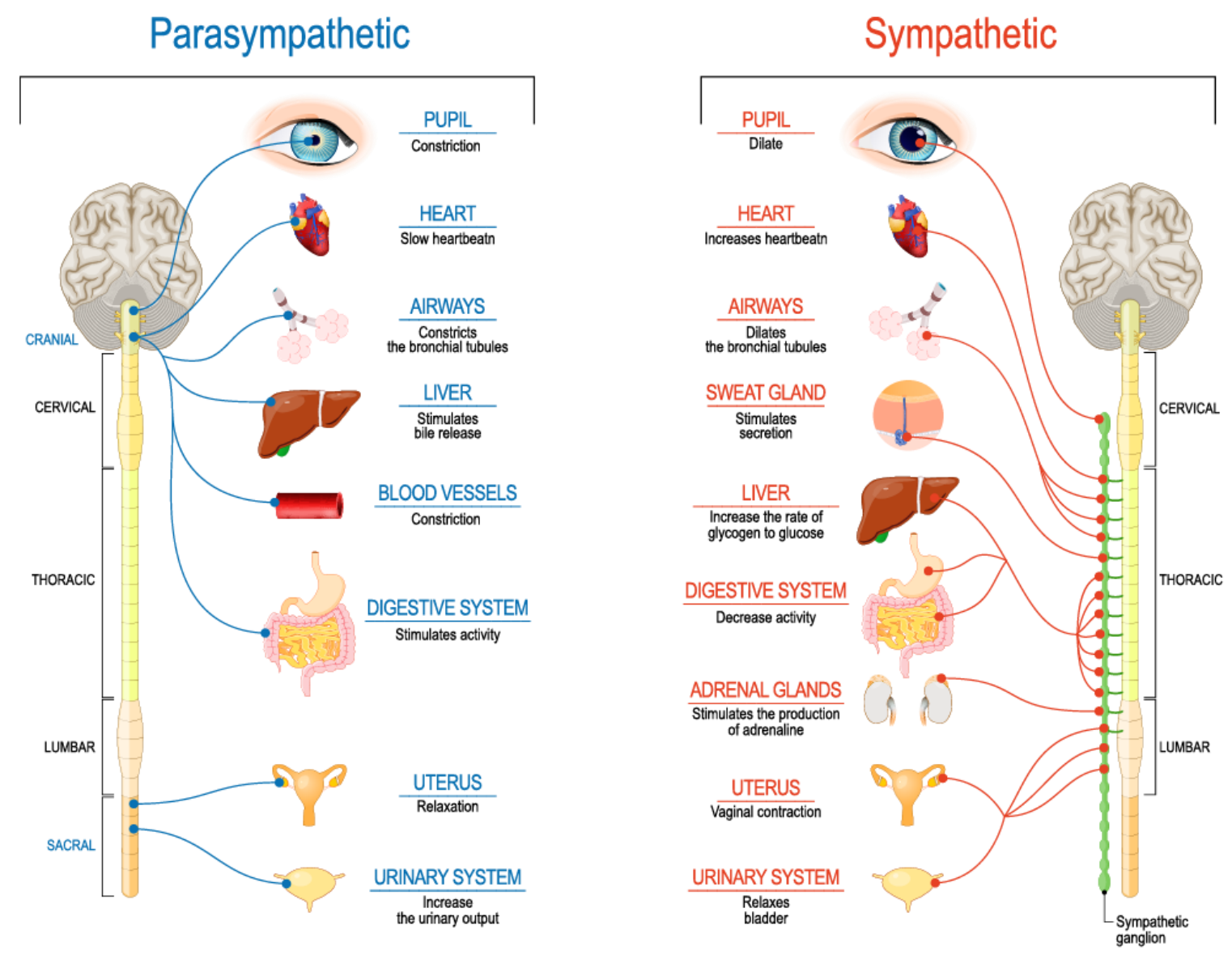

Figure 13 the different body parts Parasympathetic and Sympathetic nerve system control

The most obvious manifestations of autonomic nervous system functioning are changes in the length of the cardiac cycle over time that underlines stress and responses [52]. However, the HRV is not directly interpretable outside of the context within which it is measured. One way to investigate physiological emotion arousal and how people respond to different stimuli is analysis through the ECG (electrocardiogram) signal. ECG signal is periodic with the fundamental frequency determined by the heartbeat that shows a mixture of triangular and sinusoidal waveforms. Each significant feature of the ECG signal can be represented by shifted and scaled versions of one of these waveforms as shown below. 


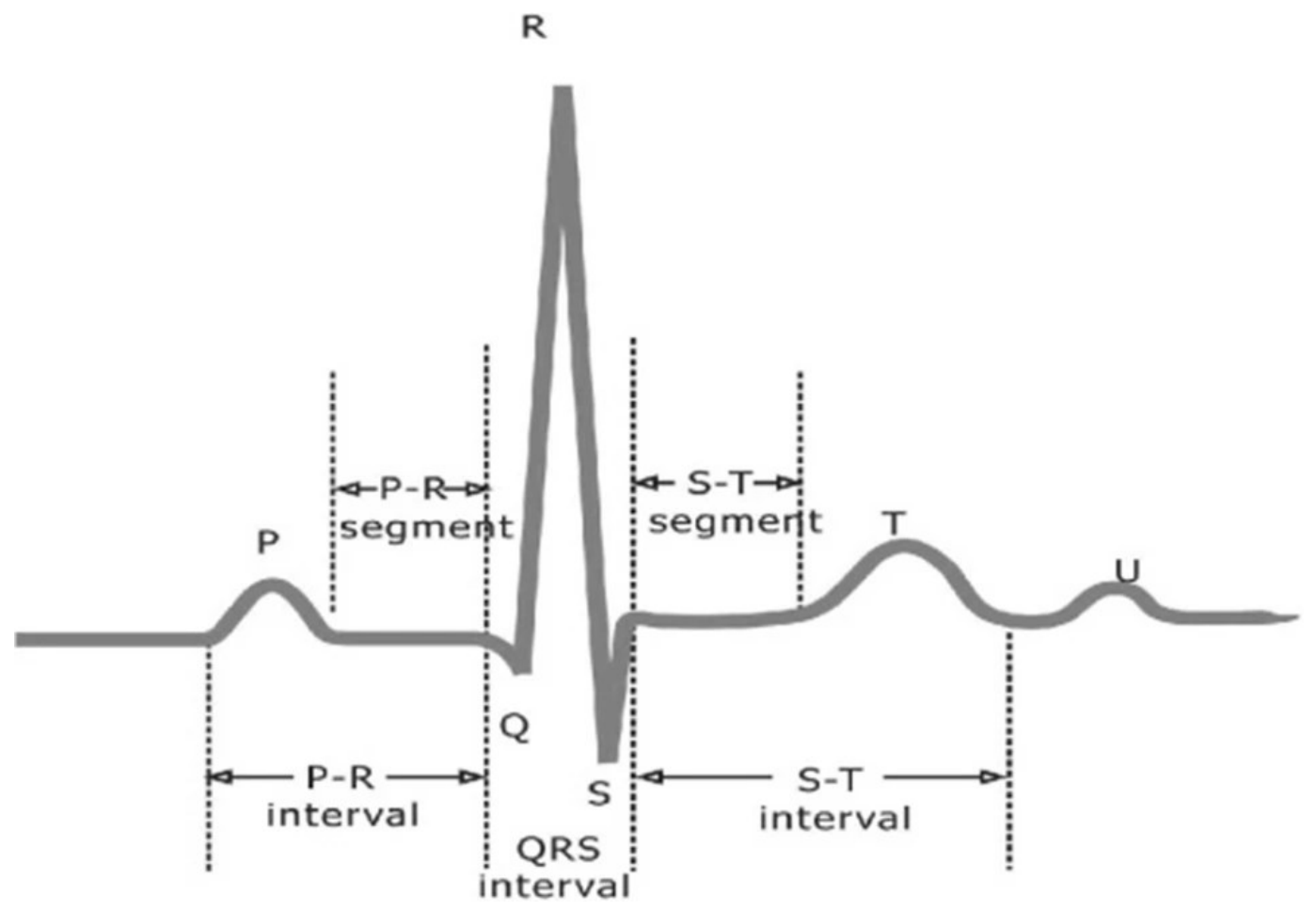

Figure 14 One-cycle ECG signal

As you can see, a single ECG signal contains various cardio actions and information. Among all the complex, " $\mathrm{R}$ " is the area from which the values for analysis are taken. The $\mathrm{R}$ stands for each success heartbeat. As a human heartbeat is a continuous movement, on the ECG signal each successful heartbeat is next to another, and the distance (in milliseconds) between each $\mathrm{R}$ is defined as the R-R intervals (RRi). Because the distance between each RRi is in the time domain, the smaller the RRi values the faster the heartbeat, and the bigger the RRi value, the slower the heartbeat.

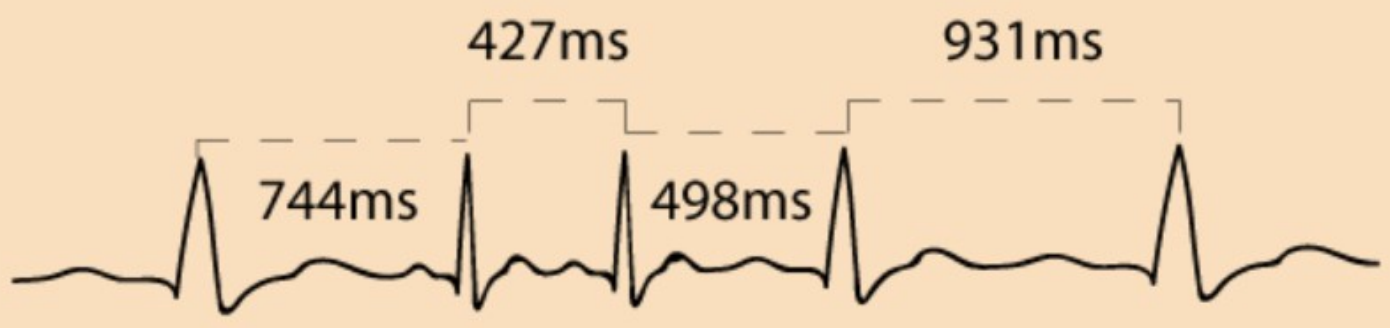

Figure 15 Each peak shows a successive RRi, and the distance from each RRi is count in millisecond 
The shorter distance of RRi manifests the faster heartbeat to prove the level of stress. However, being stress is not the goal of the training system but being concentrate and focus under the time-pressure mental status. Thus, calculate the variance of RRi is the main analysis for the HRV test. According to Segerstrom, an increase in HRV is also related to self-control abilities and concentration level [29]. A smaller RRV (variance of RRi) value shows the smaller heartbeat changes during the practice and that indicates a continuous stable mental state of a person. Hence, the decrease RRV value manifest an increased human concentration [53].

\subsubsection{Monitor Device}

This study adapted the RRV evaluation for concentration measuring and detected by the wearable HRV measuring device: Polar H10 Heart Rate Sensor to record the real-time RRV value. The monitor is normally used for aesthetic tracking and analysis with accurate real-time raw RRi data recording. Polar H10 comprises a wearable strap with the plastic electrode area on, and a connector buckles on the strap to sends the heart rate signal to the receiving device.

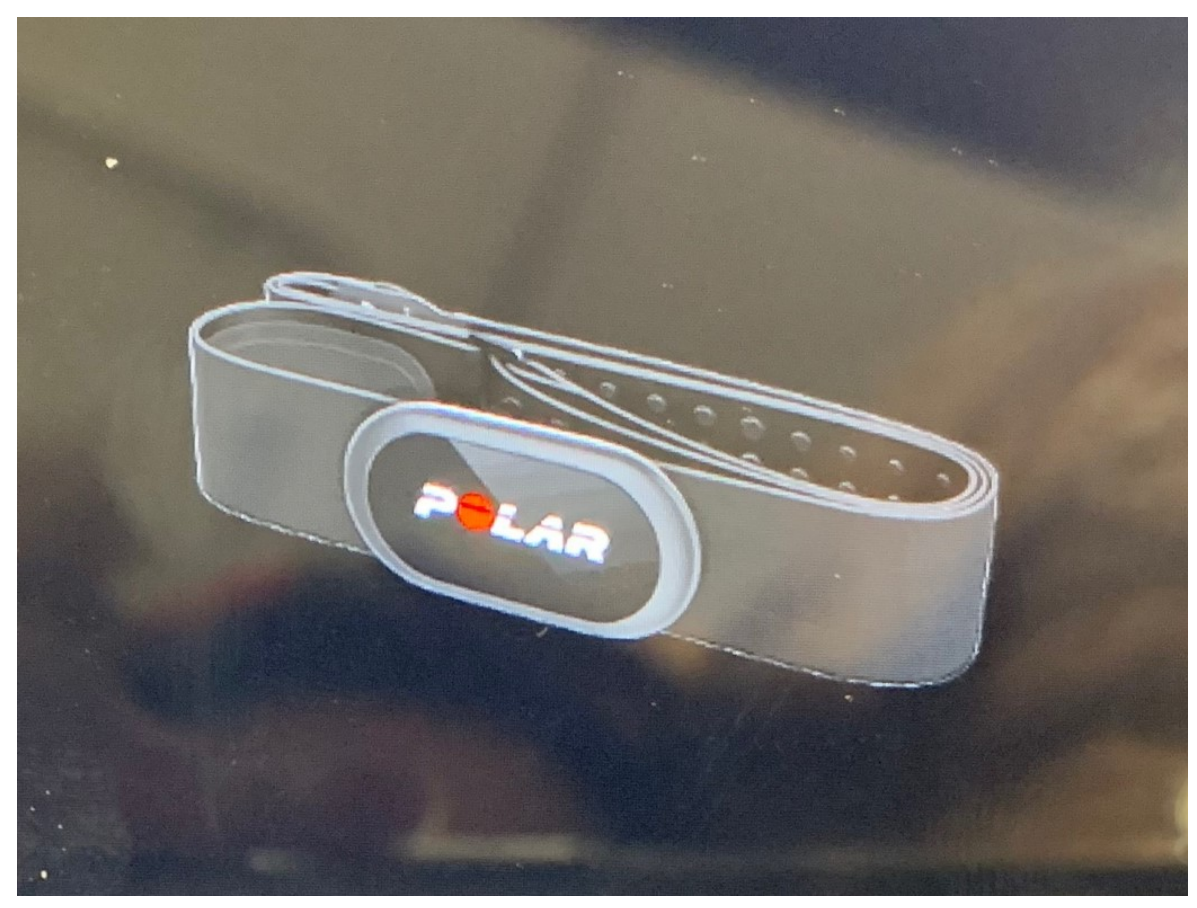

Figure 16 Polard H10 chest wearable HRV monitor. 
The sensor is compatible with the Bluetooth connection to the receiving device, like a smartphone or a tablet by using a separate application. The Polar application on the ios platform tracks the modified heart rate and blood pressure. Generally, the recorded ECG signal is often contaminated by noise and artifacts that can be within the frequency band of interest and manifest with similar characteristics as the ECG itself [54]. In order to extract useful information from the noisy ECG signals, the study uses the Android platform Lavie tablet with Polar Equine application 1.2.0 developed to track the raw ECG signal data. The application pairs with the polar H10 and detect the signal from the strap's electrode then collect the raw RRi data in form of txt. to the device.

\subsubsection{Facial Thermal}

For the past decades, different research efforts on human emotion modeling and estimation have been reported. Several Biological signals, like ECG, blood pressure, electroencephalogram have been proved for human emotion detection [55]. Visual image is also a common research topic of how facial expression express the emotions. However, the ingenuine fact of the facial expression prediction is that a man can easily fake the expression and visual image has not develop the capability to distinguish the fake and original emotions. In recent years, emotion recognition based on the temperature information reflected through the infrared thermal images has also been practiced in academic field [56]. Human cutaneous temperature change is depending on cutaneous blood perfusion controlled by the autonomic nervous system innervating the vessels that irritate the skin [57]. Although the parasympathetic system has an influence on the temperature changes through the endothelial cells, in glabrous areas such as palm, pelma, and nose-tip area, vasodilation seems to be mainly regulated by sympathetic noradrenergic fibers, the activation of which leads to vasoconstriction [58], and thus, to a decrease in local temperature. Among other facial areas, the nose tip has been shown to be the only consistently reported region to monitor the significant decreases in its 
temperature under stress conditions, indicating that the nasal thermal drop could be a stress indicator [59]. This is because the absence of underlaying muscles around nose tip area, and that avoids the thermal contamination [60] due to contraction. Meanwhile, the abundant arteriovenous anastomoses in this heairless area involved in body temperature regulation [61].

The thermal spectrum is capable of capture the superficial blood vessels flow underneath the skin and above the bone structure and muscle layer. At the same time, studies have proved such physiological activates are influenced not only by the ambient temperatures (surrounding temperatures of colling or warming) but also by mental stress [59]. Hence, infrared thermal detection, especially from the facial region, has been a popular method to capture stress, concentration, and excitement. According to Nakamura and Kuraoka's [62] research, the decrease of mean temperature during the experiment marks emotional arousal. From the directional study [26] on evaluating the facial thermal effect on emotional arousal, the maximum mean temperature decrease is around $-0.25^{\circ} \mathrm{C}$. The stronger arousal reacts to the income sources, the bigger the thermal reactions. This has been proved by Loannou et al [57] study. In their study of guilt in children, they found that the stronger the disaster sigh, the faster nose temperature decreases.

\subsubsection{Facial Thermal Device}

Consider the purpose of continuous real-time tracking at the participant's nose tip, a portable and functional facial thermal device is a preferred choice. This study employed the FLIR one pro inferred thermography camera provides by Teledyne Flir. The camera is capable of temperature detection up to $400^{\circ} \mathrm{C}$ with 19,200-pixel resolution. The camera is compatible with any iOS model with ver 10.1 or later platforms by using the Lightning connector. 


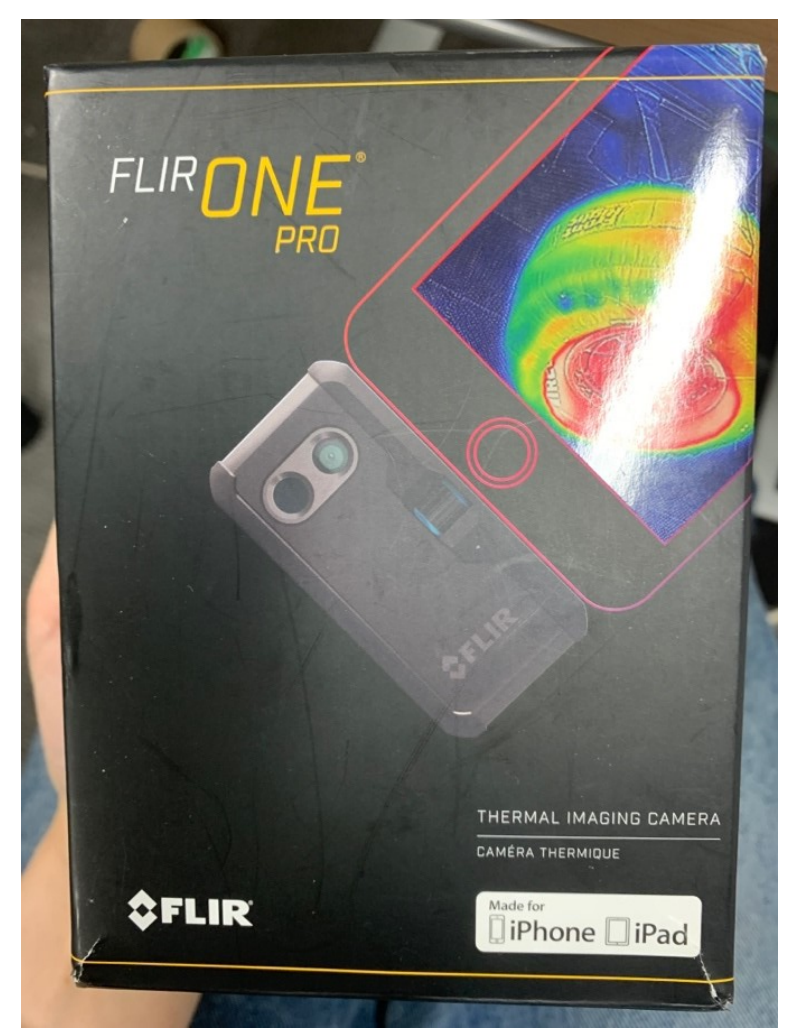

Figure 17 Flir Thermal infrared camera attached to the iOS device.

The smartphone is used as the monitor to the camera and requires a separate application FLIR. With the application, the study can capture facial temperature in the form of video and still photos. The official claim of the accuracy of the camera is $\pm 3^{\circ} \mathrm{C}$ or $\pm 5 \%$, however, the different room temperature and base temperature of each individual have affected the nose-tip temperature in the study as well. The Flir camera doesn't support automatic tracking and only provides a frame refresh rate of $8.7 \mathrm{~Hz}$. The bare minimum requires for the modern monitor is $60 \mathrm{~Hz}$, which has caused a slow response to the tracking during the 110-degree condition, where participant movement is based on the direction change of his/her head. So, the study 
active the multiple spot meters around the area of potential movement to have the continued capture of the nose-tip.

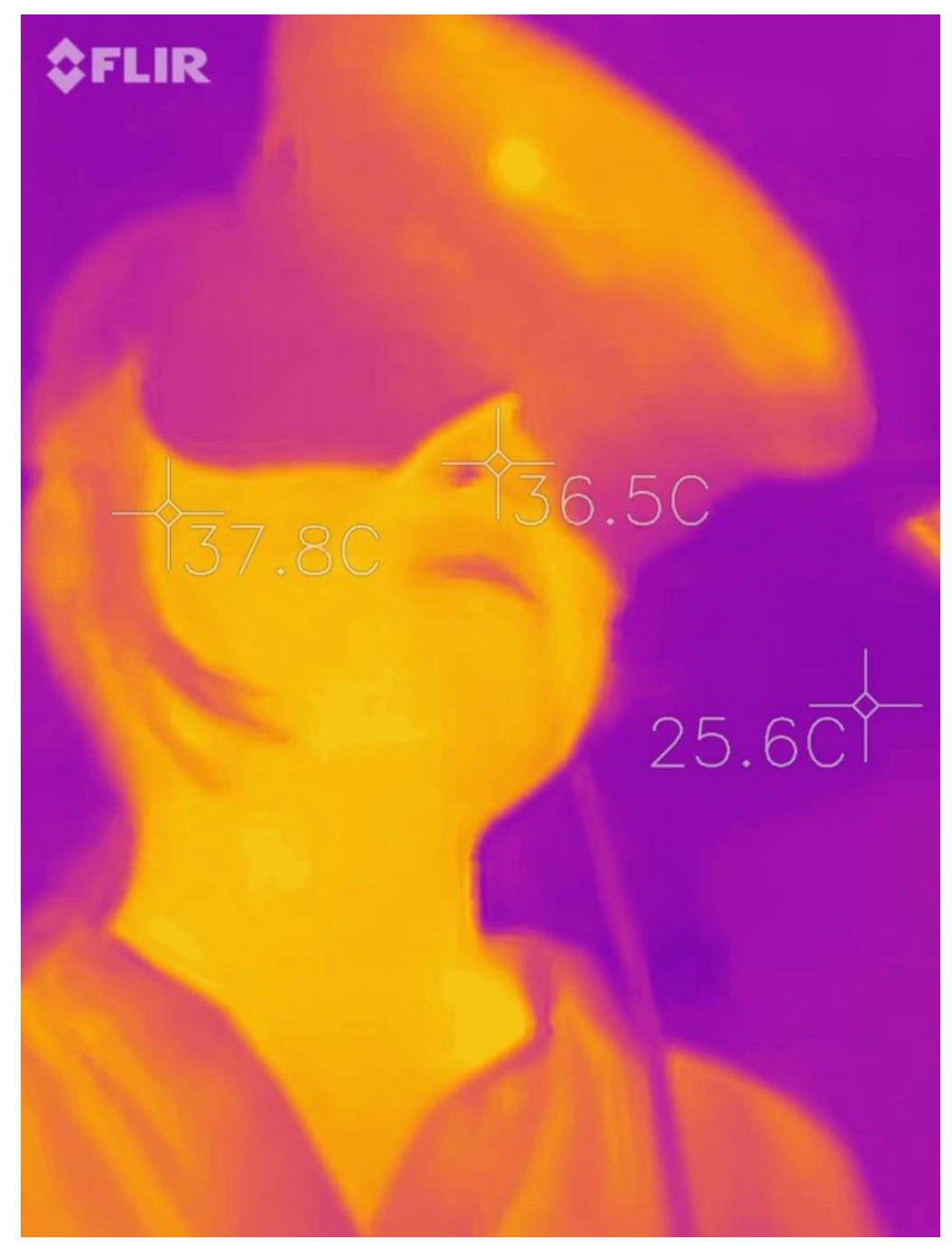

Figure 18 Application screen of capture the nose-tip temperature by using Flir infrared camera

\subsubsection{Questionnaires}

Additional to the objective biosensor capture methods mentioned above, the study is also valued the subjective observation from the participants of their sense of presence in the environment. Sense of presence is a specific focus point of VR technology. The term is referred to a degree to which participant feels that they are somewhere other than where they physically are when they experience the effects of a computer-generated-simulation [63]. Compare to 
other physiological measures of the sense of presence in VE, validated questionnaires are the most common method for measuring the construct [64].

Studies [63] suggested while immersion is a variable of the technology and can be described objectively, the sense of presence is a variable of a user's experience. Therefore, a self-report by using a questionnaire is one of the reliable measuring methods. Participate reflect the intuitive feeling of the presence in the virtual world through questionnaires by using different items and subscales. As the most common method for measuring the presence, multiple presence questionnaires are published and served for different purposes of study. Among all the listed questionnaires, Schubert et al.'s [65] iGroup presence questionnaire (IPQ) has the most citation while being the newest method. IPQ is a 13-item presence scale with three independent components: spatial presence, involvement, and experienced realism. The reason for having three separated components is because Schubert et al. investigated the cognitive process that led to a model of presence. The result of exploring each component of the model is they identified spatial construction, attention, and judgments of realness are distinct components of the presence [66]. In the final version of IPQ, they added one additional item with a mild double loading on involvement.

Table 415 published questionnaires about the sense of presence

\begin{tabular}{|l|l|l|l|l|}
\hline Authors & Year & Citations* & Items & Usage \\
\hline Banos et al. [67] & 1998 & 238 & 77 & VE \\
\hline Barfield \& Hendrix [68] & 1995 & 341 & $5+1$ & VE \\
\hline Cho et al. [69] & 2003 & 41 & 4 & $13+1$ \\
\hline Dinh et al. [70, 36, 71] & 1999 & 583 & $19+4$ & VE \\
\hline Gerhard et al. [72] & 2001 & 86 & 8 & SVE \\
\hline Kim \& Biocca [73] & 1997 & 914 & 42 & VE \\
\hline Krauss et al. [66] & 2001 & 106 & 103 & NA \\
\hline Lombard \& Ditton [74] & 2000 & 346 & & \\
\hline
\end{tabular}




\begin{tabular}{|l|l|l|l|l|}
\hline $\begin{array}{l}\text { Lombard \& Weinstein (TPI) } \\
\text { [75] }\end{array}$ & 2009 & 253 & $4-8$ & CM \\
\hline Lessiter et al. (ITC-SOPI) [76] & 2001 & 1211 & 44 & CM \\
\hline Nicholes et al. [77] & 2000 & 253 & 9 & VE \\
\hline Nowak \& Frank [78] & 2003 & 908 & 9 & SVE \\
\hline Schubert et al. (IPQ) [65] [79] & $\mathbf{2 0 0 1}$ & $\mathbf{1 4 1 1}$ & $\mathbf{1 4}$ & VE \\
\hline Usoh/Slater et al. (SUS) [80] & $1994 / 2000$ & 687 & $3 / 6$ & VE \\
\hline Witmer \& Singer (WS) [81] & 1998 & 5729 & 32 & VE \\
\hline
\end{tabular}

$\mathrm{VE}=$ Virtual Environment, $\mathrm{CM}=$ Cross-Media,

$\mathrm{SVE}=$ Shared Virtual Environment, NA $=$ items not listed

*Referred to Google Scholar, Jun 2021

Based on the present model, three principal components are fairly independent and reflect different factors. Spatial presence items represent the sense of being physically present in the VE, involvements measure the attention devoted to the $\mathrm{VE}$ and the involvement experienced, and experienced realism measures the subjective experience of realism in the VE [82].

The questionnaire has three items with reversed wording, they are SP2, INV3, and REAL1. Originally the questionnaire was conducted in German, following by the study requirement, it has been translated into English, French, Dutch, and Japanese. Because the samples of this study are native Japanese speakers and Japanese preferred speakers, we adapted the Japanese version. The Japanese version is provided by the official organization website translated by Japanese scholars for their work on presence. Translated questionnaires referred to both original German questions and most commonly used English questions to reduce the potential misunderstanding. In table 5 shows the English version of Questionnaire that translated by Slater and Usoh [30], Hendrix [83], Witmer and Singer [71], and Carlin, Hoffman, Weghorst [84, 44, 44], refer to the appendix for the full questionnaire questions: 
Table 5 English Version of IPQ items

\begin{tabular}{|c|c|c|}
\hline $\begin{array}{l}\text { IPQ } \\
\text { item } \\
\text { name }\end{array}$ & English Question & English Anchors \\
\hline G1 & In the computer-generated world I had a sense of "being there" & Not at all - very much \\
\hline SP1 & Somehow, I felt that the virtual world surrounded me. & Fully disagree - fully agree \\
\hline SP3 & I did not feel present in the virtual space & Didn't feel - felt present \\
\hline INV1 & $\begin{array}{l}\text { How aware were you of the real world surrounding while } \\
\text { navigating in the virtual world? (i.e., sounds, room temperature, } \\
\text { other people, etc.)? }\end{array}$ & $\begin{array}{l}\text { Extremely aware - moderately } \\
\text { aware - not aware at all }\end{array}$ \\
\hline INV2 & I was not aware of my real environment. & Full disagree - fully agree \\
\hline REAL1 & How real did the virtual world seems to you? & $\begin{array}{l}\text { Completely real - not real at } \\
\text { all }\end{array}$ \\
\hline REAL2 & $\begin{array}{l}\text { How much did you experience in the virtual environment seem } \\
\text { consistent with your real-world experience? }\end{array}$ & $\begin{array}{l}\text { Not consistent - moderately } \\
\text { consistent - very consistent }\end{array}$ \\
\hline REAL3 & How real did the virtual world seem to you? & $\begin{array}{l}\text { About as real as an imagined } \\
\text { world - indistinguishable from } \\
\text { the real world }\end{array}$ \\
\hline
\end{tabular}

\subsection{Study Design}

\subsubsection{Visual Conditions}

Immersion level and the sense of presence are two well-mentioned concepts when evaluating the effectiveness of a VE. In fact, they are distinguished into two categories [64], where immersion is a quantifiable aspect of display technology, primary depends on the extent to which display are [85]: 
1. inclusive (the stimulate from the real-world is excluded from the user),

2. extensive (the number of sensory modalities accommodated by the system),

3. surrounding (how wide and surround the display is),

4. and vivid (the resolution of the display).

Unlike immersion, the sense of presence is "a psychological sense of being in the virtual environment [30]." The correlation of two concepts is progressive, the higher the immersion level, the higher the level of presence. To evaluate the concentration, stress, and present level of the training VE, this study represents two immersive conditions for this experiment: 1) a 30degree viewing angle, 2436-by-1125-pixel resolution screen and no interaction function Google Cardboard equip with iPhone X. 2) a 110-degree viewing angle, 2160-by-1200-pixel resolution screen, and a motion-tracked handheld controller to interact with the environment HMD - HTC Vive. By comparing two VR conditions, the study evaluates the emotion arousal, concentration level, and the sense of the presence of the HMD we examined in the first stage.

Google Cardboard is introduced by Google in 2014, compare to other mainstream VR HMD (Oculus Rift, HTC, or Samsung Gear VE) it is portable, easy to access, and more importantly, low-cost. By 2016, Google Cardboard reached 5 million users, with over 1,000 applications available [86]. Due to this reason, many researchers have conducted Cardboard to content delivery studies [87] [18]. Google Cardboard headset consists of a piece of cardboard in the shape of folding glasses and a $45 \mathrm{~mm}$ focal length lenses. The focal length lenses reflect the image displayed by the smartphone replaced in front of the lenses. Hence, the graphical fidelity of Cardboard is differing from device to device, depending on the specific phone used in the headset. For this experiment, iPhone Xs is used for Cardboard VR condition because of the maximum smartphone size Cardboard can contain. Because Google Cardboard doesn't 
contain a screen per se, the experiment considered iPhone Xs's resolution of 2436x1125 as the evaluation condition.

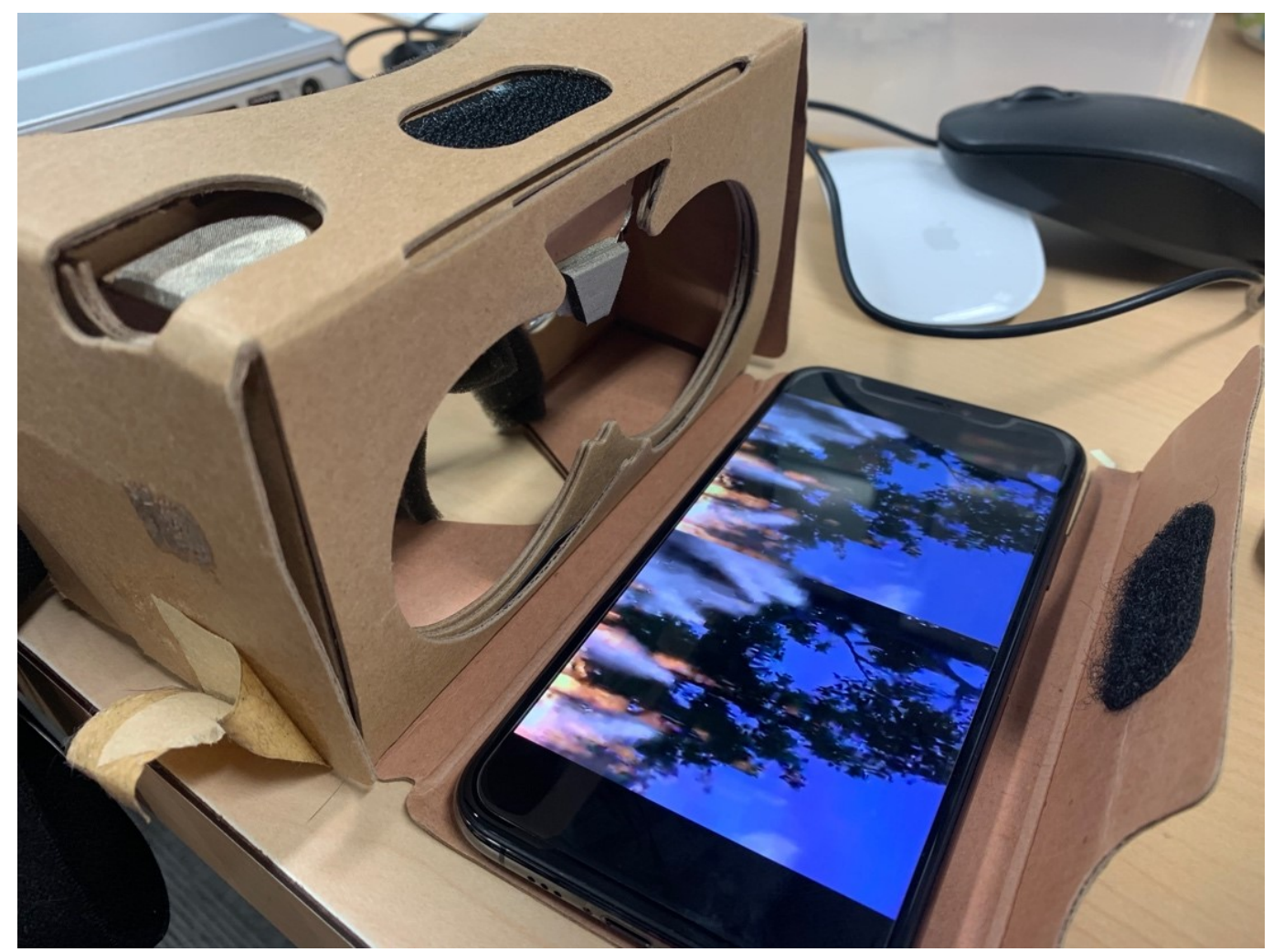

Figure 19 Google Cardboard with iPhone Xs

On the other hand, the second condition is the HMD used in the first stage experiment, HTC Vive. The hardware consists of a headset, two controllers, and two infrared laser emitter units. The headset supports a 110-degree field of view (approximately 90-degree per eye), with the 2610-by-1200-pixel display. Controllers (Joysticks) allows user to interact with the VE by using the touchpads designed on. An infrared laser emitter (lighthouse) uses for track position and orientation purposes. The lighthouse serves to limit and correct for the build-up in error that is inherent in dead reckoning based on inertial measurements [30].

Both conditions share the same VE as the none-real time wildfire training as the first stage evaluated. Because Google Cardboard doesn't support interaction function, for this condition, 
a recorded video of participant extinguish wildfire by using interactable HMD is used and designed into a 3D image.
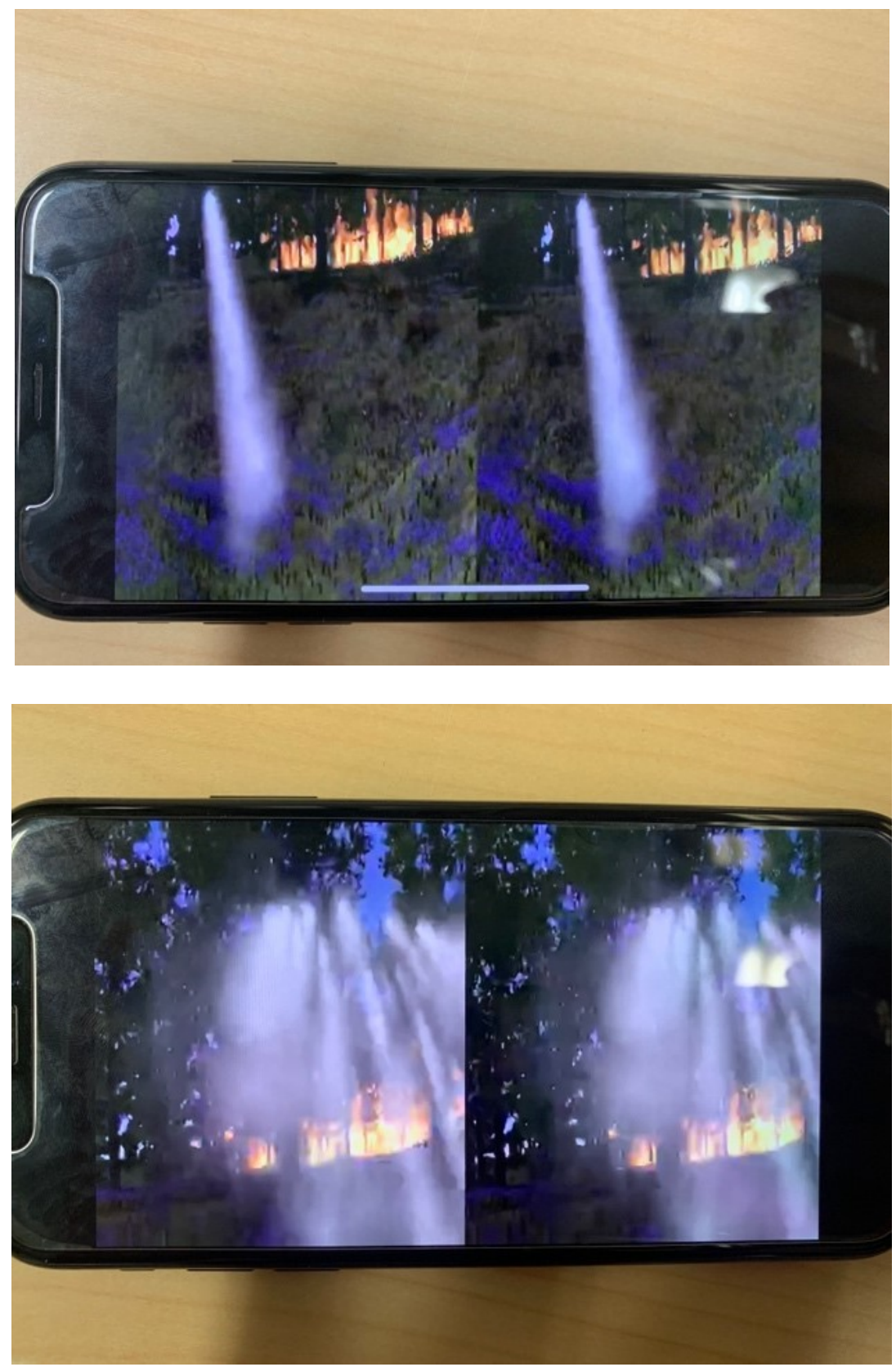

Figure 20 3D video for Google Cardboard display 


\subsubsection{Sample}

The sample consisted of 10 participates. 4 male and 6 female with ages between 24 and 26 years. Same as the stage one experiment, the evaluation of this experiment is to validate VR wildfire training system is effective for novice firefighters. The participant with no firefighting experience is also qualified for this study. As same entry-level firefighters, participants' age was selected to match with the junior firefighter's age. All participants have VR using experiences before attending this study and were familiar with both visual conditions. All participants reported normal and don't have significant cybersickness feedback.

\subsubsection{Procedures}

10 participants participate in two conditions VE: the first one has a 30-degree viewing angle, 2436-by-1125-pixel resolution, but no interaction function represented by Goggle Cardboard with iPhone Xs, and the second one is HTC Vive with 110-degree viewing angle, 2160-by-1200-pixel resolution with motion-tracked handheld controllers to interact with the environment. Participants are asked to wear the HRV measuring strip first and tested device signal and physical condition for basic data. After explained the flow of the experiment, participants had the chance to familiarize with devices and for interaction condition, to understand how to control the avatar's movement and how to extinguish the fire. When participants are comfortable with the operation, they are first asked to enter the first condition (Google Cardboard). While participants participate in the VE, HRV is tested continuously during the whole experiment, and facial skin temperature was also continuing to track the participant's nose-tip in real-time for measures the temperature change. The same process was repeated for the second condition (HTC Vive). Between two conditions, participants answered the questionnaire about how they felt present in the VE. This not only reflected the objective results, but also helped participants to subside to calm from the first condition. In addition, although Google Cardboard has no interaction function, this experiment asked participants to 
stand during the whole experiment to have a similar physical performance as the interaction function condition experiment.

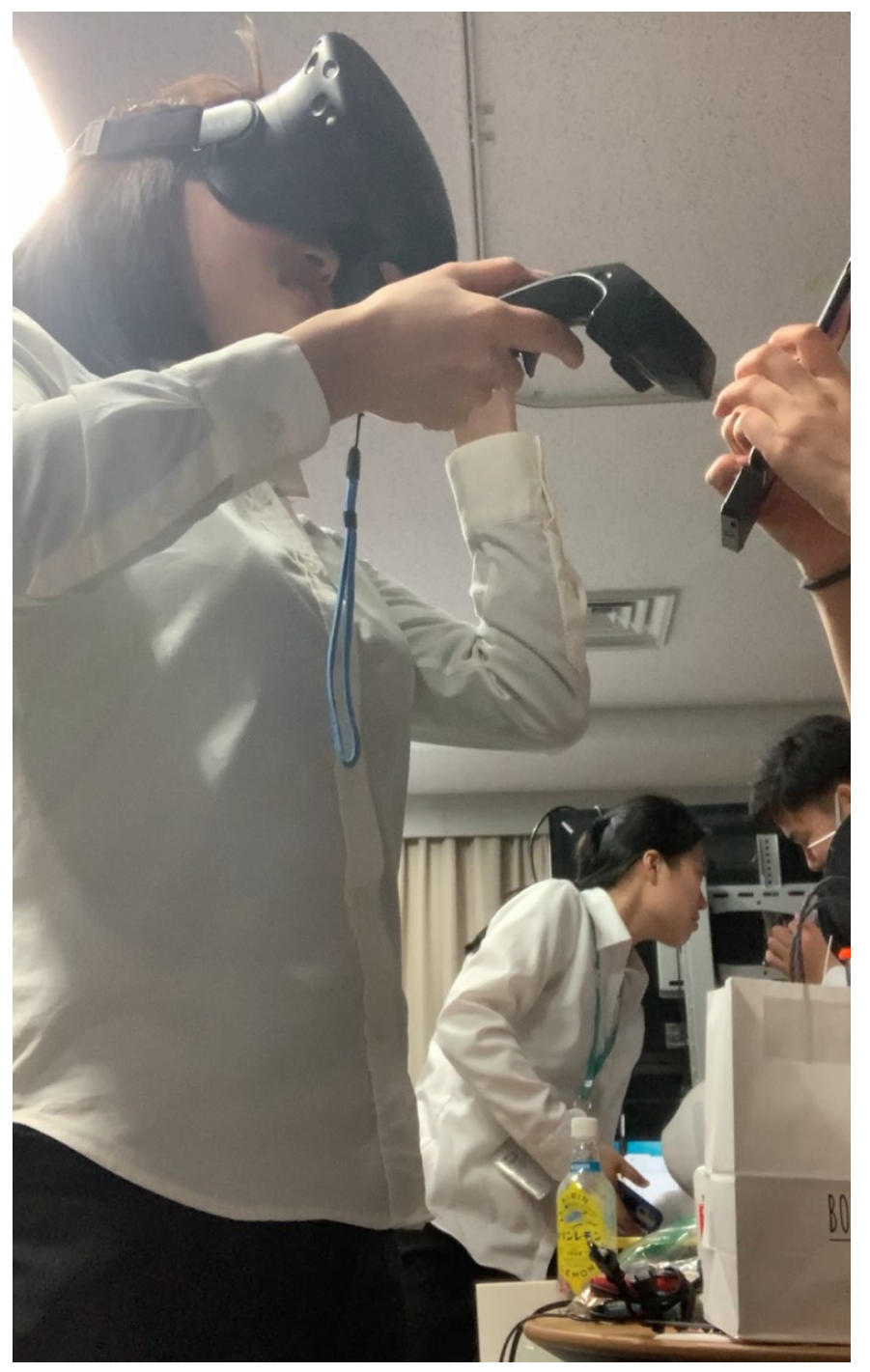

Figure 21 Participant during the higher immersion condition experiment

\section{Evaluation}

At this step, all three evaluation results performed statistical analysis by using a twotailed unequal variance t-test. Considering the measurement relies on physical condition, every data is analyzed in the individual unit to decrease the misleading consequences. All tests used a .05 significant level. 


\subsection{HRV}

The study chose the RRV value for comparing two VR conditions to evaluate the effectiveness. RRV is the variances of RR-intervals (RRi). RRi is the successive heartbeat peak during the ECG signal recording and the distance between each RRi is count in the unit of millisecond. The shorter the distance indicates a shorter time each heartbeat is, hence faster the heartbeat. Similarly to RRV, the variance of RRi, represents the consistent movement of the participant's heartbeat in a certain period of time, in this case, 5 minutes. Lower the variance means the distance in between each RRi is smaller, and hence, more sustain in the physical condition and more concentrated in mental state. This study selected the 20 smallest variances for both two he conditions during the experiment and compare the two-tailed t-test result to see which environment makes participants more concentrated. Consider the physical conditions are various from person to person, the results were also analyzed individually to avoid bias and mislead.

Figure 25 presents the RRV for 10 participants for 20 heart beats while participating in the 30-degree non-interactive environment shows in orenge and during 110-degree interactive environment shows in blue. Vive represents for 110-degree interactive environment, and CB represents for 30-degree non-interactive environment. Analysis of the results indicates statistically significant differences in RRV values where participant $1 p=0.000$, participant 2 $p=0.000$, participant $3 p=0.019$, participant $4 p=0.149$, participant $5 p=0.099$, participant 6 $p=0.008$, participant $7 p=0.0014$, participant $8 p=0.086$, participant $9 p=0.000$, and participant $10 p=0.0053$. 

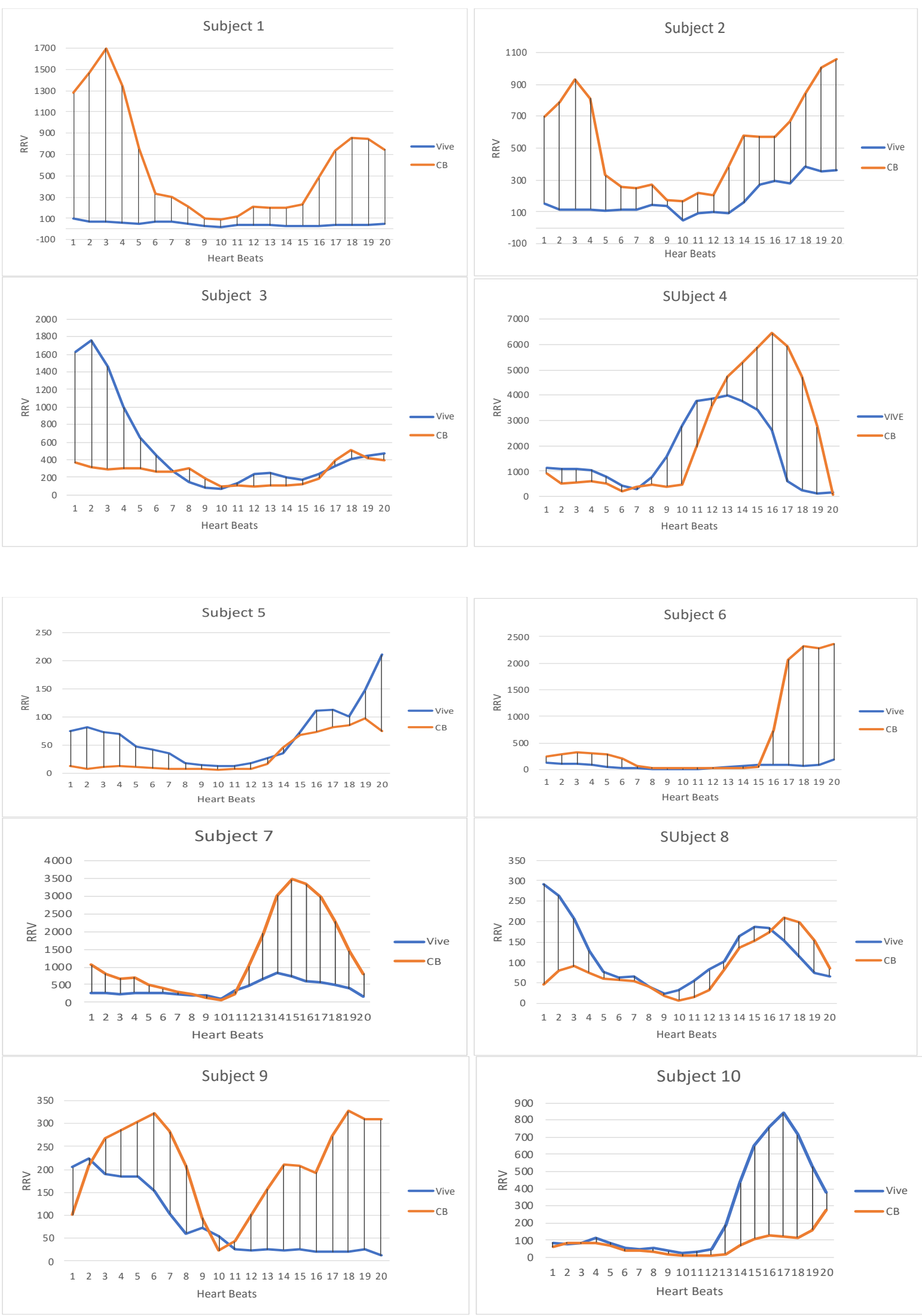

Figure 2220 smallest RR-variances comparisons for each participant in 110-degree environment and 30degree environment for all 10 participants. 
P-value has shown significant differences in the result for over the half of sample group. However, as presented in the graphs, despite p-values are significant, it's not necessary to prove that the 110-degree condition, at last, provides a more concentrated training experiment for all participants. The main reason for that first is each participant has a different physical condition. Although not all 10 participants proved the significant differences, 8 out of 10 have P-values $<0.05$, especially participants 1,6 , and 7 with consistent and low RRV during the experience in 110-degree interaction function experience than in 30-degree non-interaction-function experience where RRV are fluctuant with greater variances.

\subsection{Facial Thermal}

Functional infrared thermal imaging is considered a promising method to measure emotional autonomic responses through facial cutaneous thermal variations [26]. This study recorded the facial temperature at the nose tip - the important region of interest for facial thermal variations and compared to electrodermal responses, a robust index of emotional arousal [88]. The lower the nose temperature the more stress a participant feels during the experiment.

The participants in facial skin temperature were reduced due to the data loss caused by the camera delay during the nose track. The design of a low-quality environment experiment requires an object to turn their heads to navigate and that has caused the camera blocking for some data collections. We kept the first-time data since the emotion arouse would appear different between first-time experiment and experiment participants familiar with. The change of the room temperature influences the facial skin temperature, thus, for this study, the difference in nose temperature was measured and used.

Below in Table 6 is the results of the facial thermal variations in the unit of the participant. The result of the statistical analysis of the two-tailed t-test shows significant differences between the two conditions except for participant $6(p=0.33)$ and $8(p=0.77)$. 
Although most of the results are significant, the average difference of narrower viewing angle and lower resolution with non-interaction function environment reduced during the experiment while wider viewing angle, the high-resolution device with interaction function increase or reduce less temperature. That indicated the participant felt less stress in the low-quality environment than in the high-quality environment. However, studies indicate higher presence environment relax people while digital display causes more stress [53].

Table 6 Result of facial temperatures in Celsius

\begin{tabular}{|c|c|c|c|}
\hline Object & Average & SD & p-value \\
\hline Vive 1 & 0.34 & 0.71 & \multirow{2}{*}{$3.364 \mathrm{E}-07$} \\
\hline CB 1 & -0.15 & 0.68 & \\
\hline Vive 2 & 0.22 & 1.18 & \multirow{2}{*}{$5.75 \mathrm{E}-12$} \\
\hline CB 2 & -0.70 & 1.40 & \\
\hline Vive 3 & 0.01 & 0.87 & \multirow[t]{2}{*}{$1.519 \mathrm{E}-12$} \\
\hline CB 3 & -0.61 & 0.79 & \\
\hline Vive 4 & -0.52 & 0.93 & \multirow{2}{*}{0.0002} \\
\hline CB 4 & -1.08 & 0.61 & \\
\hline Vive 5 & 0.29 & 0.58 & \multirow{2}{*}{0.33} \\
\hline CB 5 & 0.22 & 0.52 & \\
\hline Vive 6 & 0.91 & 0.86 & \multirow[t]{2}{*}{$5.504 \mathrm{E}-07$} \\
\hline CB 6 & 1.40 & 0.83 & \\
\hline Vive 7 & -0.96 & 0.74 & \multirow{2}{*}{$1.076 \mathrm{E}-39$} \\
\hline CB 7 & 0.14 & 0.50 & \\
\hline Vive 8 & -0.22 & 1.63 & \multirow[t]{2}{*}{0.77} \\
\hline CB 8 & -0.02 & 1.11 & \\
\hline
\end{tabular}




\section{$6.3 \mathrm{IPQ}$}

The study performed parametric tests for statistical evaluation with two independent variables 30-degree viewing angle, low resolution, non-interaction function, and 110-degree viewing angle, high-resolution interaction function. The questionnaire is subscale from 0 to 10 , 0 being fully disagreed (not at all), 10 being fully agreed (felt present), and 5 is moderate. The results are below in Figure 4, the smaller the score, the less for the participant to feel the sense of presence, and the sheets are labeled in color from red to green.

The results of special presence and involvement are showing significant differences. A high-quality image with interaction function has a high sense of presence as surrounded by the virtual world and a sense of acting in the virtual space. Expect item 9 INV3 "I still paid attention to the real environment." And item 13 real 3 "How real did the virtual world seem to you?" the results of the high-qu ality image with interaction function and low-quality image with noninteraction function have minor differences.

\begin{tabular}{|r|r|r|r|r|r|r|r|r|}
\hline & Q1 G1 & & & Q2 SP1 & & & Q3 SP2 & reversed \\
\hline Sample & \multicolumn{1}{|c|}{ Vive } & CB & Sample & Vive & CB & Sample & Vive & \multicolumn{1}{c|}{ CB } \\
\hline 1 & 9 & 8 & 1 & 9 & 5 & 1 & 9 & 3 \\
\hline 2 & 9 & 8 & 2 & 7 & 6 & 2 & 9 & 7 \\
\hline 3 & 8 & 9 & 3 & 10 & 8 & 3 & 10 & 4 \\
\hline 4 & 7 & 1 & 4 & 6 & 1 & 4 & 5 & 1 \\
\hline 5 & 10 & 7 & 5 & 10 & 7 & 5 & 2 & 8 \\
\hline 6 & 8 & 7 & 6 & 8 & 3 & 6 & 7 & 8 \\
\hline 7 & 10 & 3 & 7 & 9 & 5 & 7 & 9 & 8 \\
\hline 8 & 7 & 4 & 8 & 8 & 4 & 8 & 8 & 2 \\
\hline 9 & 7 & 4 & 9 & 7 & 4 & 9 & 7 & 3 \\
\hline 10 & 5 & 1 & 10 & 8 & 2 & 10 & 10 & 1 \\
\hline $\mathbf{p =}$ & $\mathbf{0 . 0 0 9 9 6 9 9 9 4}$ & $\mathbf{p}=$ & $\mathbf{0 . 0 0 0 1 7 6 9 4 5}$ & $\mathbf{p =}$ & $\mathbf{0 . 0 1 0 5 7 4 4 5 6}$
\end{tabular}




\begin{tabular}{|r|r|r|r|r|r|r|r|r|}
\hline & Q4 SP3 & & & Q5 SP4 & & & Q6 SP5 & \\
\hline Sample & Vive & \multicolumn{1}{|c|}{ CB } & Sample & Vive & CB & Sample & Vive & CB \\
\hline 1 & 2 & 4 & 1 & 9 & 3 & 1 & 9 & 4 \\
\hline 2 & 4 & 5 & 2 & 2 & 8 & 2 & 8 & 7 \\
\hline 3 & 5 & 4 & 3 & 8 & 4 & 3 & 8 & 5 \\
\hline 4 & 6 & 6 & 4 & 7 & 9 & 4 & 6 & 1 \\
\hline 5 & 7 & 3 & 5 & 10 & 7 & 5 & 7 & 7 \\
\hline 6 & 8 & 3 & 6 & 9 & 3 & 6 & 8 & 5 \\
\hline 7 & 4 & 3 & 7 & 8 & 3 & 7 & 8 & 3 \\
\hline 8 & 4 & 5 & 8 & 7 & 4 & 8 & 8 & 5 \\
\hline 9 & 7 & 2 & 9 & 3 & 3 & 9 & 3 & 3 \\
\hline 10 & 5 & 1 & 10 & 10 & 1 & 10 & 8 & 1 \\
\hline $\mathbf{p}=$
\end{tabular}

\begin{tabular}{|r|r|r|r|r|r|r|r|r|}
\hline & Q7 inv1 & & & Q8 inv2 & & & Q9 inv3 & reversed \\
\hline Sample & \multicolumn{1}{|c|}{ Vive } & \multicolumn{1}{|c|}{ CB } & \multicolumn{1}{|c|}{ Sample } & Vive & CB & Sample & Vive & \multicolumn{1}{c|}{ CB } \\
\hline 1 & 8 & 5 & 1 & 9 & 4 & 1 & 2 & 5 \\
\hline 2 & 7 & 3 & 2 & 3 & 7 & 2 & 8 & 8 \\
\hline 3 & 9 & 2 & 3 & 8 & 9 & 3 & 7 & 6 \\
\hline 4 & 8 & 1 & 4 & 4 & 1 & 4 & 4 & 1 \\
\hline 5 & 8 & 6 & 5 & 7 & 3 & 5 & 5 & 3 \\
\hline 6 & 4 & 1 & 6 & 8 & 8 & 6 & 6 & 6 \\
\hline 7 & 6 & 3 & 7 & 8 & 3 & 7 & 8 & 8 \\
\hline 8 & 3 & 9 & 8 & 9 & 3 & 8 & 6 & 8 \\
\hline 9 & 3 & 3 & 9 & 5 & 3 & 9 & 5 & 3 \\
\hline 10 & 9 & 7 & 10 & 9 & 3 & 10 & 9 & 3 \\
\hline
\end{tabular}

\begin{tabular}{|c|c|c|c|c|c|c|c|c|}
\hline$p=$ & \multicolumn{2}{|c|}{0.019985637} & $p=$ & \multicolumn{2}{|c|}{0.01414} & $p=$ & \multicolumn{2}{|c|}{0.198750373} \\
\hline & Q10 inv4 & & & Q11 real1 & Reversed & & Q12 real2 & \\
\hline Sample & Vive & CB & Sample & Vive & CB & Sample & Vive & CB \\
\hline 1 & 9 & 4 & 1 & 9 & 5 & 1 & 8 & 4 \\
\hline 2 & 7 & 8 & 2 & 7 & 8 & 2 & 7 & 6 \\
\hline 3 & 8 & 5 & 3 & 7 & 8 & 3 & 8 & 5 \\
\hline 4 & 6 & 9 & 4 & 7 & 2 & 4 & 5 & 1 \\
\hline 5 & 8 & 6 & 5 & 8 & 6 & 5 & 7 & 7 \\
\hline 6 & 8 & 7 & 6 & 8 & 8 & 6 & 8 & 5 \\
\hline 7 & 8 & 4 & 7 & 9 & 3 & 7 & 5 & 8 \\
\hline 8 & 8 & 9 & 8 & 7 & 3 & 8 & 5 & 4 \\
\hline 9 & 5 & 3 & 9 & 9 & 5 & 9 & 8 & 3 \\
\hline 10 & 8 & & 10 & 8 & 4 & 10 & 8 & 6 \\
\hline$p=$ & 0.0307 & 736 & $p=$ & 0.0021 & 41546 & $p=$ & 0.010 & 551 \\
\hline
\end{tabular}

Figure 23 The result of Igroup presence questionnaire. Greener the score, more sense of presence participant subjectively feels. 


\section{Conclusion}

The hazers caused by wildfires have evolved and become more deadly over the years. The unpredictable natural characteristic of an open space increases the risk for firefighters. The combination of different elements including topography, vegetables, and weather create an ever-changing, yet dangerous head-fire. While sophisticated firefighters are able to be aware of the situation and make a quick decision by past experiences, young firefighters and volunteer firefighters have rare training opportunities in real wildfire conditions. The main goal of this work was to evaluate the effectiveness of a virtual environment to train firefighters for wildfires. To achieve this, the study first established the virtual environment based on the study of past wildfire cases, test the environment's fire training function effectively, and study the influence of our virtual training environment on presence. To test the effectiveness of fire behavior knowledge, the study is specifically designed to train participant's orienting head fire skills under the change of wind direction and speed. A practice scenario was provided and simulated real wildfire for comparison. The result indicates that our virtual wildfire training improved the trainee's head fire orienting skill by processing the information of wind direction.

As later from the research and feedback from the earlier experiment, it is appearing that to evaluate the effectiveness of the VR wildfire training system, emotion arousal, and mental states are also crucial. The elements that would influence the sense of presence in this study are video quality, the field of view, and operation function. By using HTC Vive with 110degree viewing angle, high display resolution with joystick interaction represents the high immersive device. On the other hand, Google Cardboard represents a low-quality device with a 30-degree viewing angle, low display resolution, and no interaction function.

The results from HRV used 20 smallest RRV from RR-intervals to represents the most concentrated period of time during the experiment in a high-quality and low-quality environment. The result showed that during the experiment in HTC Vive, participants having 
more stable and lower RRV than during the Google Cardboard, which means that objects were more concentrated in wider viewing angle, higher display resolution with the ability to interact than in narrower viewing angle, lower display resolution without interaction ability. The result from facial thermal was used to study the emotional arousal of the object in the environment. Normally, the facial temperature is reduced if the level of stress increase, however, in this case, the participant felt more stress by conducting a digital-like environment when they are more relaxed and concentrated in the high sense of presence environment.

Lastly, results from the questionnaire were used to study the subjective opinions about feeling the presence in the virtual environment. 12 out of 14 items have indicated all 10 objects have felt more immersed and surrounded by a virtual environment in the 110 -degree viewing angle than in the 30-degree viewing angle. With the high concentration, immersion of the result, this VR wildfire training is effective in simulating a wildfire environment for firefighters to train. Although the results from the virtual training environment were far different from the ones achieved in the real environment, objects have shown more level of concentration, and are immersive in the operational VR wildfire training than in observational. These are important because the system will serve as a reference for future wildfire VR training development for both physical and psychological learning. 


\section{Acknowledgement}

This paper and the research behind it would not have been possible without the exceptional support and advice from my supervisor, Professor Ogi Tetsuro. His professional knowledge, enthusiasm, and orientation to details have been an inspiration and kept my work on track.

Dr. Shuichi Fukuda and Professor Toma Tetsuya have also been generous to give me advice and directions throughout the whole study process. Both have been passionate about sharing the knowledge and drill into the professional fields which have inspired me.

Thanks to my parents and close friends who support me through the research and master studies.

Thanks to all the participants during both steps of the experiment and give authentic feedback to help the future improvement. 


\section{Reference}

[1] Evan Jeffries, Catherine Perry, "Fires, Forests, and the Futures," WWF, BCG, Boston, Gland, 2020.

[2] C. P. Group, "How many wildfire are there in Japan?," Forest Maintenance Department, Tokyo, 2019.

[3] P. CHeney, J. S. Gould and L. Mccaw, "The DeadMan Zone - a neglected area of firefighter safety," Australian Forestry, vol. 64, no. 1, 2001.

[4] C. A. D. M. W. James Done, "The next generation of NWP: explicit forecasts of convection using the weather research and forecasting (WRF) model," Atmos. Sci. Lett, vol. 5, no. 6, pp. 110-117, 2004.

[5] Sanchez-Vives M., Slater M., "From presence to consciousness through virtual reality," Nat Rev Neurosci, vol. 6, pp. 332-339, 2005.

[6] Ausburn Lynna J., and Floyd B. Ausburn., "Desktop virtual reality: A powerful new technology for teaching and research in industrial teacher education.," Journal of Industrial Teacher Education, vol. 41, no. 4, pp. 1-16, 2004.

[7] J. Vince, "VR concepts and terms," in Introduction to Virtual Reality, Springer Science \& Business Media, 2004, p. 163.

[8] S. T. Bayouth, Examining firefighter decision making process and choice in virtual reality, Iowa: Iowa State University, 2011.

[9] A. B. William R.Sherman, "Interface, Application, and Design," in Understanding Virtual Reality (Second Edition), Morgan Kaufmann, 2018, pp. 102-106. 
[10] M. R. J, "Medium," 9 Jun 2020. [Online]. Available:

https://medium.com/xrpractices/hmd-vs-cave-in-the-world-of-vr-a0c9cbfb435a. [Accessed 24 May 2021].

[11] "National Wildfire Coordinating Group," 306 2021. [Online]. Available: https://www.nwcg.gov/publications/training-courses/s-130. [Accessed 57 2021].

[12] J. F. Department, "2019 Fire Control White Paper," Fire Control White Paper, p. 27, 2 Feb 2019.

[13] "Summary Incident Report," U.S. Fire Administration, Emmistsburg, 2019.

[14] Kinateder M, Ronchi E, Nilsson D, Kobes M, Müller M, Pauli P, Mühlberger A., "Virtual reality for fire evacuation research.," in 1st Complex Events and Information Modelling at the Federated Conference on Computer Science and Information Systems, Warsaw, 2014.

[15] Harter, Derek, Shulan Lu, Pratyush Kotturu, and Devin Pierce., "An immersive virtual environment for varying risk and immersion for effective training.," in ASME 2011 World Conference on Innovative Virtual Reality, Milan, 2011.

[16] Stansfield S, Shawver D, Sobel A, "BIOSIMMER: A virtual reality simulator for training first responders in a BW scenario.," in Proceedings of the 1998 Scientific Conference on Chemical and Biological Defense Research, Sandia National Laboratories, 1999.

[17] Izard S.G., Juanes J.A., Peñalvo F.J.G., Estella J.M.G., Ledesma M.J.S. and Ruisoto P., "Virtual reality as an educational and training tool for medicine.," Journal of medical systems, vol. 42, no. 3, pp. 1-5, 2018.

[18] L. S. a. R. Jacob, "Evaluation of eye gaze interaction," in Proceedings of the SIGCHI conference on Human Factors in Computing Systems, 2000. 
[19] Jacob L.E. Sibert and R.J.K., "Evaluation of eye gaze interaction," in Proceedings of the SIGCHI conference on Human Factors in Computing Systems, 2000.

[20] McGrath JL, Taekman JM, Dev P, Danforth DR, Mohan D, Kman N, Crichlow A, Bond WF, Riker S, Lemheney AJ, Talbot TB, "Using virtual reality simulation environments to assess competence for emergency medicine learners," Academic Emergency Medicine, vol. 25, no. 2, pp. 186-195, 2018.

[21] J. Psotka, "Immersive training systems: Virtual reality and education and training," Instructional science, vol. 23, no. 5-6, pp. 405-431, 1995.

[22] Freina, Laura, and Michela Ott, "A literature review on immersive virtual reality in education: state of the art and perspectives," The international scientific conference elearning and software for education, vol. 1, no. 133, pp. 10-1007, 2015.

[23] Filigenzi MT, Orr TJ, Ruff TM, "Virtual reality for mine safety training," Applied occupational and environmental hygiene, vol. 15, no. 6, pp. 465-469, 2000.

[24] Bliss JP, Tidwell PD, Guest MA., "The effectiveness of virtual reality for administering spatial navigation training to firefighters," Presence: Teleoperators \& Virtual Environments, vol. 6, no. 1, pp. 73-86, 1997.

[25] Omodei Mary M., and Alexander J. Wearing, "The Fire Chief microworld generating program: An illustration of computer-simulated microworlds as an experimental paradigm for studying complex decision-making behavior.," Behavior Research Methods, Instruments, \& Computers, vol. 27, no. 3, pp. 303-316, 1995.

[26] Narciso David, Miguel Melo, José Vasconcelos Raposo, João Cunha, and Maximino Bessa, "Virtual reality in training: an experimental study with firefighters," Multimedia Tools and Applications, vol. 79, no. 9, pp. 6227-6245, 2020. 
[27] P. West, "VR scout," VRScout, 27 November 2019. [Online]. Available: https://vrscout.com/news/vr-firefighter-training-pico-interactive/. [Accessed 206 2021].

[28] Balinski, Brent, "Create," Engineers Australia, 10 December 2019. [Online]. Available: https://createdigital.org.au/firefighters-using-vr-haptics-train-face-real-thing/. [Accessed 21 Jun 2021].

[29] Segerstrom, Suzanne C., and Lise Solberg Nes, "Heart rate variability reflects selfregulatory strength, effort, and fatigue.," Psychological science, vol. 18, no. 3, pp. 275281, 2007.

[30] Slater, Mel, Martin Usoh, and Anthony Steed, "Depth of presence in virtual environments," Presence: Teleoperators \& Virtual Environments, vol. 3, no. 2, pp. 130144, 1994.

[31] R. T. Graham, "Hayman Fire Case Study," General Technical Report RMRS-GTR-114, Moscow, 2003.

[32] K. G. Hirsch, "Documenting Wildfire Behavior: The 1988 Brerton Lake Fire, Manitoba," Fire Management, vol. 63, no. 4, pp. 50-54, 2003.

[33] Narciso D., Melo M., Raposo J. V., Cunha J., \& Bessa M., "Virtual reality in training: an experimental study with firefighters," Multimedia Tools and Applications, vol. 79, no. 9 , pp. 6227-6245, 2020.

[34] Valentin Schwind, Pascal Knierim, Nico Haas, and Niels Henze, "Using Presence Questionnaires in Virtual Reality," in CHI Conference on Human Factors in Computing Systems Proceedings, Glasgow, 2019. 
[35] Malińska M., Zużewicz K., Bugajska J., \& Grabowski A., "Heart rate variability (HRV) during virtual reality immersion," International journal of occupational safety and ergonomics : JOSE, vol. 21, no. 1, pp. 47-54, 2015.

[36] R. M. S. Clifford, S. Jung, S. Hoermann, M. Billinghurst and R. W. Lindeman, "Creating a Stressful Decision Making Environment for Aerial Firefighter Training in Virtual Reality," in 2019 IEEE Conference on Virtual Reality and 3D User Interfaces (VR), 2019.

[37] Salazar-López E, Domínguez E, Juárez Ramos V, de la Fuente J, Meins A, Iborra O, et al., "The mental and subjective skin: Emotion, empathy, feelings and thermography," Conscious Cogn, vol. 34, pp. 149-162, 2015.

[38] Lovreglio, Ruggiero, and Max Kinateder, "Augmented reality for pedestrian evacuation research: promises and limitations," Safety science, vol. 128, no. 104750, p. 12, 2020.

[39] García-Valle, Gonzalo, Manuel Ferre, Jose Breñosa, and David Vargas, "Evaluation of presence in virtual environments: haptic vest and user's haptic skills," IEEE Access, vol. 6, pp. 7224-7233, 2017.

[40] C. B. Bulletin, "U.S. Fire Administration," 8 July 2020. [Online]. Available: https://www.usfa.fema.gov/blog/cb-070820.html. [Accessed 276 2021].

[41] J. R. a. K. M. Justin Quarisa, "Fire Engineering," Clarion Events, 1 May 2020. [Online]. Available: https://www.fireengineering.com/apparatus-equipment/how-thecosumnes-fire-department-incorporates-virtual-reality-into-its-fire-academytraining/\#gref. [Accessed 256 2021].

[42] Salas, Eduardo, Scott I. Tannenbaum, Kurt Kraiger, and Kimberly A. Smith-Jentsch., "The science of training and development in organizations: What matters in practice," Psychological science in the public interest, vol. 13, no. 2, pp. 74-101, 2012. 
[43] K. J. K. F. a. E. S. Kraiger, "Application of cognitive, skill-based, and affective theories of learning outcomes to new methods of training evaluation," Journal of applied psychology, vol. 78, no. 2, p. 311, 1993.

[44] Alexander A. L., Brunyé T., Sidman J., and Weil S. A., "From gaming to training: a review of studies on fidelity, immersion, presence, and buy-in and their effects on transfer in pc-based simulations and games," DARWARS Training Impact Group 5, pp. 1-14, 2005.

[45] C. D. W., "Virtual reality for education and workforce training," in 15th International Conference on Emerging eLearning Technologies and Applications (ICETA), KOŠICE, 2017.

[46] TF Sanquist, MP Baucum, BR Brisbois, "Attention and Situational Awareness in First Responder Operations," U.S. Department of Energy, Richland, 2016.

[47] Klein Gary A., Roberta Calderwood, and Anne Clinton-Cirocco, "Rapid decision making on the fire ground," In Proceedings of the human factors society annual meeting, vol. 30, no. 6, pp. 576-580, 1986.

[48] Lipshitz, Raanan, Mary Omodei, Jim McClellan, and Alexander Wearing, "What's burning? The RAWFS heuristic on the fire ground," Expertise out of context, pp. 103117, 2007.

[49] Fern, Lisa, Stoney Trent, and Martin Voshell, "A functional goal decomposition of urban firefighting," in ISCRAM, Washington DC, 2008.

[50] Porges, Stephen W., and Evan A. Byrne, "Research methods for measurement of heart rate and respiration," Biological psychology, vol. 34, no. 2-3, pp. 93-130, 1992.

[51] Plews, Daniel J., Paul B. Laursen, Andrew E. Kilding, and Martin Buchheit, "Heart rate variability in elite triathletes, is variation in variability the key to effective training? A 
case comparison," European journal of applied physiology, vol. 112, no. 11, pp. 3729$3741,2012$.

[52] Hollenstein, Tom, Adrian McNeely, Jenny Eastabrook, Allison Mackey, and Jessica Flynn, "Sympathetic and parasympathetic responses to social stress across adolescence," Developmental psychobiology, vol. 54, no. 2, pp. 207-214, 2012.

[53] Ogi Tetsuro, Yosuke Kubota, Tetsuya Toma, and Takeshi Chikakiyo, "Evaluation of high presence sensation based on biological information," in 16th International Conference on Network-Based Information Systems, Gwangju, 2013.

[54] Islam M. K., G. Tangim, T. Ahammad, and M. R. H. Khondokar, "Study and analysis of ecg signal using matlab \&labview as effective tools," International journal of Computer and Electrical engineering, vol. 4, no. 3, p. 404, 2012.

[55] Basu, Anushree, Aurobinda Routray, Suprosanna Shit, and Alok Kanti Deb, "Human emotion recognition from facial thermal image based on fused statistical feature and multi-class SVM," in Annual IEEE India Conference (INDICON), New Delhi, 2015.

[56] Liu, Zhilei, and Shangfei Wang, "Emotion recognition using hidden Markov models from facial temperature sequence," in International Conference on Affective Computing and Intelligent Interaction, Springer, 2011.

[57] Ioannou S, Morris P, Mercer H, Baker M, Gallese Reddy V, "Proximity and gaze influences facial temperature: a thermal infrared imaging study," Frontiers in psychology, vol. 5, no. 845, 2014.

[58] Donadio V, Nolano M, Provitera V, Stancanelli A, Lullo F, Liguori R, et al., "Skin sympathetic adrenergic innervation: an immunofluorescence confocal study," Ann Neurol, vol. 59, no. 2, pp. 276-81, 2006. 
[59] Cho Y., Bianchi-Berthouze N., Oliveira M., Holloway C., \& Julier S, "Nose heat: Exploring stress-induced nasal thermal variability through mobile thermal imaging," in 2019 8th International Conference on Affective Computing and Intelligent Interaction (ACII), Cambridge, 2019.

[60] Johnson J. M., Minson C. T., \& Kellogg Jr D. L., "Cutaneous vasodilator and vasoconstrictor mechanisms in temperature regulation," Comprehensive physiology, vol. 4, no. 1, pp. 33-89, 2011.

[61] L. Walløe, "Arterio-venous anastomoses in the human skin and their role in temperature control," Temperature, vol. 3, no. 1, pp. 92-103, 2016.

[62] Kuraoka K, Nakamura K, "The use of nasal skin temperature measurements in studying emotion in macaque monkeys," Physiology \& behavior, vol. 102, pp. 347-355, 2011.

[63] Sheridan, Thomas B, "Musings on telepresence and virtual presence," Presence: Teleoperators \& Virtual Environments, vol. 1, no. 1, pp. 120-126, 1992.

[64] Bystrom, Karl-Erik, Woodrow Barfield, and Claudia Hendrix, "A conceptual model of the sense of presence in virtual environments," Presence: Teleoperators \& Virtual Environments, vol. 8, no. 2, pp. 241-244, 1999.

[65] Schubert, Thomas, Frank Friedmann, and Holger Regenbrecht., "The experience of presence: Factor analytic insights," Presence: Teleoperators \& Virtual Environments, vol. 10, no. 3, pp. 266-281, 2001.

[66] Schwind, V., Knierim, P., Haas, N., \& Henze, N., "Using presence questionnaires in virtual reality," in Proceedings of the 2019 CHI conference on human factors in computing systems, 2019. 
[67] Baños R. M., Botella C., Garcia-Palacios A., Villa H., Perpiñá C., \& Alcaniz M., "Presence and reality judgment in virtual environments: a unitary construct?," CyberPsychology \& Behavior, vol. 3, no. 3, pp. 327-335, 2000.

[68] Barfield W., \& Weghorst S., "The sense of presence within virtual environments: A conceptual framework," Advances in Human Factors Ergonomics, vol. 19, pp. 699-699, 1993.

[69] Cho, D., Park, J., Kim, G. J., Hong, S., Han, S., \& Lee, S., "The dichotomy of presence elements: The where and what," in IEEE Virtual Reality, 2003.

[70] Dinh H. Q., Walker N., Hodges L. F., Song C., \& Kobayashi A., "Evaluating the importance of multi-sensory input on memory and the sense of presence in virtual environments," in Proceedings IEEE Virtual Reality (Cat. No. 99CB36316), 1999.

[71] Witmer, B.G., \& Singer, M.J, "Measuring Presence in Virtual Environments (ARI Technical Report 1014)," Alexandria, VA: US Army Research Institute for the Behavioral and Social Sciences, 1994.

[72] Gerhard M., Moore D. J., \& Hobbs D. J., "Continuous presence in collaborative virtual environments: Towards a hybrid avatar-agent model for user representation," in International Workshop on Intelligent Virtual Agents, Springer, 2001.

[73] Kim T., \& Biocca F, "elepresence via television: Two dimensions of telepresence may have different connections to memory and persuasion," Journal of computer-mediated communication, vol. 3, no. 2, 1997.

[74] Lombard M., Ditton T.B., Crane D., Davis B., Gil-Egui G., Horvath K., Rossman J. and Park S., "Measuring presence: A literature-based approach to the development of a standardized paper-and-pencil instrument," Third international workshop on presence, delft, the netherlands, vol. 240, pp. 2-4, 2000. 
[75] Matthew Lombard, Theresa B. Ditton, and Lisa Weinstein, "Mea-suring presence: the temple presence inventory," Proceedings of the12th Annual International Workshop on Presence, pp. 1-15, 2009.

[76] Jane Lessiter, Jonathan Freeman, Edmund Keogh, and Jules Davido , "A Cross-Media Presence Questionnaire: The ITC-Sense of Pres-ence Inventory," Presence:

Teleoperators and Virtual Environments 10, vol. 3, no. 2001, pp. 282-297, 2001.

[77] Sarah Nichols, Clovissa Haldane, and John R. Wilson, "Mea-surement of presence and its consequences in virtual environments," International Journal of Human-Computer Studies 52, vol. 3, no. 2000, pp. 471-491, 2000.

[78] Biocca Kristine L. Nowak and Frank, "The e ect of the agencyand anthropomorphism on users' sense of telepresence, copresence, and social presence in virtual environments," Presence: Teleoperators \&Virtual Environments 12, vol. 5, no. 2003, pp. 481-494, 2003.

[79] Schubert, T. W., Frank Friedmann, and H. T. Regenbrecht., "Decomposing the sense of presence: Factor analytic insights," 2nd international workshop on presence, vol. 1999, 1999.

[80] Steed, Mel Slater and Anthony, "A Virtual Presence Counter," Presence: Teleoperators and Virtual Environments 9, vol. 5, no. 2000, pp. 413-434, 2000.

[81] Singer, Bob G. Witmer and Michael J., "Measuring Presencein Virtual Environments: A Presence Questionnaire.," Tele-operators and Virtual Environments 7, vol. 3, pp. 225-240, 1998.

[82] Thomas Schubert, Frank Friedmann, Holger Regenbrecht, "igroup presence questionnaire," igroup.org, 2016. [Online]. Available: igroup.org. [Accessed 612 2020]. 
[83] C. M. Hendrix, "Exploratory studies on the sense of presence in virtual environments as a function of visual and auditory display parameters," University of Washington, Washington, 1994.

[84] Carlin A.S, Hoffman H.G, Weghorst S., "Virtual reality and tactile augmentation in the treatment of spider phobia: a case report," Behaviour Research and Therapy, vol. 35, no. 2, pp. 153-158, 1997.

[85] Slater, Mel, and Sylvia Wilbur, "Through the looking glass world of presence: A framework for immersive virtual environments," Five, vol. 95, pp. 1-20, 1995.

[86] W. Powell, V. Powell, P. Brown, M. Cook and J. Uddin, "Getting around in google cardboard - exploring navigation preferences with low-cost mobile VR," in 2016 IEEE 2nd Workshop on Everyday Virtual Reality (WEVR), Greenville, 2016.

[87] D.A. Bowman, E. Kruijff, J. LaViola and I. Poupyrev, 3D User Interfaces: Theory and Practice, Addison Wesley Longman Publishing Co., Inc., 2004.

[88] Donadio V, Incensi A, Cortelli P, Giannoccaro MP, Jaber MA, Baruzzi A, Liguori R, "Skin sympathetic fiber $\alpha$-synuclein deposits: a potential biomarker for pure autonomic failure," Neurology, vol. 80, no. 8, pp. 725-32, 2013.

[89] Kosonogov, Vladimir, Lucas De Zorzi, Jacques Honore, Eduardo S. MartínezVelázquez, Jean-Louis Nandrino, José M. Martinez-Selva, and Henrique Sequeira., "Facial thermal variations: A new marker of emotional arousal," PloS one, vol. 12, no. $9,2017$. 


\section{Appendix}

\section{Codes for VR training}

\section{Fire Management}

using UnityEngine;

using System.Collections;

public class FireVisualManager : MonoBehaviour \{

private ParticleSystem[] m_particleSystems;

[Tooltip("Should be the same number as particle systems used in the Fire, which of those particle systems should be active in the simulation's heat up step.")]

public bool[] m_heatUp;

[Tooltip("Should be the same number as particle systems used in the Fire, which of those particle systems should be active in the simulation's ignition step.")]

public bool[] m_ignition;

[Tooltip("Should be the same number as particle systems used in the Fire, which of those particle systems should be active in the simulation's extingush step.")]

public bool[] m_extinguish;

private bool $\mathrm{m}_{-}$heatState $=$false;

private bool $\mathrm{m}_{\text {_ignitionState }}=$ false;

private bool m_extinguishState $=$ false;

private bool $\mathrm{m} \_$heatStateSet $=$false;

private bool $\mathrm{m} \_$ignitionStateSet $=$false;

private bool m_extinguishStateSet $=$ false;

\section{// Use this for initialization}

void Start () \{

$\mathrm{m} \_$particleSystems $=$GetComponentsInChildren $<$ParticleSystem $>() ;$

if ( $\mathrm{m} \_$heatUp.Length $>\mathrm{m} \_$particleSystems.Length)

Debug.LogError(gameObject.name + " FireVisualManager::heatUp bigger then the number of children with Particle Systems");

if (m_ignition.Length $>\mathrm{m} \_$particleSystems.Length)

Debug.LogError(gameObject.name + " FireVisualManager::ignition bigger then the number of children with Particle Systems");

if (m_extinguish.Length > m_particleSystems.Length) 
Debug.LogError(gameObject.name + " FireVisualManager::extingush bigger then the number of children with Particle Systems");

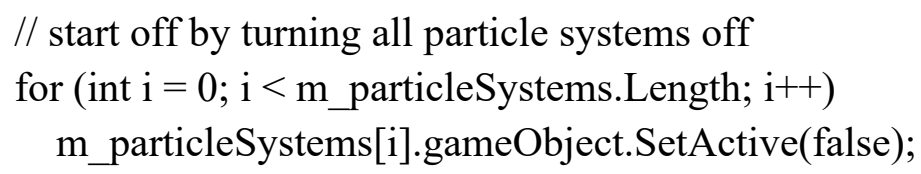

// brief Set the state to the heat state public void SetHeatState()

// brief Set the state to the ignition state public void SetIgnitionState() 


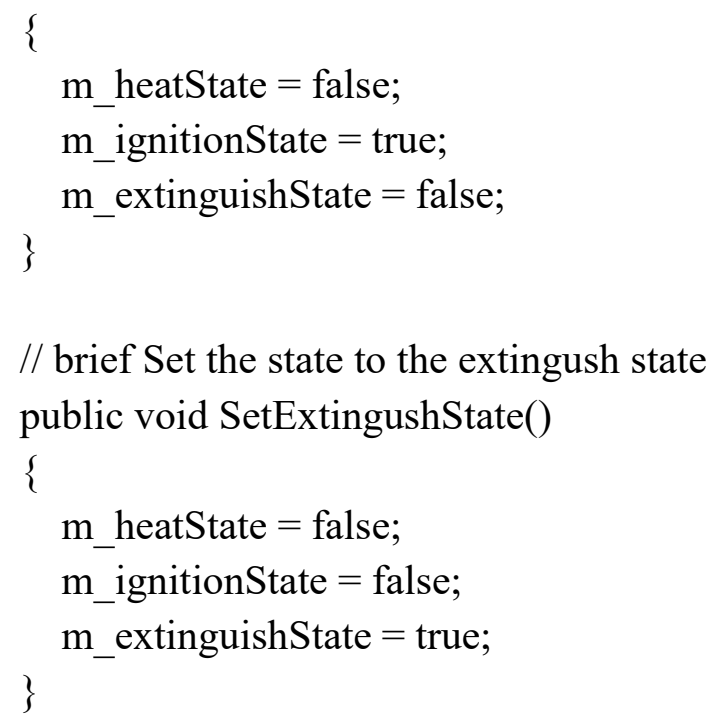

\section{Particle Controller}

using System.Collections;

using System.Collections.Generic;

using UnityEngine;

public class ParticleController : MonoBehaviour

\{

public GameObject explosion;

public GameObject fire;

public GameObject balloonPop;

public GameObject waterDrop;

public List $<$ GameObject $>$ particles $=$ new List $<$ GameObject $>($ );

public List $<$ GameObject $>$ explosionParticles $=$ new List $<$ GameObject $>()$;

// Update is called once per frame

void Update()

\{

if (particles.Count $>0$ )

\{

// clean up any particles that have stopped playing

$/ / * *$ Creating and Destroying gameObjects is not effcient if happening a lot, better to create an object pool to reuse objects.

if (!particles[0].GetComponent $<$ ParticleSystem $>$ ().isPlaying) 


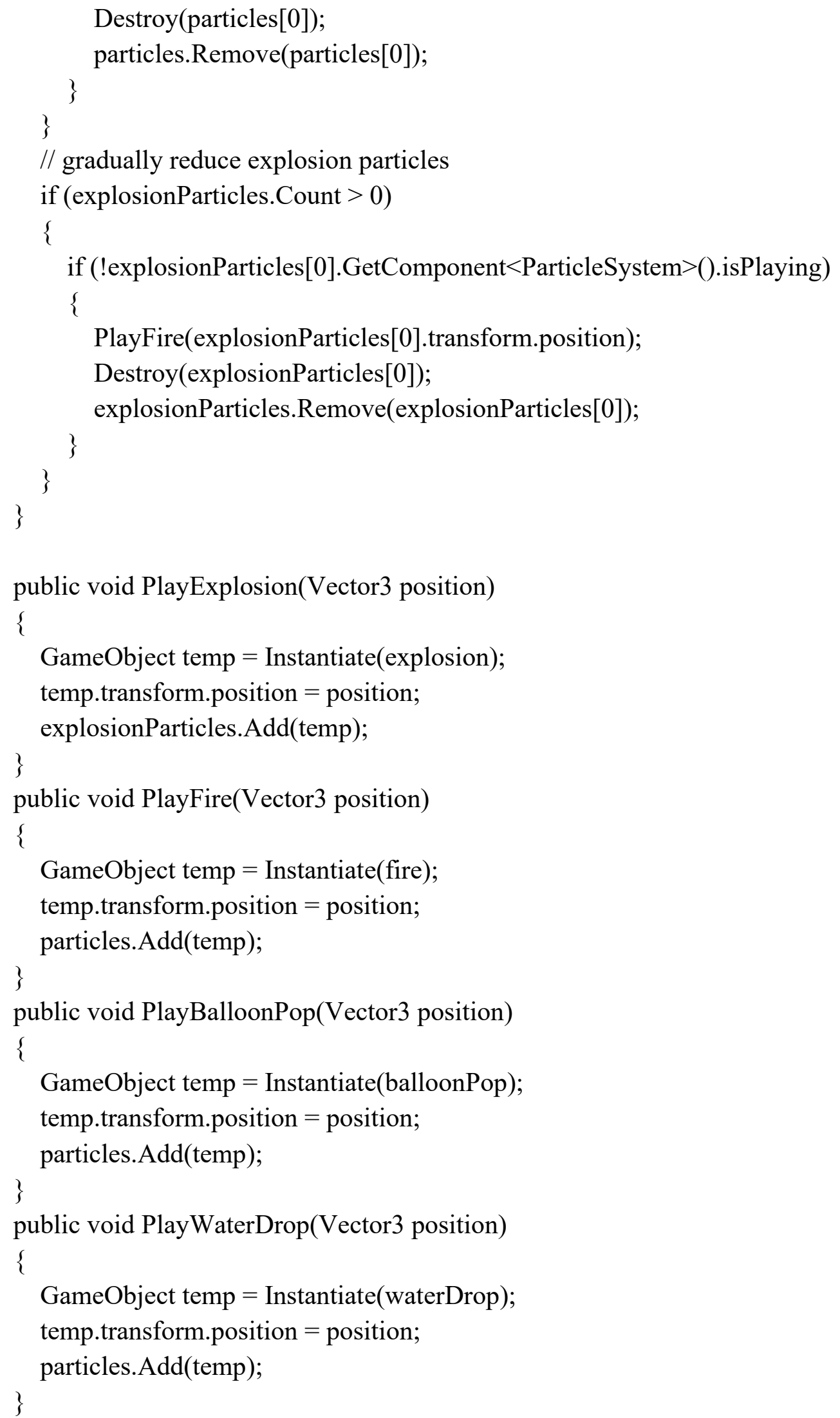




\section{Fire Out}

using UnityEngine;

public class ExtinguishController : MonoBehaviour

\{

private new ParticleSystem particleSystem;

float temp $=5$;

private void Awake()

\{

particleSystem $=$ GetComponent $<$ ParticleSystem $>()$;

\}

private void Update()

\{

var main $=$ particleSystem.main;

main.startSize $=$ new ParticleSystem.MinMaxCurve(temp); \}

private void OnParticleCollision(GameObject other)

\{

if (other.tag $==$ "Water")

\{

Debug.Log("开始灭火");

temp $-=0.2 \mathrm{f}$;

\}

\}

\}

\section{Codes for HMD Control}

\section{VR Controlling}

using System.Collections;

using System.Collections.Generic;

using UnityEngine;

using Valve.VR;

public class VRController : MonoBehaviour

\{

public float $\mathrm{m} \_$Sensitivity $=0.1 \mathrm{f}$;

public float m_MaxSpeed $=1.0 \mathrm{f}$;

public SteamVR_Action_Boolean m_MovePress = null; 


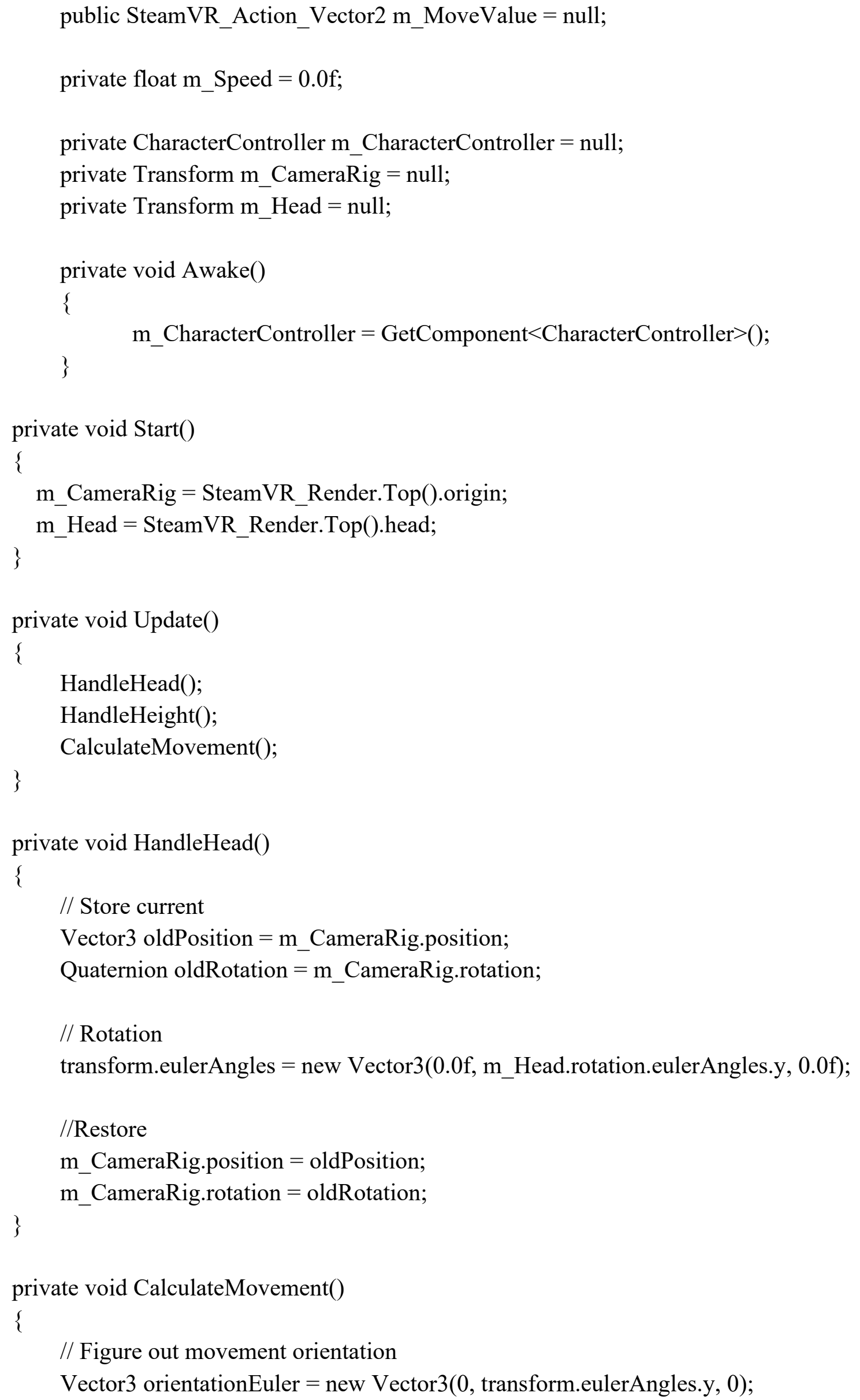




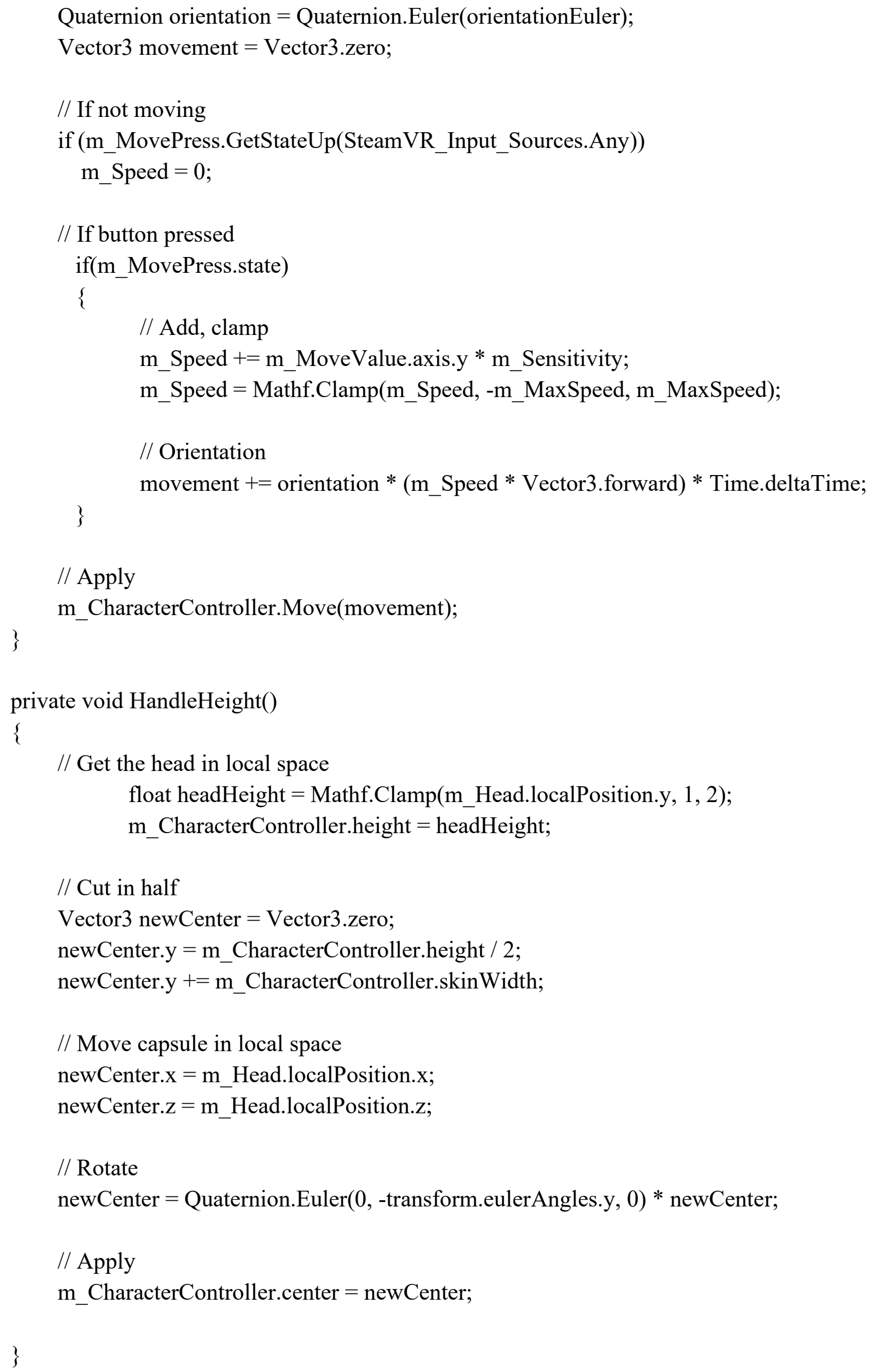




\section{SteamVR Environment}

\section{Play Area}

using UnityEngine;

using UnityEngine.Rendering;

using System.Collections;

using Valve.VR;

namespace Valve.VR

\{

[ExecuteInEditMode, RequireComponent(typeof(MeshRenderer), typeof(MeshFilter))] public class SteamVR_PlayArea : MonoBehaviour

\{

public float borderThickness $=0.15 \mathrm{f}$;

public float wireframeHeight $=2.0 \mathrm{f}$;

public bool drawWireframeWhenSelectedOnly = false;

public bool drawInGame = true;

public enum Size

\{

Calibrated,

$400 \times 300$,

-300x225,

$200 \times 150$

\}

public Size size;

public Color color $=$ Color.cyan;

[HideInInspector]

public Vector3[] vertices;

public static bool GetBounds(Size size, ref HmdQuad_t pRect)

\{

if $($ size $==$ Size. Calibrated $)$

\{

bool temporarySession $=$ false;

if (Application.isEditor \&\& Application.isPlaying $==$ false)

temporarySession $=$ SteamVR.InitializeTemporarySession(); 
var chaperone $=$ OpenVR. Chaperone;

bool success $=($ chaperone $!=$ null $) \& \&$ chaperone.GetPlayAreaRect(ref pRect $)$; if (!success)

Debug.LogWarning(" $<\mathrm{b}>$ [SteamVR] $</ \mathrm{b}>$ Failed to get Calibrated Play Area bounds! Make sure you have tracking first, and that your space is calibrated.");

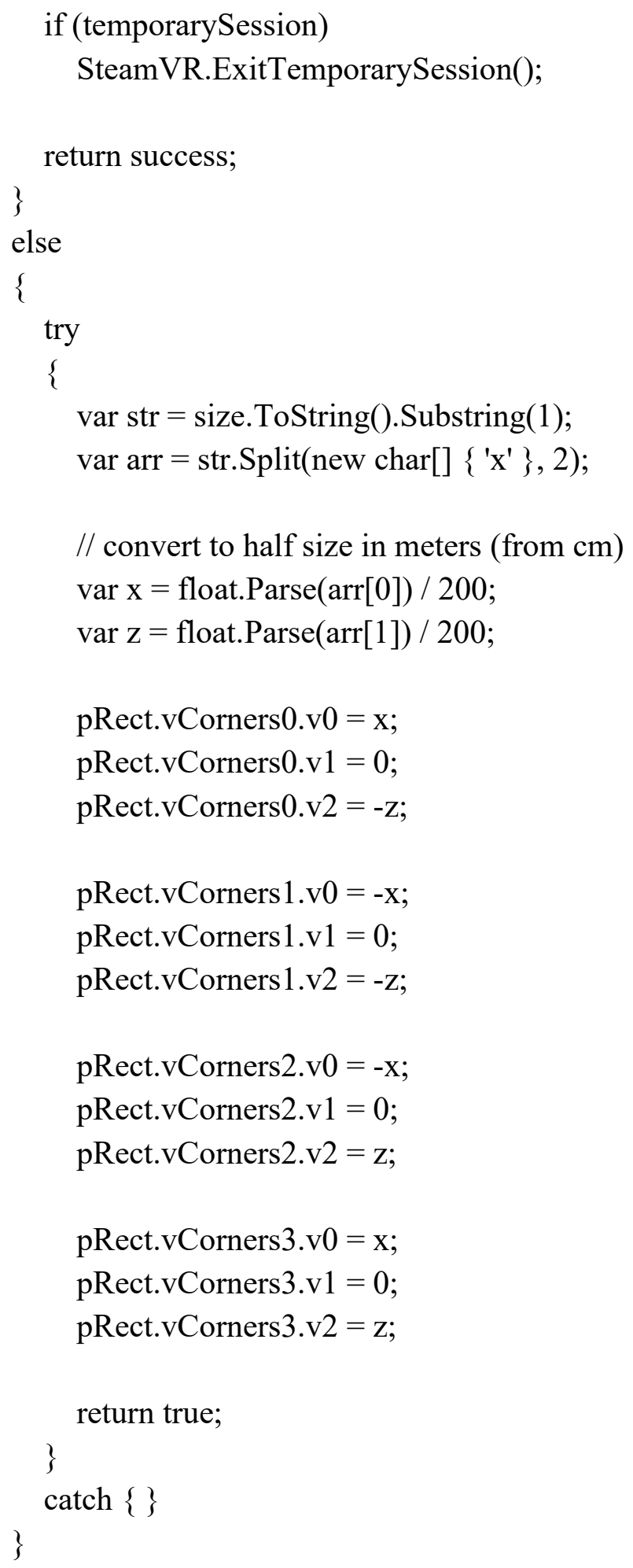


public void BuildMesh()

\{

var rect $=$ new HmdQuad_t () ;

if (!GetBounds(size, ref rect))

return;

var corners $=$ new HmdVector3_t [] \{rect.vCorners0, rect.vCorners1, rect.vCorners2, rect.vCorners3 \};

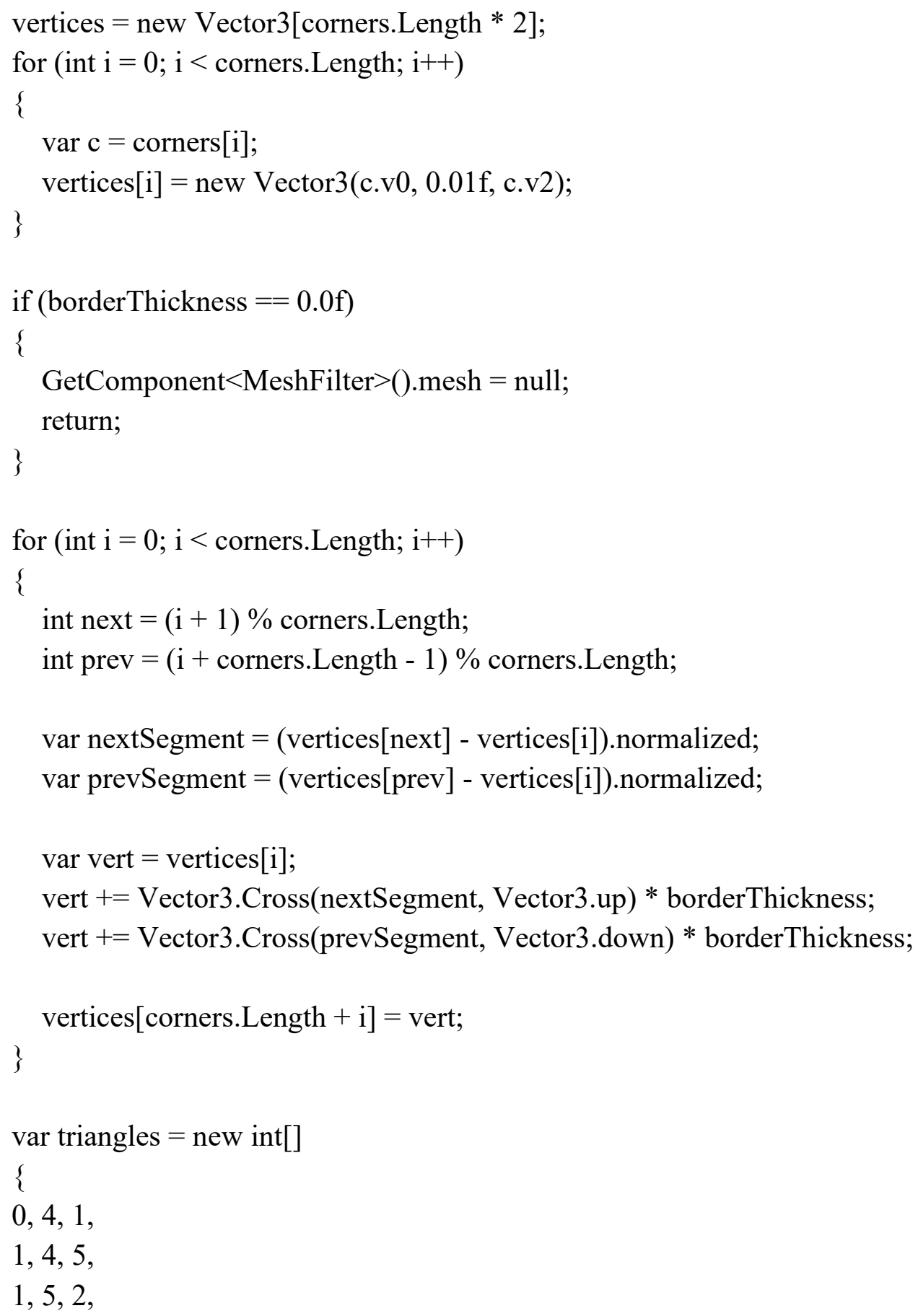




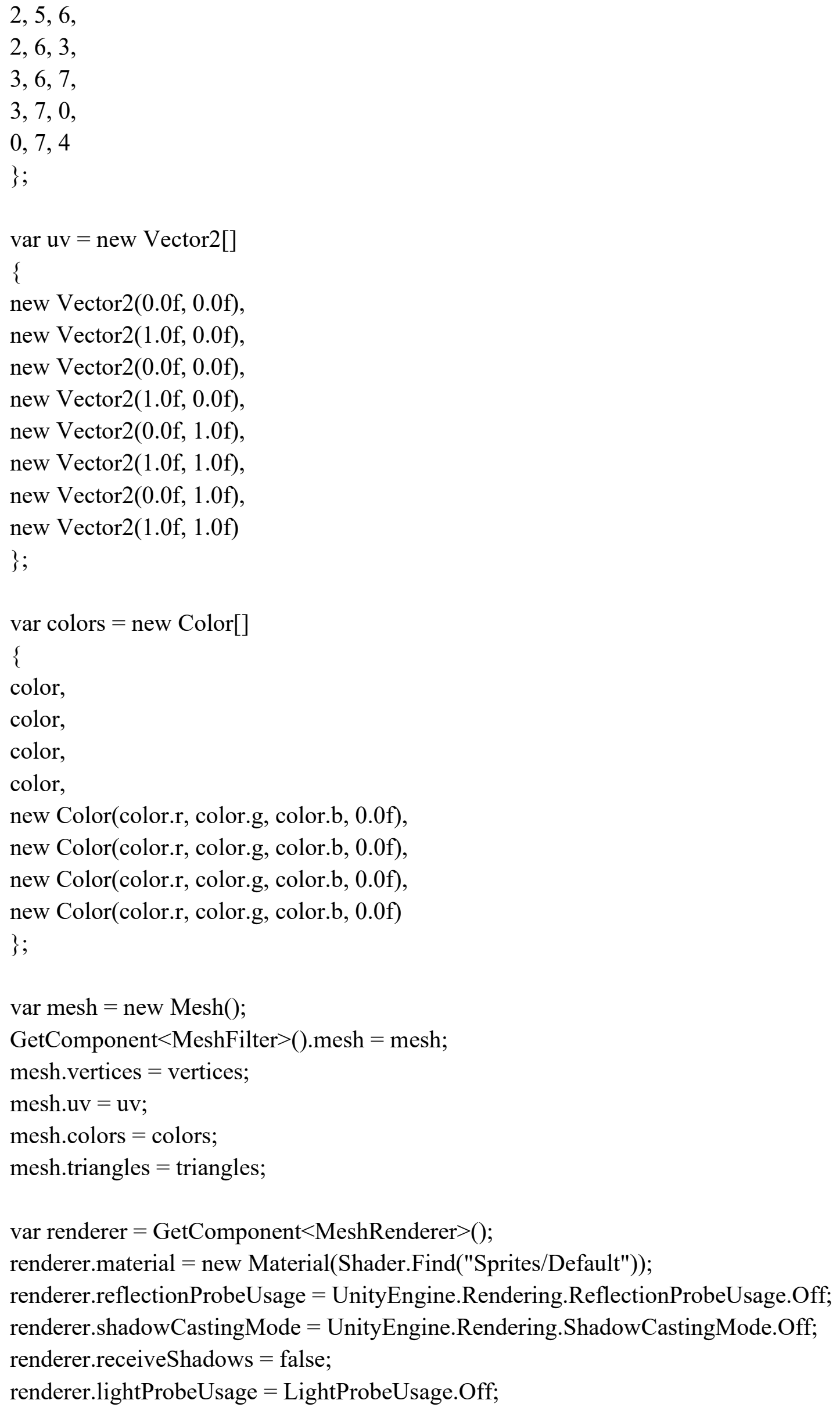


\#if UNITY_EDITOR

Hashtable values;

void Update()

\{

if (!Application.isPlaying)

\{

var fields $=$ GetType().GetFields(System.Reflection.BindingFlags.Instance $\mid$

System.Reflection.BindingFlags.Public);

bool rebuild $=$ false;

if $($ values $==$ null $\|$ (borderThickness $!=0.0 \mathrm{f} \& \&$

GetComponent $<$ MeshFilter $>($ ). sharedMesh $==$ null $)$ )

\{

rebuild $=$ true;

\}

else

\{

foreach (var f in fields)

\{

if (!values.Contains(f) || !f.GetValue(this).Equals(values[f]))

\{

rebuild $=$ true;

break;

\}

\}

\}

if (rebuild)

\{

BuildMesh();

values $=$ new Hashtable () ;

foreach (var $\mathrm{f}$ in fields)

values $[\mathrm{f}]=$ f.GetValue(this);

\}

\}

\}

\#endif

void OnDrawGizmos()

\{ 


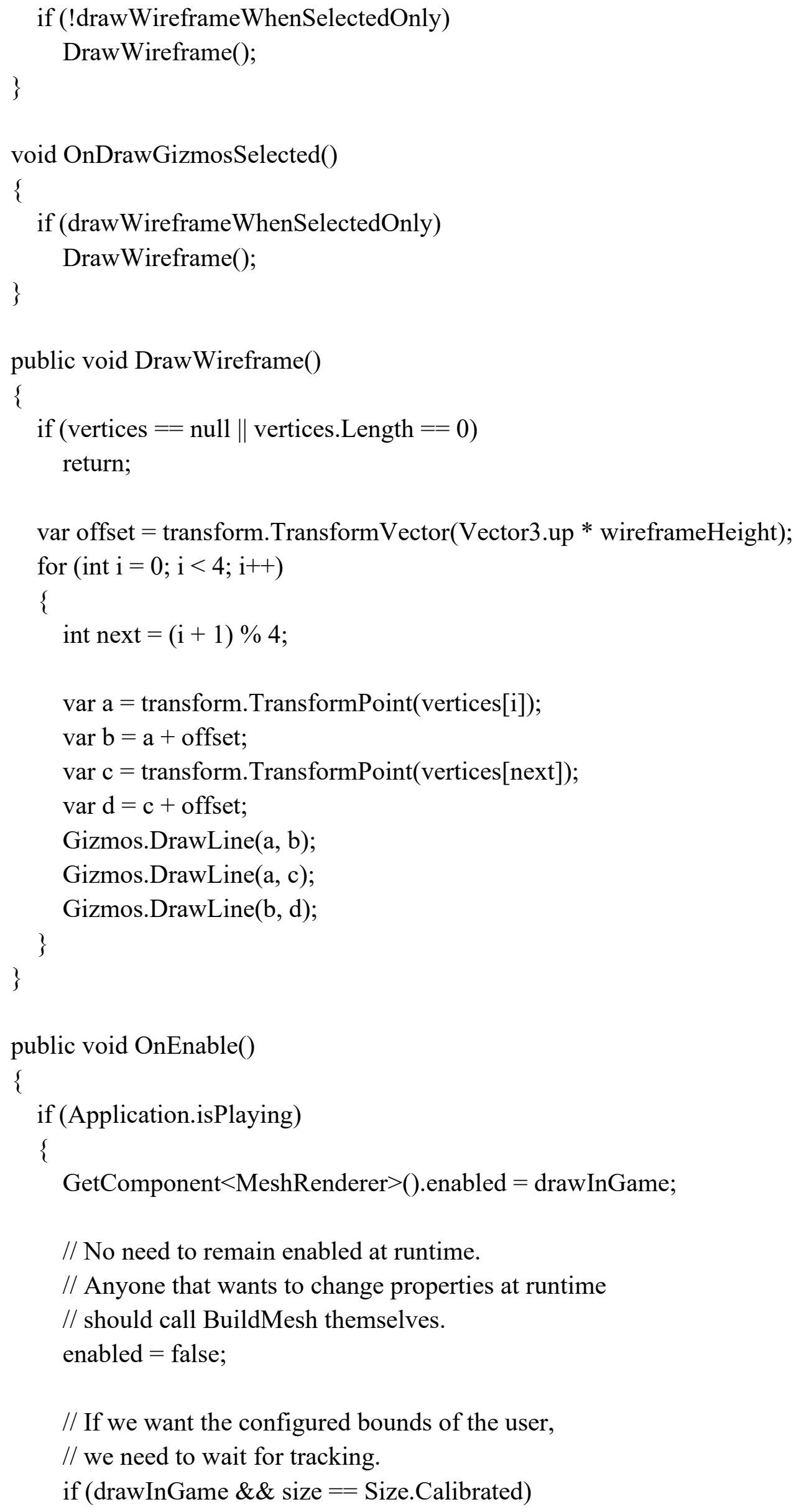




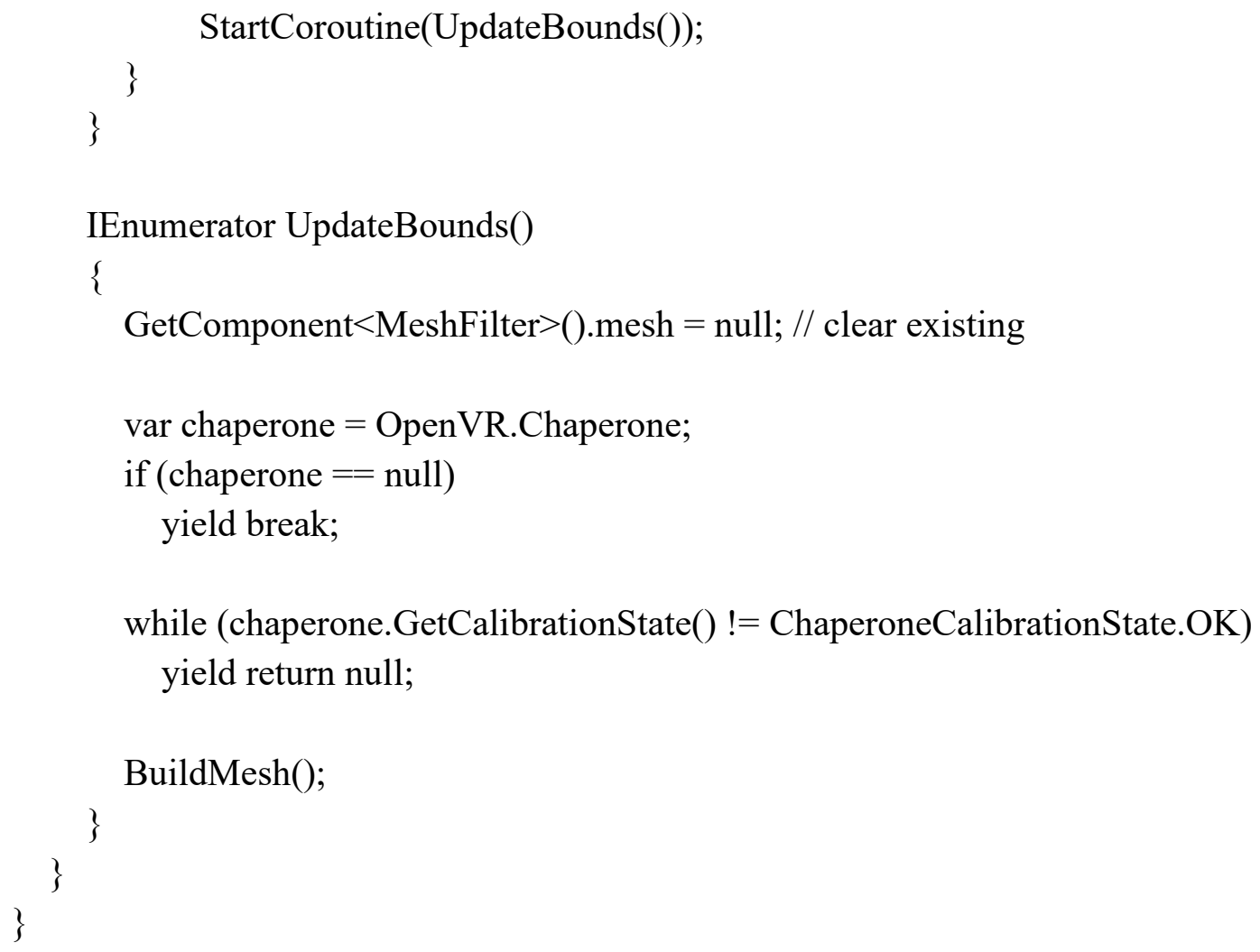

\section{VRCamera}

using UnityEngine;

using System.Collections;

using System.Reflection;

using Valve.VR;

\#if UNITY_2017_2_OR_NEWER

using UnityEngine.XR;

\#else

using XRSettings = UnityEngine.VR.VRSettings;

using XRDevice = UnityEngine.VR.VRDevice;

\#endif

namespace Valve.VR

\{

[RequireComponent(typeof(Camera))]

public class SteamVR_Camera : MonoBehaviour

\{

[SerializeField]

private Transform_head;

public Transform head \{get \{return_head; \} \}

public Transform offset $\{$ get $\{$ return_head; $\}$ \}// legacy 
public Transform origin \{ get $\{$ return_head.parent; \} \}

public new Camera camera \{get; private set; \}

[SerializeField]

private Transform _ears;

public Transform ears $\{$ get $\{$ return_ears; $\}$ \}

public Ray GetRay()

\{

return new Ray(_head.position, _head.forward); \}

public bool wireframe $=$ false;

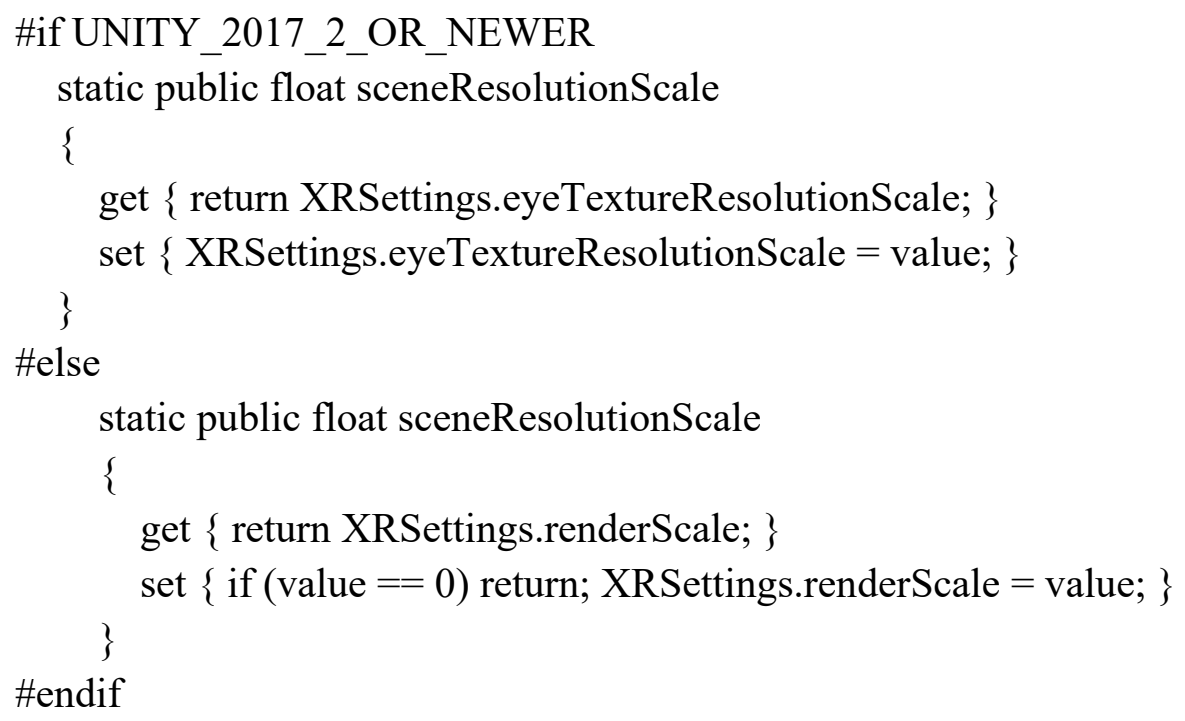




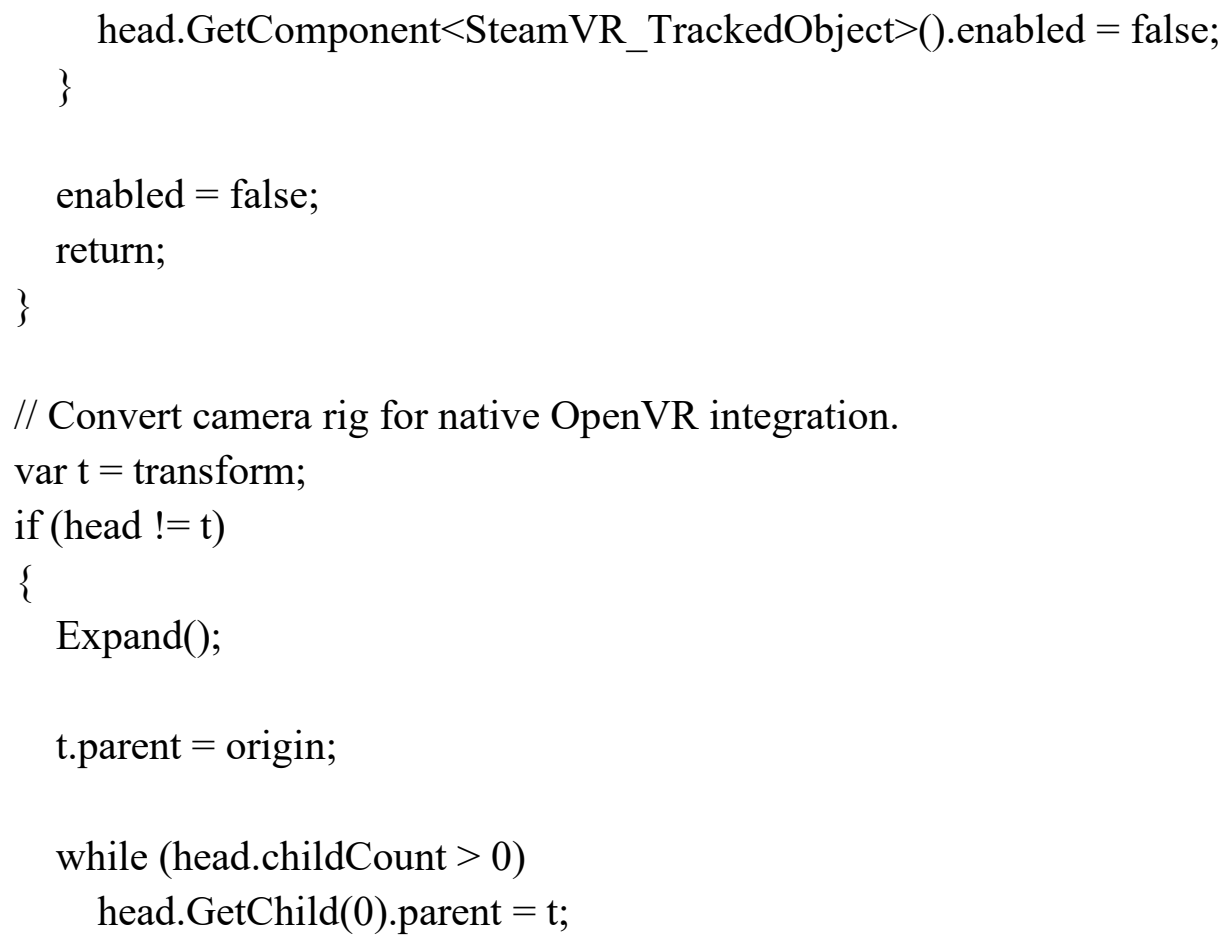

// Keep the head around, but parent to the camera now since it moves with the hmd // but existing content may still have references to this object.

head. parent $=\mathrm{t}$;

head.localPosition $=$ Vector3.zero;

head.localRotation $=$ Quaternion.identity;

head.localScale $=$ Vector3.one;

head.gameObject.SetActive(false);

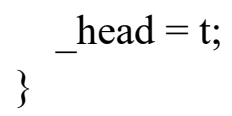


\#region Functionality to ensure SteamVR_Camera component is always the last component on an object

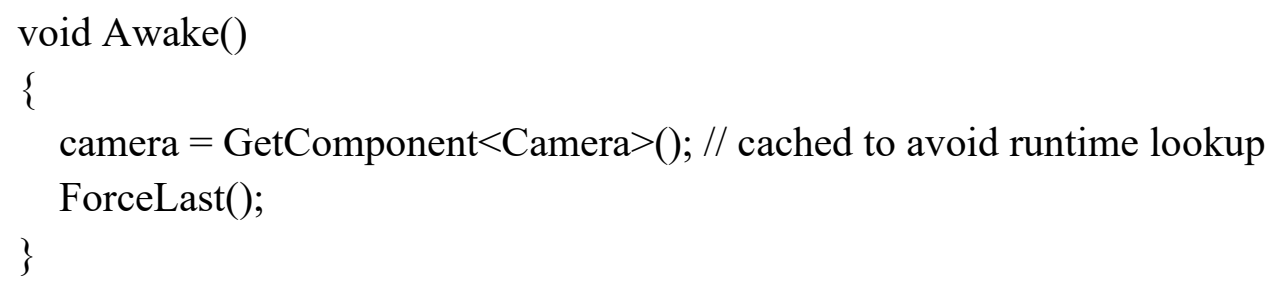


var fields $=$ GetType().GetFields(BindingFlags.Instance $\mid$

BindingFlags.NonPublic | BindingFlags.Public);

foreach (var $\mathrm{f}$ in fields)

if (f.IsPublic || f.IsDefined(typeof(SerializeField), true))

$$
\text { values }[\mathrm{f}]=\text { f.GetValue(this); }
$$

var go = gameObject;

DestroyImmediate(this);

go.AddComponent $<$ SteamVR_Camera $>$ ().ForceLast();

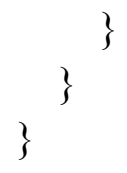

\#endregion

\#region Expand / Collapse object hierarchy

\#if UNITY_EDITOR

public bool isExpanded $\{$ get $\{$ return head != null $\& \&$ transform.parent $==$ head; $\}$ \} \#endif

const string eyeSuffix = " (eye)";

const string earsSuffix = " (ears)";

const string headSuffix = " (head)";

const string originSuffix = " (origin)";

public string baseName $\{$ get $\{$ return name.EndsWith(eyeSuffix) ? name.Substring $(0$, name.Length - eyeSuffix.Length) : name; $\}$ \}

// Object hierarchy creation to make it easy to parent other objects appropriately, // otherwise this gets called on demand at runtime. Remaining initialization is $/ /$ performed at startup, once the hmd has been identified.

public void Expand()

\{

var_origin $=$ transform.parent;

if $($ origin $==$ null $)$

\{

_origin $=$ new GameObject(name + originSuffix).transform;

_origin.localPosition $=$ transform.localPosition;

_origin.localRotation $=$ transform.localRotation;

_origin.localScale $=$ transform.localScale;

\}

if (head $==$ null)

\{ 


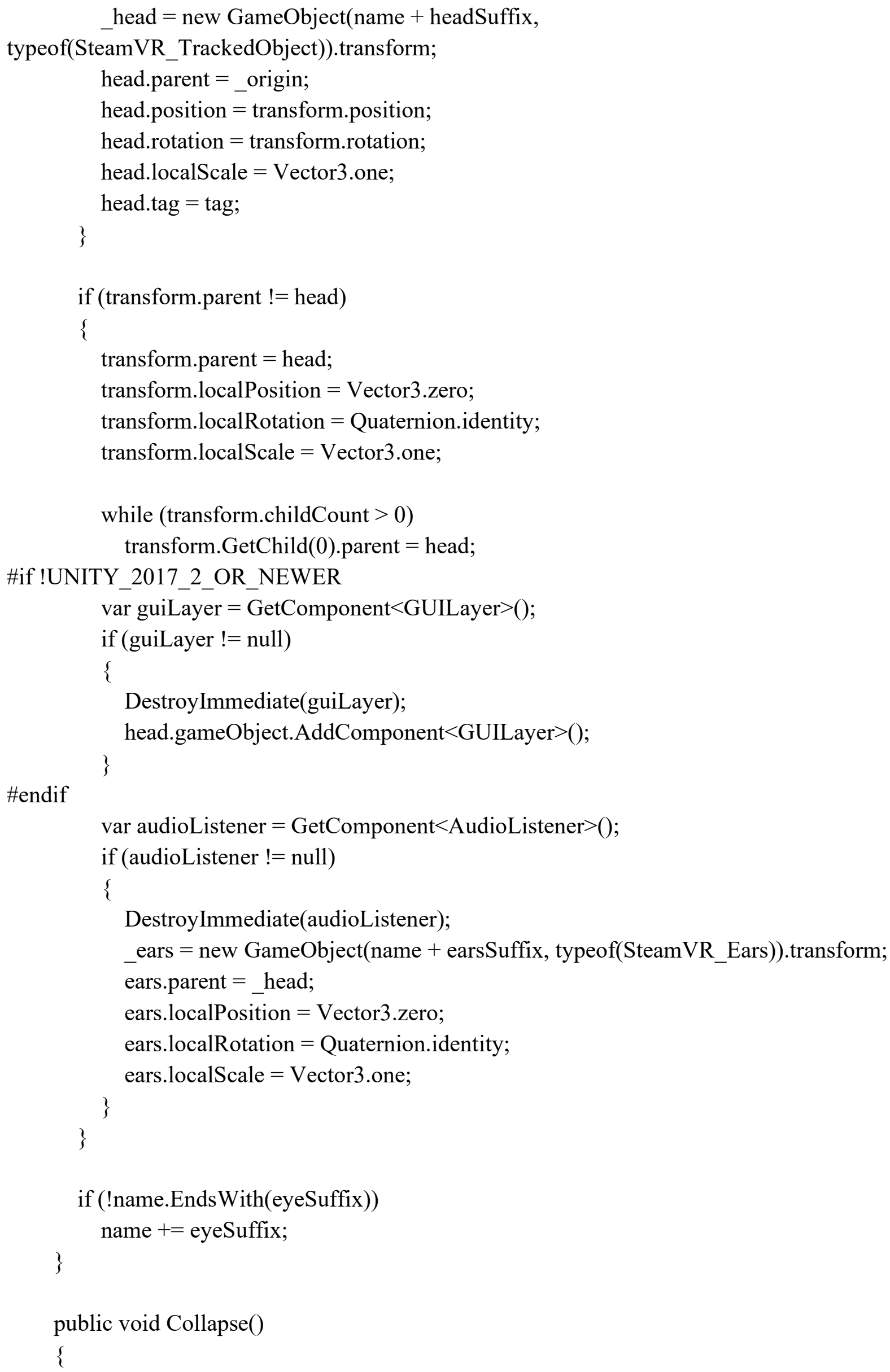




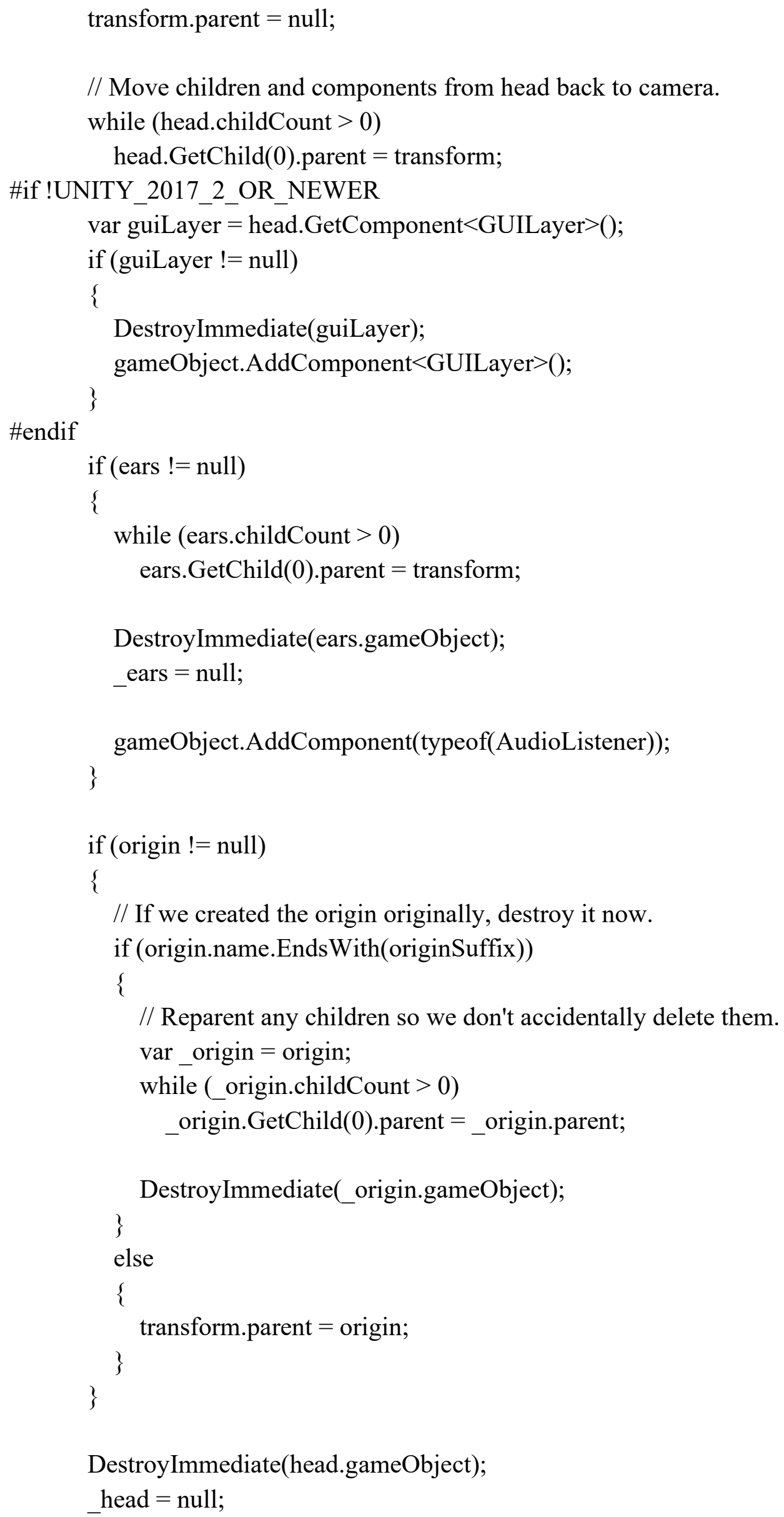

DestroyImmediate(head.gameObject); _head = null; 
if (name.EndsWith(eyeSuffix))

name $=$ name.Substring $(0$, name.Length - eyeSuffix.Length $)$;

\}

\#endregion

\} 


\section{Questionnaire}

\section{English IPQ items}

\begin{tabular}{|c|c|c|c|c|c|c|}
\hline $\begin{array}{l}\text { Numb } \\
\text { er }\end{array}$ & $\begin{array}{l}\mathrm{PQI} / \mathrm{II} \\
\mathrm{Nr} . \\
\text { (interna } \\
\text { 1) }\end{array}$ & $\begin{array}{l}\text { IPQ } \\
\text { item } \\
\text { name }\end{array}$ & $\begin{array}{l}\text { loading } \\
\text { on ... }\end{array}$ & English question & English anchors & $\begin{array}{l}\text { Copyrigh } \\
\text { t (item } \\
\text { source) }\end{array}$ \\
\hline 1 & s62 & G1 & PRES & $\begin{array}{l}\text { In the computer } \\
\text { generated world I } \\
\text { had a sense of } \\
\text { "being there" }\end{array}$ & not at all--very much & $\begin{array}{l}\text { Slater \& } \\
\text { Usoh } \\
(1994)\end{array}$ \\
\hline 2 & s44 & SP1 & SP & $\begin{array}{l}\text { Somehow I felt that } \\
\text { the virtual world } \\
\text { surrounded me. }\end{array}$ & $\begin{array}{l}\text { fully disagree--fully } \\
\text { agree }\end{array}$ & IPQ \\
\hline 3 & s30 & SP2 & SP & $\begin{array}{l}\text { I felt like I was just } \\
\text { perceiving pictures. }\end{array}$ & $\begin{array}{l}\text { fully disagree--fully } \\
\text { agree }\end{array}$ & IPQ \\
\hline 4 & s28 & SP3 & SP & $\begin{array}{l}\text { I did not feel present } \\
\text { in the virtual space. }\end{array}$ & $\begin{array}{l}\text { did not feel--felt } \\
\text { present }\end{array}$ & $? ? ?$ \\
\hline 5 & s31 & SP4 & SP & $\begin{array}{l}\text { I had a sense of } \\
\text { acting in the virtual } \\
\text { space, rather than } \\
\text { operating something } \\
\text { from outside. }\end{array}$ & $\begin{array}{l}\text { fully disagree--fully } \\
\text { agree }\end{array}$ & IPQ \\
\hline 6 & s33 & SP5 & SP & $\begin{array}{l}\text { I felt present in the } \\
\text { virtual space. }\end{array}$ & $\begin{array}{l}\text { fully disagree--fully } \\
\text { agree }\end{array}$ & IPQ \\
\hline
\end{tabular}




\begin{tabular}{|c|c|c|c|c|c|c|}
\hline 7 & s64 & INV1 & INV & $\begin{array}{l}\text { How aware were } \\
\text { you of the real } \\
\text { world surrounding } \\
\text { while navigating in } \\
\text { the virtual world? } \\
\text { (i.e. sounds, room } \\
\text { temperature, other } \\
\text { people, etc.)? }\end{array}$ & $\begin{array}{l}\text { extremely aware- } \\
\text { moderately aware- } \\
\text { not aware at all }\end{array}$ & $\begin{array}{l}\text { Witmer } \\
\text { \& Singer } \\
(1994)\end{array}$ \\
\hline 8 & s37 & INV2 & INV & $\begin{array}{l}\text { I was not aware of } \\
\text { my real } \\
\text { environment. }\end{array}$ & $\begin{array}{l}\text { fully disagree--fully } \\
\text { agree }\end{array}$ & IPQ \\
\hline 9 & s40 & INV3 & INV & $\begin{array}{l}\text { I still paid attention } \\
\text { to the real } \\
\text { environment. }\end{array}$ & $\begin{array}{l}\text { fully disagree--fully } \\
\text { agree }\end{array}$ & IPQ \\
\hline 10 & s38 & INV4 & INV & $\begin{array}{l}\text { I was completely } \\
\text { captivated by the } \\
\text { virtual world. }\end{array}$ & $\begin{array}{l}\text { fully disagree--fully } \\
\text { agree }\end{array}$ & IPQ \\
\hline 11 & s48 & $\begin{array}{l}\text { REAL } \\
1\end{array}$ & REAL & $\begin{array}{l}\text { How real did the } \\
\text { virtual world seem } \\
\text { to you? }\end{array}$ & $\begin{array}{l}\text { completely real--not } \\
\text { real at all }\end{array}$ & $\begin{array}{l}\text { Hendrix } \\
(1994)\end{array}$ \\
\hline 12 & s7 & $\begin{array}{l}\text { REAL } \\
2\end{array}$ & REAL & $\begin{array}{l}\text { How much did your } \\
\text { experience in the } \\
\text { virtual environment } \\
\text { seem consistent } \\
\text { with your real world } \\
\text { experience? }\end{array}$ & $\begin{array}{l}\text { not consistent- } \\
\text { moderately } \\
\text { consistent-very } \\
\text { consistent }\end{array}$ & $\begin{array}{l}\text { Witmer } \\
\text { \& Singer } \\
(1994)\end{array}$ \\
\hline 13 & s59 & $\begin{array}{l}\text { REAL } \\
3\end{array}$ & REAL & $\begin{array}{l}\text { How real did the } \\
\text { virtual world seem } \\
\text { to you? }\end{array}$ & $\begin{array}{l}\text { about as real as an } \\
\text { imagined world-- } \\
\text { indistinguishable } \\
\text { from the real world }\end{array}$ & $\begin{array}{l}\text { Carlin, } \\
\text { Hoffman, } \\
\& \\
\text { Weghorst } \\
(1997)\end{array}$ \\
\hline
\end{tabular}




\begin{tabular}{|c|c|c|c|c|c|c|}
\hline 14 & s47 & $\begin{array}{l}\text { REAL } \\
4\end{array}$ & REAL & $\begin{array}{l}\text { The virtual world } \\
\text { seemed more } \\
\text { realistic than the } \\
\text { real world. }\end{array}$ & $\begin{array}{l}\text { fully disagree--fully } \\
\text { agree }\end{array}$ & IPQ \\
\hline
\end{tabular}

\section{Japanese IPQ items}

g1 コンピュータで作られた世界の中で、私はそこにいる感じがした。

sp1＼cjkstart私は仮想世界に取り囲まれている気がした。(English quiestion)

私は、私の向こうに仮想環境が続いているような気がした。(German quiestion)

sp2私はただ単に映像を見ているような気がした。

sp3＼cjkstart私は仮想空間にいる気がしなかった。

sp4＼cjkstart私は何かを外部から操作しているのではなく、仮想空間の中で振る舞っているような気がした。

sp5 私㤆想空間の中に居合わせているように感じた。

inv1 あなたは、仮想世界を通って移動して行く間に、周りの現実世界をどのくらい意識していましたか （例えば物音、室温、他の人間など）？

inv2＼cjkstart私は、現実環境をもはや意識しなかった。

inv3私は未だ現実環境を注意していた。

inv4＼cjkstart私は仮想世界によって完全に魅了されていた。(English quiestion)

私の注意は、仮想世界によって完全に魅了されていた。(German quiestion)

real1 あなたには仮想世界がどのくらい現実のように見えましたか? (English quiestion) あなたには仮想環境がどのくらい現実のように見えましたか? (German quiestion)

rea12 あなたの仮想環境の経験は、あなたの現実環境の経験とどのくらい似ていましたか?

rea13 あなたには仮想世界がどのくらい現実のように見えましたか?

rea14私には現実世界よりも仮想世界の方がより現実にみえた。 